

م

б”

이믐

\ $\square$

ए人

电牙

$\Sigma \equiv$

$=\mathrm{m}$

金坚

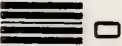

를

 



\title{
Zur Kenntniss
}

der

\section{Chlorophyllfarbstoffe}

\author{
und ihrer Verwandten.
}





\section{Zur Kenntniss}

\section{Chlorophyllfarbstoffe}

\section{und ihrer Verwandten.}

Spectralanalytische Untersuchungen

1)r. Gregor Kraus,

ord. Professor der Botanik an der Universität Erlangen.

Vit う̆ Ilolzschnitten und 3 lithogr. Tafeln.

S'TUTTGART.

E. Schweizerbart'sche Verlagshandlung (E. Koch).

1872. 
Druck von Fr. Schweizerbart in Stuttgart. 


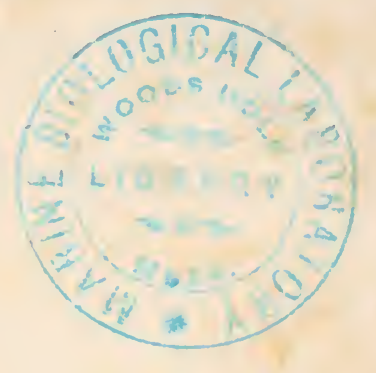

Die vorliegende Schrift hat einen doppelten Zweck. Einmal soll sie die Botaniker bekannt machen mit einem Apparate, der es, wie ich glaube, in hohem Grade verdient, in die mikroskopische Technik eingeführt zu werden, dem Mikrospectroscop.

Fürs Zweite sollen -in derselben: Untersuchungen veröffentlicht werden, welche mit Hülfe des genannten Instruments über die Zusammensetzung des Chlorophyllfarbstoffs gemacht worden sind.

Die Versuche lehnen sich kritisch an die vorhandenen deutschen und französischen Vorarbeiten an, die ihrerseits in enger Beziehung stehen zur Physiologie des Chlorophylls.

Eine jüngst erschienene englis che Abhandlung gleichen Themas konnte nur noch zum Schluss besprochen werden, was übrigens vorstehender Abhandlung um so weniger Abtrag thut, als jene ohne Rücksicht auf Vorgänger und physiologische Gesichtspunkte gearbeitet ist.

Im Laufe der Arbeit stellte sich bald heraus, dass zur sicheren Basirung derselben unumgänglich nothwendig sei, das Spectrum des Chlorophylls selbst, das 7. Z. noch keineswegs sicher gestellt war, einer eingehenden Prüfung zu unterziehen. Dass der 
grössere Theil der Arbeit sich damit scheinbar entlegenen Fragen zuwendete, dürfte um so willkommener sein, da für die verschiedenen jetzt in den Vordergrund tretenden Fragen über die Thätigkeit des Culorophylls die genaue Kenntniss seiner Absorptionen erforderlich sein wird.

Erlangen, den 13. Mai 1872. 


\section{I n h a I t s ü ber sicht.}

I. Apparat und Anwendung . . . . . . . . . . $1-18$

1. Beschreibung der Microspectralapparate S. 1.

2. Zur Anwendung des Apparates S. 10.

3. Literatur desselben S. 16.

II. Das Chlorophyllspectrum . . . . . . . . . . 19- Ti

1. Anforderungen an das Spectrum, Darstellungsmethode S. 19.

2. Herstellung der Lösung, Concentrationen S. 23.

3. Spectrum der weingeistigen Chlorophylllösung,

a. Die Bänder der ersten Hälfte S. 27.

b. Die Bänler der zweiten Hälfte S. 32 .

c. Identität des Spectrums bei höheren Pflanzen S. 36 .

d. Historisches und Kritisches S. 37.

4. Spectrum lebender Blätter S. 46.

5. Einfluss des Lösungsmittels und der Temperatur auf die Lage der Bänder S. 53.

6. Zur Kenntniss der Veränderungen des Chlorophyllspectrums S. 61.

a. Das zersetzte Chlorophyll S. 61 .

b. Einwirkung von Säuren S. 68 .

III. Entmischung des Chlorophylls

1. Kritik der bisherigen Versuche S. 78.

2. Trennung der Chlorophyllfarbstoffe,

a. Allgemeines - Methode S. 87.

b. Der goldgelbe Chlorophyllbestandtheil S. 93 .

c. Der blaugrüne Chlorophyllbestandtheil S. 97.

3. Das Chlorophyllspectrum, eine Combination der Spectra der beiden Farbstoffe S. 99.

4. Muthmassliche andere Bestandtheile des Chlorophylls S. 102.

5. Verbreitung der Farbstoffe im Pflanzenreich S. 104.

6. Farbstoffe bunter Organismen S. 105. 
IV. Die Verwandten des gelben Chlorophyllbestandtheils . 111-122

1. Der Farbstoff etiolirter Pflanzen S. 112.

2. Blumen-, Frucht- und Samengelb S. 114.

Anhang: Sorвy's Arbeit über die Farbstoffe herbstlicher Blätter . . . . . . . . . . . . . . 123

Ergebnisse . . . . . . . . . . . . . 130

Tafelerklärung . . . . . . . . . . . . 132 


\section{Apparat und Anwendung.}

\section{Der Mikrospectralapparat.}

Die vorliegenden Untersuchungen sind mit Apparaten angestellt, die ursprünglich nur zur Spectralanalyse mikroskopischer Gegenstände construirt wurden; dieselben erfüllen aber nicht allein diesen Zweck in ganz ausgezeichneter Weise, sie sind anch, wie meine Untersuchungen hoffentlich beweisen, zu gewöhnlichen makro-spectralanalytischen Beobachtungen über die Absorptionen von Flüssigkeiten so brauchbar als jedes andere, grössere Spectroskop, ja sie sind, scheint mir, für den Pflanzenphysiologen, was Handhabung und Leistung anlangt, in vielen Fällen letzteren sogar vorzuziehen.

Nerkwürdiger Weise sind diese schätzenswerthen Instrumente ausserbalb ihres Vaterlandes kaum praktisch gewürdigt worden, jedenfalls aber vom deutschen botanischen Publikum gänzlich unberücksichtigt geblieben.

Dies wird es rechtfertigen, wenn ich dieselben in Folgendem abbilde, beschreibe und über ihre doppelte Anwendung Einiges hinzufüge, bevor ich meine damit angestellten Untersuchungen selbst mittheile.

Die hier verwendeten Mikrospectralapparate sind Spectraloculare, d. h. der ganze Apparat, welcher zur Entwerfung des Spectrums eines Objektes nothwendig ist, ist im Ocular des Mikroskops selbst untergebracht, welches, wie ein gewöhnliches Ocular dem Mikroskop aufgesetzt und gehandhabt wird. Im einfachsten Falle unterscheidet es sich ron diesem nur dadurch, dass $\mathrm{z}$ w is chen seiner oberen und unteren Linse in der Bildebene ein verstellbarer Spalt vorhanden ist, während sich über der oberen (dem Auge zugewendeten) Linse ein abnehmbares, lichtzerlegendes Prisma befindet. Am vollständigeren Apparate sind aısserdem noch Vorrichtungen für ein Vergleichsspectrum und ein 
Messapparat zur Lagebestimmung der Absorptionsbänder oder Linien angebracht.

Ich habe für meine Arbeiten zwei Apparate benutzt, anfänglich den kleinen von Mrkz in M ün chen construirten, später ausschliesslich den schönen mit genauem Messapparat und ausgezeichneten Prismen versehenen grösseren Mikrospectralapparat, den John Browning in London im Verein mit SORBY erfunden hat.

Es mag der erstere, obwohl nur nachconstruirt, und an Ausrüstung und Leistung dem zweiten weit nachstehend, zuerst besprochen werden, da er vermöge der Einfachheit seines Baues leichteren Einblick in diesen gestattet.

Der "Spectralapparat für Mikroskope“, wie ihn Siguund Merz in Carl's Repertorium für Physik Bd. V, S. 390 beschrieben und auf Taf. XXI, Fig. 4-6 abgebildet hat, unterscheidet sich, wie ans beistehender Durchschnitts-Figur 1 zu ersehen ist, nur durch die Er-

Fig. 1.

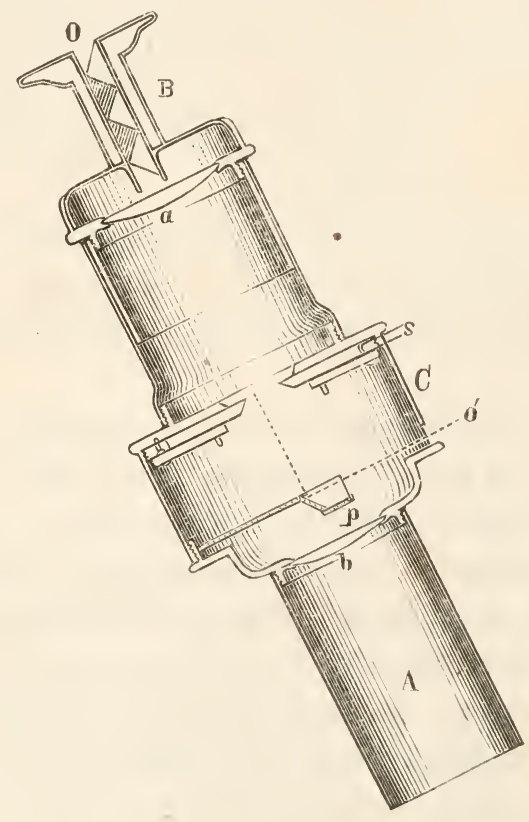

A. Aufsatzrohr des Spectraloculars.

B. Abnehmbares Prisma à vision directe.

C. Erweiterung des Oculars, in welcher der durch die Schraubes regulirhare Spalt, das Vergleichsprisma p und die Oeffnung für dasselhe o' liegt. a und b, obere und untere Linse des Oculars. 
weiterung $\mathrm{C}$ und den Aufsatz B von einem gewöhnlichen mit 2 Linsen (a und b) versehenen Ocular.

Derselbe ist, in meinem Exemplar, ohne das Aufsatzrohr A, welches dem Mikroskop angepasst sein muss, circa 85 Millimeter hoch. Nimmt man, wenn man denselben dem Mikroskop aufsetzt, zunächst den Theil B, welcher das zerlegende Prisma enthält, hinweg, so gewahrt man zum Unterschiede vom gewöhnlichen Ocular ein Gesichtsfeld, das nicht kreisförmig, sondern von dem, je nach der Stellung der Schraube s, einander gegenüber 2 gleichgrosse Stücke von verschiedener Dimension hinweggenommen sind. Durch die Vorrichtung im Innern der Erweiterung, die des Näheren aus Fig. 2 zu ersehen ist, lässt sich das Ge-

Fig. 2.

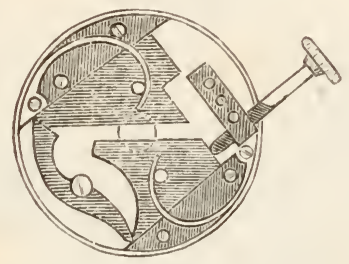

Spaltregulirung des Merz'schen Spectraloculars.

sichtsfeld bis auf einen Spalt, wie er zur Entwerfung eines reinen Spectrums nothwendig ist, verengern. Flüssigkeiten, die man in der Oeffinung des Objecttisches unterbringt, oder mikroskopische Objecte, wie gewöhnlich auf den Mikroskoptisch gelegt, werden in dem Spalte selbst, der in der Bildebene liegt, dentlich gesehen und eingestellt werden kömnen.

Der abnehmbare obere Theil $\mathrm{B}$ enthält das Prisma, welches das Licht des Spaltes, oder des darin im Bild erscheinenden Objectes zerlegt. Es ist, wie in der Fig. 1 angedentet, ein Anrcr'sches Prisma, aus 5 Prismen, 2 Flint- und 3 Crownglasprismen combinirt, die das Licht geradlinig hervorgehen lassen*. Setzt man dasselbe, und zwar die Prismen mit der brechenden Kante dem Spalt parallel auf das Ocular, so gewahırt man, wenn kein Object unter dem Mikroskope

* Ueber den Gang der Strahlen in einem solchen Prisma vgl. z. B. Sch ellen, Spectralanalyse. 2. Aufl. S. 121, Fig. 48. 
liegt, beim Einsehen in die Oeffnung o (Fig. 1) ein schönes, lichtstarkes Spectrum, in dem bei gewölmlichem Tageslicht und engem Spalt mit Leichtigkeit die Frulenhofre'schen Linien D, E, b und F, bei einiger Uebung auch B, C und (t wahrgenommen werden. Letztere nebst zahlreichen anderen dentlich und scharf erst bei Somnenlicht.

Es ist klar, dass die ganze Vorrichtung zunächst als ein kleiner Spectralapparat für gewöhnliche Absorptionsuntersuchungen bequem benutzt werden kann, wenn man z. B. in die Tischöffnung absorbirende Flüssigkeiten enthaltende Gläschen einsetzt.

Soll aber die Vorrichtung, wie sie bestimmt ist, zui Beobachtungen ron Absorptionen mikroskopischer Gegenstände rerwendet werden, so hat man bei hinweggenommenem Prisma (B) das Object, etwa eine chlorophyllhaltige, oder mit Anthokyan gefüllte Zelle, ein einzelnes Chlorophyllkorn u. s. w. wie gewöhnlich bei weitgeöffnetem Spalt einzustellen und dann den Spalt möglichst zu verengern, wobei Sorge zu haben, dass' das Object a ch nit verengertem Spalt noch.völlig sichtbar sei. Wird dann das Prisma in der angegebenen Weise aufgesetzt, so gewahrt man, soweit das Object im Spalte reicht, das Spectrum desselben, über und unter demselben das Spectrum des Tageslichts. Näheres unten bei der "Anwendung " des Apparates.

Das Spectrum ist so lichtstark, dass es die Anwendung aller mir zu Gebote stehenden Linsensysteme, selbst das Hartwack'sche Immersionssystem mit Leichtigkeit vertrug.

Die Brauchbarkeit des Apparates wird wesentlich erhöht durch die Beigabe eines Vergleichsprismas, mittelst welchem das Spectrum eines beliebigen anderen Gegenstandes zugleich mit dem des untersuchten bei o verglichen werden kann. Zu diesem Behufe ist die Erweiterung c mit einem drehbaren Ring versehen, durch dessen Drehung die quadratische Oeffinung $0^{\prime}$ (Fig. 1) geöffnet und zugleich das Glasprisma (p) so vor den Spalt geschoben wird, dass es einen kleinen Theil desselben einnimmt. Die durch die Oeffinung $0^{\prime}$ fallenden Strahlen (vgl. Fig. 1) werden von der Wand des Prismas nach o reflectirt und gelangen dort zugleich mit den Strahlen des eigentlichen Untersuchungsobjectes in's Auge. Bringt man z. B. vor die Oeffinung o' von einem. kleinen Stativ getragen in einem Probirröhrchen befindliche Chlorophylllösung, so werden die durchgegangenen Strahlen vom Prisma p nach o gesendet und dort durch das Anici'sche Prisma analysirt. Die 
Absorption der Lösung würde unmittelbar verglichen werden können, z. B. mit der Absorption eines Blattes, das auf dem Objecttische liegt. In gleicher Weise könnte man in einiger Entfernung von der Oeffnung auf einem Stativ einen Buxsex'schen Brenner aufstellen, und daran mit charakteristischen Spectren versehene Metalle verbrennen; die Lage der Metalllinien könnte zur Lagebestimmung der Absorptionsbänder

Fig. 3 .

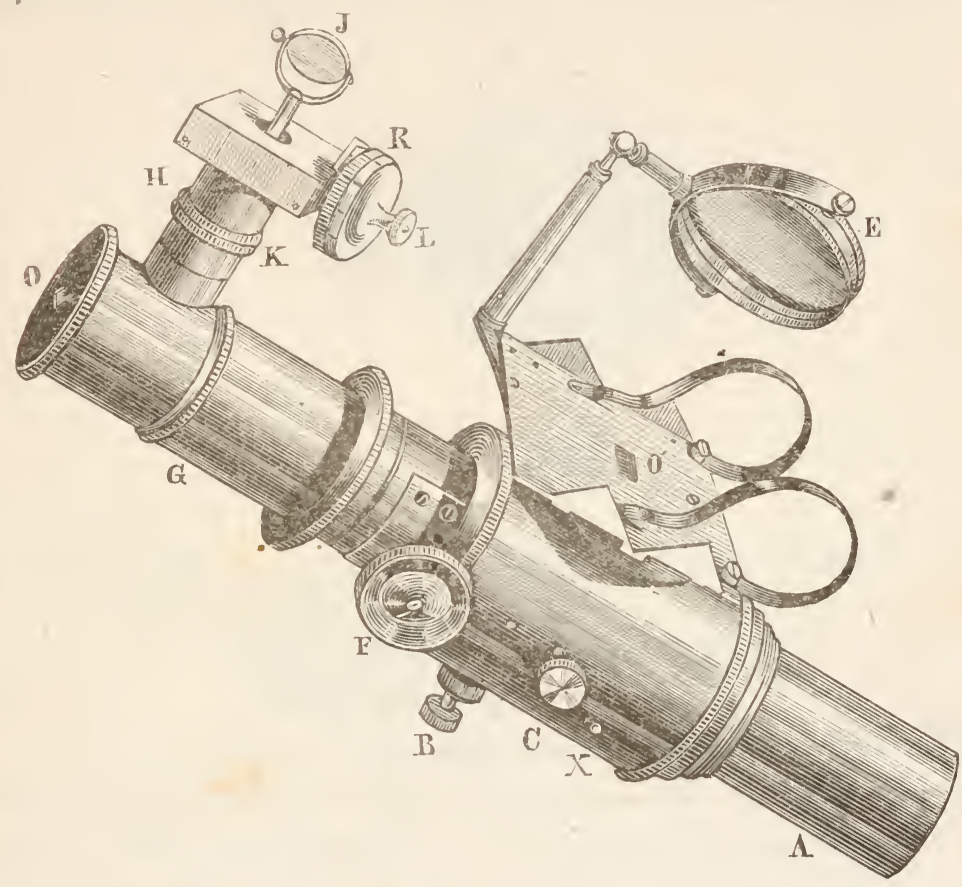

Der Sorby-Browrixg'sche Mikrospectralapparat. '2/3 nat. Grösse.

- A Aufsatzrohr des Apparates zum Mikroskop.

B Schraube zur Erweiterung und Verengerung.

C Schraube zur Verkürzùng des Spaltes.

E Spiegel zur Beleuchtung der Vergleichsobjecte, die ihr Licht durch die Oeffnung ó senden.

F Schraube zur Hebung oder Senkung des oberen Theiles G, in welchem obere Ocularlinse und zerlegendes Prisma befindlich.

H Messapparat.

$J$ Beleuchtungsspiegel desselben.

K Einstellschraube für das Lichtkreuz.

L Schraube zur Bewegung desselben.

R Mikrometertrommel zum Ablesen der Grösse der Bewegung, welche die Schraube L macht. 
mikroskopischer Gegenstände oder von Flüssigkeiten benutat werden. Auf diese Art könnte das Vergleichsspectrum zu einer Art Messapparat damn dienen, wenn man bei künstlichem Lichte arbeitet und die Frauenhofer'schen Linien nicht als Anhaltspunkte benutzt werden können. Merz selbst hat zur Lagebestimmung in diesem Falle die Anwendung von (farblosen) Didymgläsern vorgeschlagen, die er, in den Mikroskoptisch passend, beigibt. Durch Einlage derselben erhält man zwei starke Absorptionslinien um die D-Linie herum, ferner zwei schöne

Fig. 4.

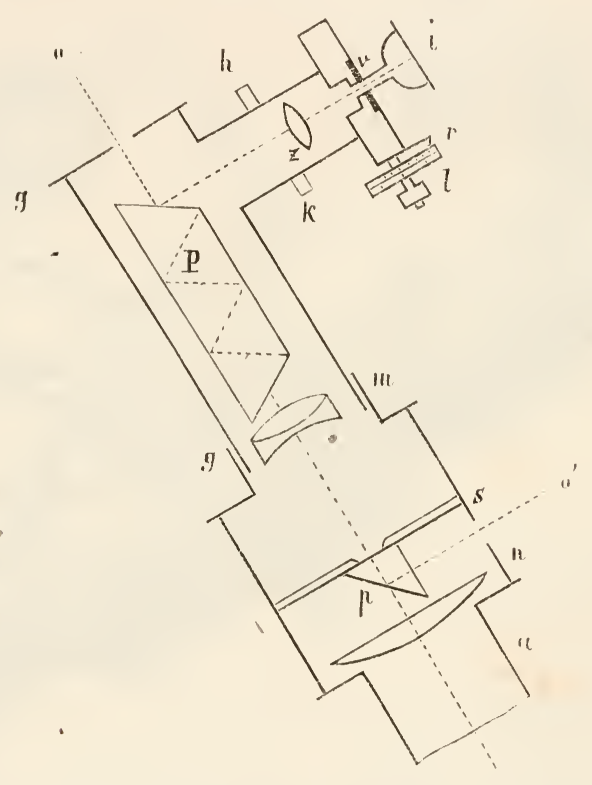

Schematischer Durchschnitt des Apparates.

a Aufsatzrolir.

n Untere Ocularlinse.

m Obere Ocularlinse.

s Spalt.

p Vergleichsprisma.

gg Oberer Theil mit dem Prisma à vision directe.

h Messapparat.

i Beleuchtungsspiegel.

k Einstellschraube.

z Einstellinse für das Lichtkreuz der Platte v.

l Schraube zur Bewegung des Lichtkreuzes.

1. Trommel, die Grösse der Bewegung abzulesen. 
aber schwache Linien im Grün, nahe von $\mathrm{E}$ und $\mathrm{F} *$. Das Fehlen eines genauen Messapparates ist übrigens der empfindlichste Mangel all dem MERz'schen kleinen, sonst gut gearbeiteten Apparate.

Dieser Mangel besonders brachte es mit sich, dass zu den folgenden Untersuchungen fast ausschliesslich der mit allem Wünschenswerthen in vorzüglichster Weise ausgestattete A p parat zur Verwendung kam, den John Brownisg in London nach seinen und Sorby's Ideen construirt hat. (Fig. 3, S. 5.)

Fig. 5.

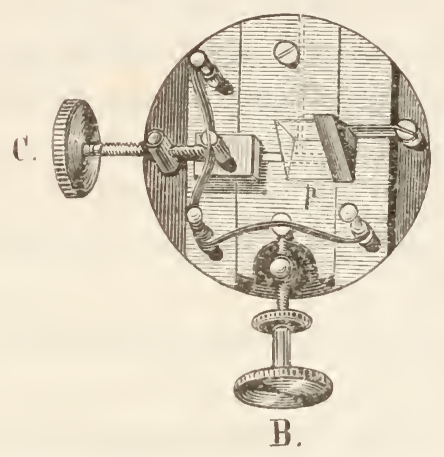

Spaltregulirung des Apparates von unten gesehen.

B Schraube zur Verengerung.

C Schraube zur Verkürzung des Spaltes.

p Vergleichsprisma.

I)er Apparat ist, das Aufsatzrohr A, das dem Mikroskoptubus speciell angepasst sein muss, abgerechnet, 158 Millimeter hoch, und desshalb nicht gut beim Sitzen am Mikroskoptisch zu gebrauchen. Dagegen lässt sich, wemn man das Mikroskop nicht unmittelbar auf den Tisch, sondern auf ein kleines Stativ postirt, mit demselben stehend ausserordentlich bequem arbeiten.

Nehmen wir auch hier zunächst den oberen Theil G (Fig. 3), gg (Fig. 4) hinweg, der $z$ gleichem Zwecke wie beim vorigen Apparat abnehmbar ist, und hier neben dem analysirenden Prisma à vision directe auch die obere Ocularlinse $m$ (Fig. 4) und den Messapparat $\mathrm{H}$ (Fig. 3), h (Fig. 4) enthält, so haben wir in der Erweiterung wiederum den Spalt s (Fig. 4), der durch die Schraube B (Fig. 3 und 5) erweitert

* Teber Didymspectra rgl. Bunsen in Liebig's Ann. Bd. 137, S. 1 und Pogg e ud. Ann. Bd. 128, S. 100 ff. 
und verengert, durch die Schraube $\mathrm{C}$ zugleich verkürzt werden kann, welch' letztere Einrichtung es ermöglicht, dass kleinere Gegenstände, die nicht die ganze Länge des Spaltes einnehmen, für sich allein spectralanalytisch geprüft werden können.

Der obere abnehmbare Theil stellt ein Rohr dar, das durch die Schraube F (Fig. 3) beweglich und dadurch dem Spalt genähert oder von ihm entfernt werden kann. Diese Einrichtung ist insoferne von Wichtigkeit, als dadurch möglich wird, die einzelnen Theile des Spectrums genauer einzustellen*. Das zerlegende Prisma, von ausgezeichneter Qualität, ist à vision directe aus 5 Prismen construirt.

Setzt man diesen Theil auf und. verengert den Spalt gehörig, so sieht man bei gewöhnlichem Tageslicht ein Spectrum von ungemeiner Klarheit und Lichtstärke an dem die Linien von B bis $G$ in ausserordentlicher Schärfe hervortreten; bei Sonnenlicht hat man ein Spectrum von $\mathrm{A}$ bis zu den beiden Linien $H$, das von zahllosen feinen Linien wie übersäet erscheint.

Eine Vorrichtung für's Vergleichsspectrum ist in sehr vollkommener Weise angebracht.

Zunächst ist für die Vergleichsgegenstände ein eigener Tisch rorhanden, auf dem dieselben durch Federn vor der Oefinung $0^{\prime}$, die durch Hebelarme (Fig. 3, X) auch verschliessbar ist, festgehalten und durch einen besonders angebrachten Spiegel (E Fig. 3) beleuchtet werden können. Das Vergleichsprisma (p Fig. 4 und j) ist unbeweglich, der Gang der Strahlen in Fig. 4 angedentet $\left(00^{\prime}\right)$.

Der glänzendste 'Theil des Apparates aber ist der von Brownixt: erfundene ingeniöse Messapparat H (Fig. 3), h (Fig. 4).

Es befindet sich am oberen Theil, seitlich ein horizontales Rohr angebracht, in welches durch einen niedlichen Metallspiegel Fig. 3, J, Fig. 4, i Licht geworfen werden kann, so dass es auf das Prisma P fällt und von diesem nach 0 in das Auge des Beobachters gelangt. Das freie Ende des Rohrs (gegen den Spiegel hin) ist durch eine geschwärzte Platte Fig. 4, v geschlossen, auf welcher bei meinem Instrument zwei unter $90^{\circ}$ gebogene Linien $x$-förmig ( $>$ ) durchsichtig gelassen sind. Es ist möglich diese hellen Linien, die an der Stelle, wo die Winkelspitzen gegeneinander stehen, einen scharfen Punkt geben, lurch die Schraube K Fig. 3 und k Fig. 4 und die Linse $z$ (Fig. 4) so

* Vgl. Roscoe, spectralanalyse, übers. von Schorlemmer, 1870, S. 142. 
einzustellen, dass ihr durch den Spiegel Ji beleuchtetes Bild unter $45^{\circ}$ auf das Prisma $P$ fällt und von dort deutlich sichtbar nach o ins Auge des Beschaners geworfen wird. Man gewahrt, wenn die Linien richtig eingestellt sind, dieselben als ein weisses helles Lichtkreuz auf dem Spectrum, welch' letzteres in der Richtung a 0 ins Auge gelangt.

Durch die Schraube L Fig. 3, l Fig. 4 ist die geschwärzte Platte so beweglich, dass das Lichtkreuz der Länge nach über das ganze Spectrum, durch alle Farben desselben hinwegbewegt werden kann, so dass es möglich ist, einen beliebigen fixen Punkt in demselben, z. B. eine Frauenhofer'sche Linie mit dem Punkte, wo die beiden Winkel des Lichtkreuzes zusammenstossen, in genaue Coincidenz zu bringen, mit anderen Worten das Kreuz auf eine Fraukinofer'sche Linie, und bei der Weiterbewegung nach und nach auf alle Linien genau einzustellen.

Zugleich ist nun die Grösse der Bewegung, die man macht, wenn das Kreuz von einer Linie zur anderen, etwa von D auf F rückt, messbar an einer Mikrometertrommel, Fig. 3, R, Fig. 4, r, die bei mir in 100 Theile getheilt ist, und deren Eintheilung beim Drehen der Schraube L und 1 und Bewegen des Krreuzes über das Spectrum an einem \%eiger vorübergeht. So ist es möglich, die Anzahl der Theilstriche abzulesen, die man von einem Punkte des Spectrums zum anderen gehend zurücklegt. Der Optiker hat bei meinem Instrument die Einrichtung so getroffen, dass wemn das Lichtkreuz auf der Linie A steht, der Zeiger auf 0 der Eintheilung zeigt. Wird das Kreuz auf die Linie B bewegt, so zeigt der Zeiger 30, auf C 70 us. s. W. Es ist, wie man sieht, auf diese Weise möglich, die Lage sämmtlicher Fr.úfrnofer'schen Linien zu messen. Die Messung ergab für mein Instrument folgende Lagen der Linien; es lag die Linie

$\begin{array}{ccccccccc} & \text { A } & \text { B } & \text { C } & \text { D } & \text { E } & \text { b } & \text { F } & \text { G } \\ \text { bei } & 0 & 30 & 70 & 170 & 345 & 380 & 510 & 865 .\end{array}$

Zeichnet man sich nun in der gewöhnlichen Weise ein Spectralband und versieht dasselbe mit. einer beliebig gross gewählten Eintheilung (Skala), so hat man ofienbar die richtige gegenseitige Lage der Fracenhofer'schen Linien, wenn man dieselben bei den Zahlen der Skala einträgt, welche den gefundenen Zahlen am Apparat entsprechen. Man erhält auf diese Weise ein Normalspectrum mit welchem man Absorptionen n. s. w., deren Lage man hestimmen will, leicht vergleichen kann. 
Demn es ist klar, dass man auf dieselbe Weise, wie man die Lage der Linien bestimmt hat, auch die Lage eines Absorptionsbandes bestimmen kaim. Trägt man die Lage desselben wie dort in das Spectrum ein, so ist dieselbe genau bestimmt.

Für meine Untersuchungen habe ich das Normalspectrum, in welches die Fratenhorer'schen Linien und zu beobachtende Absorptionen einzutragen sind, in folgender Weise entworfen.

Ich hielt es für hinreichend, das Spectrum nicht grösser als ewa 1 Decimeter zu zeichnen. Dieses wurde mit einer 100theiligen Skala versehen. Jeder Theilstrich stellte dabei 10 Theile der Mikrometertrommeleintheilung vor und wurde demgemäss auch bezeichnet. Diese Grösse des Spectrums und insbesondere die Eintheilung ist nicht allein genügend, sie ist auch nicht einmal ausführlicher möglich, da, wenigstens bei meinem Iustrument, Bewegungen von einem Theilstrich der Trommel zum anderen an dem Lichtkreuz nicht, sóndern höchstens solche von 5 zu 5 wahrgenommen werden können. Die Stellen der Frauenhofer'schen Linien wurden an der Skala, nicht im Spectrum angedeutet, damit durch dieselben nicht das Bild eines Absorptionsspectrums verundeutlicht werde. In dieses Spectrum wurden die Absorptionen bei den verschiedenen Zahlen selbst eingetragen und auf diese Weise eine genane und vergleichbare Lagebestimmung der Absorptionen gewonnen.

\section{Zur Anwendung des Apparates.}

Wenngleich die im Vorstehenden geschilderten Mikrospectralapparate oder Spectraloculare, wie ihr Name sagt, wesentlich mikroskopischen Intentionen ihre Entstelıung verdanken, so können dieselben doch auch mit gutem Erfolge zu gewöhnlichen spectralanalytischen Beobachtungen in der Physiologie verwendet werden; und, nachdem ich dieselben in dieser Hinsicht hinreichend zu prüfen und verwenden Gelegenheit hatte, stehe ich nicht einen Moment an, dieselben nicht allein den grösseren Apparaten in ihrer Leistumgsfähigkeit gleich zu achten, sondern ihnen vor denselben in mancher Hinsicht den Vorzug zil geben.

Sehen wir zunäehst ah von ihrer speciellen $A$ ufgabe, so empfehlen sich dieselben zur Untersuchung der Absorptionserscheinungen ron Flüssigkeiten 11. S. W., Gieweben 11. s. w. dem Phrsiologen durch zwei sehr werthvolle Eigenschaften, durch ausserordentliche Be- 
quemlichkeit der Handhabung und grosse Lichtstärke der Spectren.

Es ist für den Mikroskopiker gewiss sehr schätzenswerth, durch diese Apparate der Aufstellung eines grossen, eben nicht gerade handlichen Instrumentes, wie die gewöhnlichen Spectralapparate sind, und der Gewöhnung an eine Anzahl andersartiger Manipulationen enthoben zu sein. Der einfache Ocularwechsel - ein schwaches Objectiv hinwegzunehmen ist kaum nöthig - genügt, dem Mikroskopiker aus seinem gewöhnlichen Arbeitsinstrument ein Spectroskop herzustellen, an dem er, wie beim Mikroskopiren in senkrechtem Selien beobachtet und die Beobachtungsgegenstände auf dem Objecttische hat; Flüssigkeiten in kleinen Röhrchen in die Oeffnung des Tisches senkt, Blätter, Petala, Schnitte, auf Objectträgern einfach auf den Tisch legt, ohne sie erst langwierig an Stativen unterbringen zu müssen.

Dabei ist nun besonders hervorzuheben, dass. ich im Vergleich mit den Leistungen grösserer Instrumente nicht allein keinen Unterschied zu Ungunsten der kleinen bemerkt habe, vielmehr einen sehr wesentlichen Vortheil fand in der ausserordentlichen Lichtstärke des von den kleinen Apparaten entworfenen kleinen Spectrums. Das auf einen nicht zu grossen Raum ansgestrente Licht des Spaltes erlaubt in vielen Fällen noch da scharf zu sehen, wo wegen Mangel an Licht bei grösseren Spectren die Beobachtung zweifelhaft oder unmöglich wird. So glaube ich es der Lichtschwäche der grossen Apparate nicht zum geringsten Theile zuschreiben zu müssen, dass im blanen und violetten Theile die schönen Absorptionsbänder des Chlorophylls oder des gelben Farbstoffs, z. B. etiolirter Pflanzen, bisher meistentheils übersehen wurden, oder dass der feine Streif im Grün, welchen das Chlorophyll liefert, öfter dasselbe Schicksal hatte.

Noch mehr als bei den klaren Lösungen kommt die Lichtstärke des Apparates in Anschlag, wenn ganze Blätter. Schnitte, überhaupt Theile lebender Körper, wie sie der Physiologe ror sich hat, die vermöge ihres Banes undurchsichtiger sind, spectralanalytisch geprüft werden sollen. Die Fehler, die bis in die jüngste Zeit, selbst trefflichen Beobachtern über die Absorptionen lebender Blätter unterlaufen sind, indem sie die Existenz der Bänder II, III und IV, die an Lösungen klar hervortreten, läugneten, hahen ihren Grund meines Erachtens nur in der Lichtschwäche der Spectra der gewöhnlichen Apparate, welche bei so undurchsichtigen Medien die feinen Bänder nicht erkennen liessen. 
Was die Instrumente in ihrer speciellen Bestimmung so ausserordentlich werthvoll macht, habe ich schon an einem anderen Orte (Sitzungsber. der physic.-med. Soc. zu Erlangen vom 13. März 1871) hervorgehobeu. Ob es gleich für den Physiologen ebenfalls sehr schätzenswerth ist, mikroskopisch geringe Mengen vou Flüssigkeiten, Krystallen u. s. w. oder kleine Objecte, wie die Farbstoffiuhalte einzelner Zellen, einzelne Chlorphyllkörner, einzellige gefürbte Algen, Gonidien u. s. w., sei es num analytisch oder in Hinsicht der „Durchleuchtung (Sıchs) prüfen zu können: so lege ich den Hauptwerth des Instrumentes für den Physiologen doch nach einer anderen Seite hin. Es scheint mir viel werthvoller, wie ich a. a. 0 . sclron hervorgehoben, dass es durch diese Instrumente möglich ist, lebende Objecte selbst prüfen zu köunen. Die Bedentung dieser Möglichkeit springt von selbst in die Augen in den Fällen, wo es notorisch zur Zeit unthunlich ist, einen absorbirenden, zu untersuchenden Stoff aus dem lebenden Körper жи nehmen, ohne denselben iu seinen Eigenschaften wesentlich zu ändern. In anderen und sehr zahlreichen Fällen, wird aber erst der Mikrospectralapparat dem Physiologen die Frage entscheiden, ob ein Körper aus dem lebenden Verband geuommen, seine bisherigen Eigenschaften verliert, eine Frage, die selbstverständlich in einer Wissenschaft, der das Leben zu erforschen obliegt, von höchster Wichtigkeit ist. So wird z. B. die Frage, ob Chlorophyll in Lösung wesentlich anders geeigenschaftet sei als das im Blatte; die Frage, welche Aenderungen die Blumenfarbstoffe, die beim Ausziehen öfter ihre Farbe ändern, oder selbst farblos werden (Marquart, Blüthenfarben, 1835, S. 49 ff.), erleiden, spectralanalytisch durch unseren Apparat leicht gelöst, da es mit ihm möglich ist, lebeude Zellen oder Gewebe spectralanalytisch zu prïfen.

Einige Beispiele mögen uns die Anwendung des Apparates zu mikro- und makrospectralaualytischen Untersuchungen zeigen.

Will man den Apparat für mikroskopische Gegenstände benutzen, so eutfernt man vor Allem das über der obereu Ocularlinse befindliche zerlegende Prisma, das stets abnehmbar ist, und stellt die regenstände wie gewöhnlich ein. Man öffuet zu diesem Behufe den Spalt so weit als möglich; Gewebe oder ganze Organe (Blïtter) beobachtet man mit schwachem Objectiv (Hartnack n. 4.) und die Einstellung hat dann keine Schwierigkeit. Einzelne Zellen, Gonidien von Flechtelı, einzellige Algen oder Theile rom Zelliuhalt, wie Chlorophyll- 
körner, Harbstoffkrystalle, -Kugeln u. s. w. werden bei starken Vergrösserungen - selbst Immersion ist anwendbar - eingestellt und zwar so, dass sie möglichst im Centrum des Gesichtsfeldes liegen, da sie auf diese Weise allein beim Verenger'n des Spaltes, wie beim Verkürzen desselben stets sichtbar bleiben. Es ist nach meinen Erfahrungen besser, den Gegenstand nicht scharf einzustellen, sondern etwas tiefer liegen zu lassen. Setzt man dann bei möglichst verengertem Spalte das Prisma auf, so erhält man (wofern der Spalt nicht so verkürzt ist, dass bloss der zu beobachtende Gegenstand in demselben erscheint) über und unter der Stelle, wo der Gegenstand liegt, das normale Tages- oder Lampenlichtspectrum; an Stelle des Objectes gehen zwei parallele Linien, die Grenzen des Gegenstandes bezeichnend, der Länge nach durch das ganze Spectrum und zeigen zwischen sich, wofern der Gegenstand absorbirt, die Absorptionen desselben. Freilich erscheint das Spectrum des Körpers nur dann rein und frei von Linien, die den Grenzlinien parallel laufen, wenn der Gegenstand nahezu homogen erscheint, wie beispielsweise ein Oeltropfen, oder ein nicht genan eingestelltes Stärkekorn, die im Spectrum beobachtet, stets nur die zwei Grenzlinien ihres Körpers durch das Spectrum laufend zeigen, während dazwischen weder Absorption noch sonst eine Differenzirung des Spectrums vorhanden ist.

Bei Körpern dagegen, die im Innern verschieden lichtbrechende Differenzirungen zeigen, wie Protaplasmagebilde, wird das Spectrum des Gegenstandes häufig sehr getrübt durch das Auftreten heller und dunkler Linien, die den Stellen stärkerer und schwächerer Lichtbrechung entsprechen, und die es vielleicht verhindern, ganz scharfe Absorptionsbilder zu erhalten.

Stelit man sich z. B. in der angegebenen Weise einzelne Chlorophyllkörner aus den Blättern von Vallisneria, Cliria, Agapanthus, oder von Moosen in der angegebenen Weise ein - ich fand es sehr zweckmässig, sie in Glycerin zu legen — so erhält man bei gewöhnlichem Tages-, 'noch besser bei Sonnenlicht zwischen zwei die Grenze bildenden Linien (Taf. I, Fig. 1) eine sehr deutliche Absorption des Roth zwischen B und C, und eine Hinwegnahme von Blan und Violett. Von den übrigen Streifen sieht man nichts, sei es, was wahrscheinlich, dass die Menge des Farbstoffs in einem Einzelkorn zu gering ist, sei es, dass der Mangel an Homogeneität der Substanz das Gewahrwerden der feinen Verdüsterungen im Orange, Gelb und Grün 
verhindert. Selbstverständlich gehört zur Beobachtung der Absorption so kleiner Körper eine ziemliche Uebung; aber selbst der Ungeübte dürfte das Vorhandensein einer Absorption beim einzelnen Chlorophyllkorn dann leicht sehen, wenn er gleichzeitig einen nicht absorbirenden Körper, etwa eine Stärkekorn in dem Spalt mit eingestellt und mit beobachtet.

Der Nachweis der Lichtabsorption durch ein einziges Chlorophyllkorn ist physiologisch insofern ganz interessant, als dadurch experimentell bewiesen wird, dass in der That einzelne Chlorophyllkörner leistungsfähig sind, und dass demnach z. B. die einzeln schwimmenden transitorischen Chlorophyllkörner der Haare oder zahlreicher Epidermen dicotyler Blätter (Pringsh. Jahrb. IV. 314) zu assimiliren im Stande sein dürften.

Die Chlorophyllkörner sind die kleinsten Theile des Pflanzenkörpers*, an denen ich Absorptionen nachweisen komute. Mit grösserer Leichtigkeit als an ihnen lassen sich Spectra von Flechtengonidien (Parmeli(1); von Pleurococcus vulgaris und miniatus entwerfen. An den Diat omeen ist das für Chlorophyllfarbstoffe so ansgezeichnete Band im Roth schon von Sмiтн ** gesehen worden.

Ein ausserordentlich hübsches Object für die Demonstration der Absorptionen einer einzigen Zelle, sind die "Anthokyan"-haltigen unterseitigen Epidermiszellen von Tradescantia zebrina (in den Sitzungsber. d. Erlanger phys.-med. Soc. 13. März 1871 steht fälschlich discolor). Man erhält durch einfaches Abziehen mit der Pincette sehr leicht grössere Stücke Epidermis, deren intacte Zellen einen lebhaft purpurfarbenen Saft enthalten. Eine Zelle mit dem Object i von HaRTNACK vergrössert, gibt im Spectralapparat das schöne auf unserer Taf. I, Fig. 2 dargestellte Spectrum. Die Strahlen vom rothen Begimn des Spectrums bis zur Linie D (gelb) gehen ungehindert durch; unmittelbar hinter dieser Linie liegt ein schmälerer aber dunklerer beider-

* An Theilen von Chlorophyllkörnern habe ich keine Absorptionen erhalten. Nebenbei mag bemerkt werden, dass ich in Uebereinstimmung mit Preyer (Die Blutkrystalle, Jena 1871, S. 109), und im Gegensatz zu den englischen Augaben (in den ersten Beschreibungen des Mikrospectralapparats) nicht an einzelnen Blutkörperchen, wohl aber an einigen wenigen geldrollenartig zusammengelagerten die Blutbänder wahrnehmen konnte.

** The Spectrum of Diatomin. Sillima n's Journal, July 18́69. Quat. Journ. Micr. Scienc. Vol. IX. 1869, p. 419. Auszug in The Candian Naturalist. New. Ser. Vol. IV. 1869, p. 342. 
seits abgeschatteter Streifen, an unserer Skala 170-192-220 im Liclıtgrün. Zwischen ihm und einem dahinter vor E gelegenen breitern aber blassern Band (260-330) ist eine schwache Verdunkelung, die auch durch das ganze Grün bis gegen F hin geht, bemerklich. Mitmnter scheint es, als ob hinter b noch eine kleine Anschwellung der Absorption auftrete. Die Blumenblätter der Pflanze geben dasselbe Bild. Setzt man zu den Zellen Essigsäure, wodurch der Farbstoff zunächst mehr geröthet wird, so gewahrt man successive eine Aenderung des Spectrums: der Streifen im Gelb rerschwindet, während das Band im Grün, an seiner Stelle bleibend, nach beiden Seiten hin sich verbreitert.

Ein ähnliches Spectrim habe ich an den mit violettem Zellinlalt versehenen Zellen der Blumen von gestreiftem Crocus vernus gesehen.

Von den Epidermiszellen rothschaliger A epfel habe ich nur den ersten Streifen, verhältnissmässig unscharf wahrgenommen; die unterseitigen Epidermiszellen voll Sedum hybridum geben ebenfalls nur eill Band und dies etwas weiter gegen das Violett geschoben. Die obigen Erfahrungen über die Reaction des rothen Saftes bei Tradescantia gegen Essigsäure weisen meines Erachtens darauf hin, dass aus diesen verschiedenen Spectren nicht auf verschiedene Farbstoffe, sondern wahrscheinlich auf verschiedene Abänderungen geschlossen werden muss, die derselbe je nach der Beschaffenheit des Zellinhaltes erleidet. Vielleicht ist bei genanerem Verfolge solcher Reactionen in diesen ein Mittel zu finden, wie man indirect aus dem spectralanalytischen Verdalten der rothen Säfte die Zusammensetzung des Zellsaftes oder wenigstens das Vorhandensein bestimmter Säuren oder Salze erschliessen kann.

In ähnlicher Weise wie Zellen habe ich auch farbstoffhaltige Gewebe, z. B. eine und melnrere Lagen von den Zellen, welche die gelben Farbstoffspindeln in der Frucht von Solanum pseudocapsicum enthalten, oder einzelne Zelllagen aus etiolirten Blättern untersucht. Bei derlei lufthaltigen Geweben ist es vor Allem gerathen, dieselben nicht direct einzustellen. Das Resultat ist, abgesehen von dem Unterschiede in der Stärke der Absorption, nicht verschieden von dem, welches man bei der Untersuchung etwa ganzer Blätter u. s. w. erhält, und ist für letztere im speciellen Theile der Untersuchung (s. unten) mehrmals angeführt.

Benutzt nran den Apparat für gewölnliche makrospectral- 
a nalytische Untersuchung von Flüssigkeiten, so kann ein schwaches Objectir an demselben gelassen oder abgenommen werden. Die Flüssigkeiten selbst kömnen in passenden, in einer Korkhülse steckenden (und dadurch auf dem Objecttisch festgehaltenen) "Mustergläschen “, die einen flachen Boden besitzen und die man, nach Belieben, anch graduiren kann, beobachtet werden. Im Uebrigen ist es nicht einmal nothwendig, diese an sich schon sehr einfache Methode zu befolgen. Man kann die Flüssigkeiten im gewöhnlichen Probirröhrchen brevi manu in die Tischöffinung halten, und hat dabei noch den unschätzbaren Vortheil, dass man durch stärkeres oder schwächeres Neigen des Röhrchens sofort alle möglichen Dicken der Flüssigkeitsschichte vor dem Spectroskop kann vorbeipassiren lassen. Diese letztere kurze Methode habe ich mit dem besten Erfolge fast immer angewendet, und auf diese Weise niemals' Schwierigkeiten in der Auffindung einer gesuchten Schichtendicke gehabt.

Will man fremdes, von oben her fallendes Licht abhalten, so genügt es, ror den Objecttisch eine undurchsichtige Platte, etwa schwarz. beklebte Pappe, von ęinem Stativarm getragen, z.u setzen; übrigens genügt das Vorhalten der Hand, in den meisten Fällen ist es überhaupt unnöthig.

\section{Geschichte und Literatur des Apparates.}

Es dürfte Manchem willkommen sein, über die Geschichte des Apparates Einiges zu erfahren. Es möge desshalb die Literatur desselben, so vollständig ich sie kenne, hier mit ganz kurzer Andentung des Inhalts aufgeführt werden.

\section{Der Sorby-Browning'sche Apparat.}

1) On the Application of Spectrum Analysis to Microscopical Investigations, and especially to the Detection of Bloodstains by $\mathrm{H}$. C. Sorby.

The Quaterly Journal of Science. Vol. II. N. VI. April 1865, 1. 198-202.

The Chemical News. N. 281. April 1865, p. 186 sq.

Erste Publication des Erfinders; der Apparat ist noch kein Spectralocular, sondern die zerlegenden Prismen unter dem Tisch des Mikroskops angebracht.

2) On the Application of the Spectroscope to the Microscope by Juhn Browning. 
Transactions of the Microscopical Society of London. N. Ser. Vol. XIII. 1865 , p. $10 i-113 *$.

Erste, aber unvollkommene Anwendung des Apparates in Form eines Oculars.

3) On a new Microspectroscope and a new Method of Printing a Description of the Spectrum seen with the Spectrum-microscope. The Chemical News. 1867, n. 387, 3. Mai, p. 220 f.

Gemeinschaftliche Mittheilung von Sorby und Browsing über den Apparat, der die heutige Gestalt hat, aber nur mit einem Vergleichsprisma und Tisch dafür ausgestattet ist.

4) On a definite Method of Qualitative Analysis of Animal and Vegetable Colouringmatters by means of the Spectrum-microscope by H. C. Sorby.

Proceedings of the R. Society of London. Vol. XV. 1867, n. 92, p. 433-436.

Kurze Anzeige Bot. Ztg. 1868, S. 78.

Enthält insbesondere die Beschreibung des SorBy'schen Messapparates.

5) On a Method of Measuring the Position of Absorption Bands with a Micro-spectroscope by JoHn Browning.

The Monthly Microseopical Journal. Febr. 1870, p. 68 ff.

Beschreibung des simmreichen BrownIng'schen neuen Messapparates.

Vgl. ferner den neuesten Preiscourant** Brownivg's, wo Abbildungen und kurze Beschreibungen der Apparate angegeben.

Die erste dentsche Beschreibung ist in der deutschen Uebersetzung von Roscoe's Spectralanalyse (von Schorlemmer, Braunschweig 1870, S. 122 und 141) gegeben, wo auch eine Abbildung und auf S. 286 ff. die Literatur zum Theil angegeben ist. - Eine ansführliche Beschreibung des Apparates in SchelLev's Spectralanalyse. 2. Aufl. 1871. S. $18 \pi$ bis 197. Literatur S. 618. - Eine Besprechung der Apparate: Kraus, Sitzb. d. Erlanger phýs.-med. Soc. 3. Heft S. 62 (13. März 1871); von Valentin in M. Schultze's Areh. f. mikr. Anat. Bd. VIII. 1871, S. 220 ff.

* Noch ror dieser Mittheilung Browning's befindet sich a. a. 0. S. 85 bis 87 eine "Note" von Wil. Huggins über einen Apparat, an welchem die Prismen üb er dem Mikroskop angebracht sind.

** Der Apparat kostet rollständig 5 Pfd. Strlg. 10 Sh. Der Messapparat 2 Pfd. Strlg. 2 Sh. 
II. Deutsche Spectraloculare.

S. Merz, Spectralapparat für Mikroskope. CARL's Repertor. f. Physik. Bd. V, 18, S. $390 *$.

III. Spectralapparate zu mikroskopischen Zwecken, die nicht Spectral oculare sind.

W. Preyer in Max Schultze's Archiv für mikr. Anatomie. II. 1866. S. $92-101$.

S. Stricker in Pflüger's Arch. f. ges. Phys. I. 1868. S. 651-う6.

CRookes, W., On a new Arrangement of Binocular Spectrum-microscope. Proc. R. Soc. London. 1869. Vol. XVII, p. 443-448.

E. AввE, Jenaische Zeitschrift f. Med. u. Naturw. V. 1870. S. 459-70. Die Hartnack'schen Apparate, die Preyer (Blutkrystalle, S. 112 Anm.) erwähnt, sind mir unbekannt.

* Irrthümlich wird von Valentin (a. a. O.), wie von Schellen, Spectralanalyse, 1. Aufl. angegeben, dass Steinheil in München Mikrospectralapparate construire. 


\section{Das Chlorophyllspectrum.}

\section{Anfordernngen an das Spectrum, Darstellungsmethode.}

Eine specielle Betrachtung des Chlorophyllspectrums lag ursprünglich nicht in dem Plane meiner Untersuchung, die eigentlich auf eine Zerlegung des Chlorophylls gerichtet war, von dem man ziemlich allgemein annahm, dass es eine Mischung von mehreren Farbstoffen sei, ohne dass es bisher gelungen war, der einzelnen Mischungsbestandtheile wirklich habhaft 7.1 werden. Im Laufe der Arbeit ergab sich aber bald, dass aus dem Chlorophyllspectrum selbst Schlüsse auf seine Zusammensetzung aus mehreren Farbstoffen gemacht werden können und dass es nützlich sei, dasselbe eingehender kennen zu lernen. Andererseits zeigte sich bei näherer Betrachtung der bisher in der Literatur verzeichneten Spectren des Chlorophylls, dass dieselben in den einzelnen Absorptionsbändern, ganz besonders bei den für uns so wichtigen des blanen und violetten Theiles des Spectrums weder unter sich noch mit dem, was ich selbst beobachtet, in wünschenswerther Weise harmonirten. Daher enstund die Nothwendigkeit, eine Toruntersuchung über das Chlorophyllspectrum selbst zu unternehmen.

Es versteht sich von selbst, dass ich unter diesen Umständen nicht auf eine Erschöpfung des Themas ausging, sondern nur das für meinen Zweck dienliche in's Auge fasste. Dazu schien mir aber eine genauere Bestimmung des Spectrums nach folgenden drei Punkten nothwendig.

1. Hinsichtlich der Zahl der Absorptionsbänder. Die bisherigen Angaben sind nicht einmal in diesem ersten und auffallendsten Punkte bei der Charakteristik eines Spectrums völlig einig. In der 
ersten Hälfte des Spectrums (Roth bis Blau), die noch am richtigsten beschrieben und gezeichnet worden ist, werden bald vier, bald drei, mitunter gar nur zwei Absorptionsstreifen angegeben; wir werden aber sehen, dass bei normalem Chlorophyll deren constant vier sind. In der zweiten Hälfte (Blau und Violett) aber sind die bisherigen Angaben durchaus unzureichend, weil sie boi ungeeigneten Concentrationsgraden der Flüssigkeit gemacht wurden. Dieser Theil ist aber gerade der wichtigste für uns, weil sich in ihm die Absorptionen zweier Farbstoffe combiniren. Es sind dort stets 3 Absorptionsbänder vorhanden, so dass also das ganze Chlorophyllspectrum 7 Absorptionsbänder aufzuweisen hat.

2. Hinsichtlich der Lage der Absorptionsbänder. Ebensowenig als in ersterer sind in dieser Beziehung die Angaben übereinstimmend. Wenn man die verschiedenen Zeichnungen der Spectra unter einander vergleicht, muss man sich wundern, dass bis auf die neuesten die Lage der Absorptionsbänder keineswegs gleich angegeben wird. Es geht das so weit, dass nicht einmal das charakteristische und auffallende erste Band (im Roth zwischen B und C) immer in der gleichen Lage gezeichnet ist. Und zwar variiren die Angaben sowohl hinsichtlich der absoluten Lage der Bänder - so wollen wir die Lage eines Bandes nennen, wie man sie durch Bestimmung der Lage zu den Frauenhofer'schen Linien oder Ablesung an der Scala findet - als hinsichtlich der relativen Lage, d. h. des gegenseitigen Abstandes zweier Bänder. Beide Lagen. müssen wohl unterschieden werden; wir stellen unten fest, dass die Lage der Bänder reinen. Chlorophylls bei gleichem Lösungsmittel absolnt und relativ immer dieselbe ist. Die absolute Lage der Bänder ändert sich mit dem Lösungsmittel und zwar erleiden, wie es scheint, nach der Dichtigkeit des Lösungsmittels die Absorptionsbände: in toto Verschiebungen nach dem rothen oder violetten Spectralende hin. Die relative Lage wird durch chemische Aenderungen des Chlorophylls alterirt, wobei selbstverständlich einzelne Bänder auch ihre absolute Lage ändern müssen, aber nicht alle zu ändern brauchen.

3. Hinsichtlich des Baues der Absorptionsbänder. In dieser Beziehung wurden besonders drei Eigenschaften näher berücksichtigt.

Für's erste die Begrenzung eines Bandes. Im Chlorophyllspectrum selbst bieten sich besonders zwei sehr auffallende Arten der 
Begrenzung. Bei einem, dem im Roth liegenden tief schwarzen Band ist bekanntlich die Grenze sehr scharf, so dass sie beiderseits (besonders gegen das rothe Ende hin) wie abgeschnitten erscheint, wenn auch die nähere Betrachtung schattenartige Ränder erkennen lässt. Bei den übrigen Bändern dagegen Jaufen die Ränder ganz allmälig aus, so dass von der dunkelsten Mitte eines Bandes alle Grade der Erhellung bis zum völligen Lichte wahrzunehmen sind. In einem Falle (unserm Band VI) scheint die eine Seite rascher auszulaufen als die andere. Die wenigsten Zeichnungen lassen diese Eigenheiten erkennen; sie geben entweder - und dies in den meisten Fällen - alle Bänder beiderseits scharf begrenzt, oder wie HaRTing's und ANGSTRöm's Abbildungen die Ränder aller fast gleich verwaschen.

Ferner sollte berücksichtigt werden die relative Breite der Absorṕtionsstreifen. Abgesehen von der Breite eines Bandes, die mit der Concentration oder Schichtendicke der absorbirenden Flüssigkeit zusammenhängt, hat jeder Streifen ein ganz bestimmtes Breitenverhältniss zu den übrigen. Dies ist hier gemeint. Wir lernen im ersten Theile des Spectrums vier verhältnissmässig sch male Bänder kennen, die nach ihrer Reihenfolge von Roth her an relativer Breite abnehmen, im zweiten Theile 3 Bänder von ansehnlicher Breite, die ebenfalls unter sich in gesetzlichem Verhältniss stehen. Die Breitenverhältnisse ändern sich bei Zersetzungen des Chlorophylls wesentlich. Die bisher gezeichneten Spectra leiden in dieser Hinsicht - das HaGENBACH'sche ausgenommen - alle an Ungenauigkeiten.

Es gehört hieher weiter die Stärke oder Intensität der Absorption. Bekanntlich kann die Absorption des Lichts im Spectrum von einer kaum wahrnehmbaren Schwächung der Strahlen bis zur völligen Auslöschung derselben gehen. In dem einen Fall erscheint die Stelle nur schwach gedämpft, hauchartig getrübt, und das Absorptionsband mehr oder weniger grau; im anderen fehlt an der betreffenden Stelle alles Licht, das Band erscheint tief schwarz. Zwischen beiden Extremen liegt eine Reihe von Mittelstufen. Das Chlorophyllspectrum selbst bietet eine ziemliche Mannichfaltigkeit hinsichtlich der Stärke der Absorption dar und es ist besondere Aufmerksamkeit darauf verwendet worden, die Bänder in ihrer verhältnissmässigen Stärke genau wiederzugeben, ein Umstand, dem man bisher nicht genug Rechnung getragen. 
Endlich ist zu den Eigenthümlichkeiten des Baues auch die Art und Weise des Anwachsens eines Streifens bei zunehmender Concentration der Lösung u. s. w. 7.u rechnen. Während unter diesen Umständen die meisten Streifen beiderseits etwa gleich zunehmen, ist bekannt, dass das so wichtige erste Band im Roth auf der brechbareren Seite einem stärkeren Wechsel unterworfen ist. Es lag mir ferner, Eigenthümlichkeiten dieser Art einer näheren Erforschung zu unterziehen, da ich daraus für meine Arbeit vorläufig keinen Nutzen absehen kounte.

Aus diesem Grunde ist es auch unterblieben, das Spectrum bei zahlreichen wachsenden oder abnehmenden Concentrationen oder Schichtendicken der Lösung zu untersuchen, eine Methode, die seit sie von Haktivg (Pogg. Ann. Bd. 96) für das Chlorophyll zuerst eingeführt, in letzterer Zeit stets in Anwendung gebracht worden ist. Unter diesen Umständen war es nun auch möglich wirkliche Bilder, naturgètreue Abbildungen der Spectra, nicht bloss Schemata zu geben, die mir um so wünschenswerther erschienen, als, das Hagknbach'sche Chlorophyllspectrum ausgenommen, kaum eine wirklich richtige Abbildung des Chlorophyllspectrums existirt.

Hinsichtlich der Beschreibung und Bezeichnung der Bänder sei noch Folgendes bemerkt.

Bekanntlich hat Sorby (Proc. of the Royal Soc. of Lond. XV. 436 und Chem. News 1867. 220) eine neue Methode zur kurzen Bezeichnung der Spectra eingeführt, nach welcher die Absorptionsbänder durch Zahlen und wenige Zeichen hinreichend charakterisirt werden können. Die Lage der Bänder wird durch die Zahlen der (bekannten) Scala und die Stärke der Absorption durch untergesetzte Punkte oder Striche angedeutet.

Die Methode, wenn sie gleich von der näheren Physiognomie der Spectra und dem Bau der Bänder nicht hinreichend Kenntniss gibt, mag doch überall da mit Vortheil angewendet werden, wo es sich um die Charakteristik zahlreicher Spectra, die nicht alle gezeichnet werden können oder um kurze Uebersichten derselben handelt. "Für unsere Zwecke war sie insoferue entbehrlich, als die geringe Zahl unserer Spectren genau beschrieben werden musste und graphisch wieder gegeben werden konnte.

In gewissem Sinne freilich ist sie auch hier in Verwendung gekommen, indem häufig die Spectra bloss rückssichtlich der Lage ihrer 
Bänder verzeichnet wurden. Ich habe in diesem Falle aber nicht allein die Mitte, sondern auch Anfang und Ende des Bandes möglichst genau bezeichnet. Ich sage so genau als möglich, denn es versteht sich von selbst, dass bei breiten, zu beiden Seiten allmälig schattenartig verlaufenden Absorptionen die Angabe von Anfang und Ende etwas willkührlich ausfallen muss. Bei der Bezeichnung der einzelnen Bänder habe ich die in der Chlorophyllliteratur einmal eingeführte Numerirung der Bänder mit römischen Ziffern, nach Massgabe ihrer Lage vom rothen Spectrumende angefangen, beibehalten*. Die bei der Charakteristik der Metallspectra übliche Bezeichnungsmethode mittelst griechischer Buchstaben nach Massgabe der Intensität der Bänder, die neuerlich auch bei der Bezeichnung der Absorptionsbänder (z. B. des Blutes) angewendet worden ist. habe ich nicht anwenden wollen, weil es mir in vielen Fällen unmöglich schien, ohne Willkührlichkeit eine Bezeichnung zu geben.

\section{¿. Herstellung der Lösung, Concentrationen.}

Bei der Untersuchung des Chlorophyllspectrums wurde, wie bisher üblich war, von der alcoholischen, seltener ätherischen Lösung des Chlorophyllfarbstoffs ausgegangen.

Die Lösung wurde in der gewöhnlichen Weise, d. h. durch Ausziehen grüner Pflanzentheile (Blätter) in toto hergestellt und zwar wurde für alle Untersuchungen ein genau einheitliches Verfahren beibehalten. Die grünen Theile wurden zunächst in einem Probirröhrchen ein- oder mehrmal mit Wasser ausgekocht, das Wasser abgegossen und darauf mit kochendem Alcohol von 95 Volumprocenten $(0,816$ spec. Gew.) der Farbstoff sofort entzogen. Die so bereitete Lösung wurde unmittelbar zur Verwendung gebracht. Niemals wurden grössere Quantitäten bereitet und zu den Versuchen aufbewahrt.

Es ist nicht nothwendig, ausführlich auseinanderzusetzen, dass alle Darstellungsmethoden des Chlorophylls, die man früher als̃ „Reindarstellungen" betrachtet und angewandt hat, nicht diesen Erfolg hatten, sondern zur Erzeugung von Zersetzungsprodukten des Chlorophylls führten. Es war bekanntlich Berzelius **, der zuerst durch wiederholtes Abdampfen und schliessliches Lösen des Chlorophylls in rauchender

* Diese Numerirung stammt von Angström, der sie bei seiner Zeichnung der Spectra von Trifolium und Euglena (Pogg. Ann. Bd. 93, Taf. IV, Fig. 10-11) zum erstenmale angewandt hat.

** Annal. der Chem. et Pharm. XXI und XXVII. 
Salzsäure „reines Chlorophyll“ präpariren wollte. Nach seiner Methode, hin und wieder mit Modification, haben auch Mulder*, Мовот** und zuletzt Pfaundere*** ihre Analysen des Chlorophylls gemacht.

Weln man, wie wir thun, von dem Grundsatz ausgeht, dass der Farbstoff nur dann richtig und unverändert erhalten ist, wenn er das Spectrum des Chlorophylls im Blatte selbst gibt, so ergibt sich einfach schon aus dem Spectrum, welches Harting (Pogg. Ann. Bd. 96, Taf. IV, Fig. 20) von dem nach BerzeLius bereiteten reinen Chlorophyll gegeben hat, dass durch eine solche Präparationsmethode ein hochgradiges Zersetzungsproduct des Chlorophylls geliefert werden muss. Denn dieses Spectrum zeigt nicht allein die Verschiebung des Bandes II und den Mangel des III., es sind auch die charakteristische Anschwellung des Bandes IV und die Veränderungen im 2. Theile des Spectrums vorhanden, die wir später als wesentliche Merkmale durch Säure zersetzten Chlorophylls werden kemnen lernen.

Nan hat daher mit Recht - obwohl meines Wissens Niemand Gründe gegen obige Methode direct ausgesprochen - seit lange von einer sogenannten Reindarstellung des Chlorophylls völlig abgesehen und sich, in Ermanglung anderer Darstellungsmethoden, begnügt, den Farbstoff $\dagger$ mit Alcohol oder Aether u. s. w. einfach auszuziehen.

Es ist nun allerdings keine Frage, dass man durch das Ausziehen der Pflanzentheile "mit Haut und Haaren" eine Reihe von dem Farbstoff fremden Körpern nothwendig in die Lösung mitbekommt; so gewiss eine Reihe von fett- und wachsartigen Körpern, aus dem Inhalt oder von der Oberfläche der Zellen stammend $\dagger \dagger$, ferner eine Menge von Salzen, dem gleichen Orte entstammend und mit dem Chlorophyll so wenig als jene verwandt. Es ist auch keine Frage, dass diese fremden Beimengungen quantitativ und qualitativ verschieden ausfallen werden, nach der Natur des Lösungsmittels - Alcohol, Aether, Schwefelkohlenstoff - und nach dem Grade seiner Concentration - hochund niederprocentiger Alcohol und Aether. Es ist endlich auch daran erinnert worden, dass in die Chlorophylllösung auf diese Weise ein

* Journ. f. pract. Chem. XXXIII.

** Ann. scienc. nat. III. S. XIII. T.

*** Ann. der Chem. u. Pharm. Bd. CXV.

† Die Löslichkeit des Chlorophyllfarbstoffs in Alcolıol ist von den beiden Rouelle entleckt worden, nach Ed. Morren, Dissertation sur les feuilles vertes et colorées 1858, p. 59 .

†† Sachs, Experimentalphysiol. S. 336. 
gelber, in Wasser löslicher Farbstoff übergehe, den man gleichfalls ausser Beziehung zum Chlorophyllfarbstoff setzte*.

Man hat desshalb vielfach, wenigstens eine kleine Reinigungsprocedur der zu extrahirenden Blätter in Anwendung gebracht: das schon oben erwähnte Auskochen der Pflanzentheile mit destillirtem Wasser. Die specielle Absicht bei dem Verfahren war freilich eine etwas verschiedene.

Stockes (Yogg. Anu. Erg.-Bd. IV, S. 217), welcher zuerst die Blätter "mit Wasser auskochte" gibt nur den Zweck und beobachteten Erfolg des Verfahrens an, ohne die Ursachen desselben zu erwähnen. „Mein Zweck,“ sagt er, „beim Auskochen der Blätter war, den grünen Farbstoff in einem der Isolation mehr genäherten Zustande zu erhalten, allein es hatte auch überdies den Yortheil, die Lösung weniger zur Zersetzung geneigt zu machen."

Ein späterer Untersucher des Chlorophylls, Simuler (Pogg. Ann. CXV, S. 609), kochte die untersuchten ,Grasblätter * vorher mit.Wasser aus, „um den Gerbstoft zu entfernen." Er fand, dass das „hellbraune Decoct grünlich-gelb fluorescirte."

Micheli (a. a. O. S. 7 ) endlich beabsichtigte durch das Kochen mit Wasser einen gelben, nicht fluorescirenden Farbstoff zu entfernen, von dem er annahm, dass el mit dem Chlorophyllfarbstoff nichts zu thun habe **.

Meine eigenen Erfahrungen und Absichten bei der Behandlungsweise sind folgende.

Es ist zunächst gewiss, dass durch das Auskochen der Blätter mitunter ein gelber Farbstofi ausgezogen wird, dies ist jedoch nach meinen Erfahrungen verhältnissmässig selten der Fall; wir werden unten auf ihn zurückzukommen haben. Stets aber erhält man durch das Kochen eine Anzahl Salze in Lösung, wie man sich leicht überzengt, wemn man das Decoct oder nur einen Tropfen desselben auf dem Platin-

* Micheli, Quelques observations sur la matière colorante de la chlorophylle. Arch. d. scienc. d. biblioth. univ. de Genève, Mai 1867.

** „La purification des feuilles dans l'eau paraît les débarasser d'un principe colorant particulier qui ne fait pas partie de la chlorophylle. Lorsqu' on broie énergiquement des feuilles fraîches dans de l'eau distillée, celle-ci se colore en jaune: elle reste incolore, si les feuilles ont été traitées par la methode que je viens de décrire. Cette liqueur jaune n'est point fluorescente: son principe colorant est detruit et précipité par l'acide sulphurique." Vgl. auch Hagenbach, 1. c. S. 251 und 256 . 
blech zur Trockene verdampft. Allerdings habe ich nicht bemerken können, dass diese löslichen Salze, wenn sie in die Chlorophyllsolution übergehen, auf diese eine Wirkung der Art geübt lätten, dass das Spectrum der Flüssigkeit sichtlich alterirt worden wäre; wenigstens war es mir nicht möglich zwischen dem Chlorophyll ausgekochter und nicht ausgekochter Blätter spectralanalytisch einen Unterschied zu finden. Das Auskochen der Blätter meinerseits hatte vielmehr folgende zwei Gründe.

Einmal habe ich die Wahrnelımung gemacht, dass unausgekochte frische Blätter sich sehr schwer, vorher ausgekochte dagegen mit Alcohol sehr leicht extrahiren lassen. Ueber die Ursachen dieser Erscheinung habe ich nicht weiter nachgeforscht, nur so viel ist gewiss, dass, wenn man unter dem Mikroskop Alcohol einerseits zu freiliegenden durch Kochen getödteten, andererseits zu ebensolchen frischen Chlorophyllkörnern hinzusetzt, in dem ersteren Falle sich der Alcohol sofort grün färbt, im anderen die Färbung längere Zeit aussteht.

Fürs Zweite aber ist eine alcoholische Chlorophylllösung, die aus vorher gekochten Blättern bereitet wurde, in der That, wie STokES richtig gesehen, dauerhafter und zur Zersetzung weniger geneigt, als eine aus frischen Blättern sofort bereitete. Den Grund dafür glaube ich in der Entfernung des grössten Theiles löslicher Salze finden zu müssen. Wir werden nemlich weiter unten sehen, dass durch Einwirkung von (sauren) Salzen, durch ihren blossen Zusatz zu einer alcoholischen Chlorophylllösung, diese letztere sehr rasch zersetzt wird und es liegt nahe, einen ähnlichen Zusammenhang zwischen der Zersetzung und den allverbreiteten sauren organischen Salzen in den Pflanzentheilen zu suchen. Gewiss darf auch in ähnlicher Weise gedeutet werden, dass eine Chlorophylllösung, die über den extrahirten Blättern selbst stehen bleibt, sich viel leichter zersetzt als eine abgegossene. Andererseits dürfte der Mangel an solchen Salzen in der Solution den hohen Grad von Veränderlichkeit bedingen, den man an Lösungen wahrnimmt, die mit absolutem Alcohol oder absolutem Aether gemacht sind.

Die Entfernung eines gelben Farbstoffs schien mir insofern nebensächlich, als erfahrungsgemäss spectralanalytisch von ihm höchstens eine continuirliche Absorption der zweiten Spectralhälfte zu erwarten war.

Aus der ganzen Bereitungsweise, wie sie im Vorstehenden geschildert wurde, folgt von selbst, dass eine Lösung von genau bestimmter 
Concentration nicht angewendet werden konnte; höchstens wäre es möglich, von einer beliebigen Lösung als Normallösung ausgehend, bestimmte geringere Concentrationen durch gesetzmässige Verdünnung oder stärkere Concentration durch Vergrösserung der absorbirenden Flüssigkeitsschicht zu erzielen. Es lag aber, wie oben bemerkt, für uns Nichts daran, das gradweise Zu- und Abnehmen der Absorption näher kennen zu lernen. Für uns waren bloss zwei Concentrationen nothwendig. Einmal eine gewöhnliche mittlere, bei welcher die Bänder der ersten Spectrumhälfte gesondert, aber stark und in ihren charakteristischen Eigenschaften hervortreten, zum Studium der Bänder der ersten Hälfte.

Fürs Zweite eine ganz schwache, bei welcher die Lösung nur sehr diluirt grün, vielmehr gelblich-grün gefärbt erscheint - eine Concentration, bei welcher die Streifen im ersten Theil bis auf I (undeutlich ist auch II vorhanden) verschwunden sind, dagegen die Bänder der zweiten Spectrumhälfte ausserordentlich klar hervortreten und studirt werden können. Uebrigens stellten die beiden Iösungen für uns jedesmal nur approximatir die gewünschten Concentrationen dar; jede der Lösungen kounte durch Variiren der Schichtendicke zur Beobachtung verschieden starker Absorption verwendet werden. Es war, bei der Untersuchungsmethode, die wir, wie oben angegeben, verwendeten, möglich, durch einfaches Stärker- oder Schwächerneigen des Probirgläschens ineinander übergehend alle Schichtendicken herzustellen und so auf die kürzeste Weise diejenige zu finden, bei welcher die Bänder am deutlichsten hervortreten.

\section{Beschreibung des Spectrums einer weingeistigen Chlorophyllösnng.}

a) Die Bänder der ersten Spectrumhälfte.

Jede Chlorophylllösung mässiger Concentration zeigt im ersten Theile des Spectrums, wie wir das Spectrum vom Anfang des sichtbaren Roth bis zur Linie F hin ein- für allemal nennen wollen, constant vier Absorptionsbänder, die bei gleichem Lösungsmittel und gleicher Concentration stets in derselben Zahl, Lage, Stärke und von gleichem Bane wiederkehren. Es sind (Taf. I, Fig. 3-4)

1) das grosse, tiefschwarze, an den beiden Rändern fast linienscharf abgeschnittene Band I, zwischen den Frauenhofer'schen Linien B und $\mathrm{C}$, bei dünneren Lösungen näher der ersteren gelegen. Mit ibm sind an Intensität und Breite die folgenden drei nicht zu vergleichen, 
2) Von ihm durch eine mässige Verdunkelung des Roth getrennt, liegt im Orange ein zweites Band, II, in der Mitte von starker Dunkelheit, aber nicht schwarz, nach beiden Seiten kurz schattenartig verlaufend, fast genau in der Hälfte zwischen den Linien C und D.

3) Nach einer geringeren Lichtschwächung folgt Band III, unmittelbar hinter den Natriumlinien D, ansehnlich weniger dunkel als II, oder wie dieses gebaut und nach beiden Seiten abgeschattet.

4) Eine fast unmerkliche, schleierartige Lichtschwächung liegt dann über dem ganzen Grün von dem dritten Band an bis zur totalen Absorption des Lichts, die zwischen $\mathrm{b}$ und $\mathrm{F}$ allmählig anhebt, um den ganzen zweiten Theil des Spectrums zu bedecken. Und in dieser Verschleierung des Grün liegt noch einmal ein äusserst schwaches, oft nur schwer sichtbar zu machendes, ganz schmales Band IV, vor E.

Die Lage der Bänder an der Scala für eine Lösung in $95 \% \mathrm{Al}$ cohol ist:

I

$35-60-80$
II $105-120-135$
III

$180-190-200$

\section{IV}

$305-315$.

Die allmälige Verdunkelung des zweiten Theils (Blau und Violett) beginnt bei 440 und ist bei $480 \mathrm{zu}$ einer totalen und continuirlichen bis ans Ende des Spectrums reichenden Absorption angeschwollen.

Weitaus die stärkste und von jeher als charakteristisch bezeichnete Absorption ist das als I bezeichnete Band zwischen B und C. Hier ist das Licht total absorbirt und tiefe Finsterniss vorhanden. Das Band ist, wie ich bei allen normalen Lösungen ausnahmslos gefunden, beiderseits so scharf begrenzt, dass es auf den ersten Blick aussieht, als ob eine Abschattung der Ränder gänzlich mangelte. Bei genauerem Zusehen gewahrt man aber sehr kurze Schatten zu beiden Seiten, und zwar einen kürzeren auf der weniger brechbaren rothen Seite gegen $B$, als auf der gegen $\mathrm{C}$ gelegenen. Hier ist der Schatten merklich länger und gibt somit eine Andeutung des breiten Schattenansatzes, den wir bei dem Bande am lebenden Blatte kennen lernen werden. Dieser Schatten scheint es offenbar zu sein, welcher bei zunehmender Concentration der Lösung oder Dickenzunahme der Flüssigkeitsschicht sich verdunkelnd eine Verbreiterung des Bandes gegen $\mathrm{C}$ hin und über dieses hinaus zur Folge hat. Es ist nemlich eine Eigenthümlichkeit dieses Bandes, dass es bei zunehmender Absorption vorwiegend auf seiner brechbareren Seite wächst, ein Umstand, auf den, meines Wissens, A skenasy (Bot. Ztg. 1867, S. 226, Taf. V, Fig. 1) zuerst auf- 
merksam gemacht und der seither von allen Beobachtern bestätigt worden ist. Vgl. Hagenbach, Pogg. Ann. 1870, Taf. II, Fig. 8; Gerland et Rauwenhoff, Arch. Néerl. 1870, Taf. I, Fig. 1 ff.

In jüngster Zeit ist von zwei Seiten her eine Eigenthümlichkeit des Bandes hervorgehoben worden, die ich trotz wiederholtem und genauem Untersuchen der Frage nicht finden konnte, ich meine die von Schönn, Gerland und Rauwenhoff angegebene Duplicatur des Bandes.

Schösx gibt in einer Notiz ,über Blattgrün und Blumenblau* (Fresenius, Zeitschr. f. anal. Chem. 9. Jahrg. 1870, S. 327) an: „Der Streifen im Roth besteht aus zwei schwarzen Bändern und der etwas licht durchlassenden Mitte."

Von ihm unabbängig haben E. Gerland und N. W. P. RauwexHOFF in ihren ..Recherches sur la chlorophylle et quelques-uns de ses dérivés" (Arch. Néerl. T. VI. 1871, p. 2 und 6 des Separatabdr.) ein Aehnliches gefunden. Sie sagen: „Quant à la bande I, elle s'est montrée à nous, comme à M. Schöxs, composée de deux bandes distinctes, que nous appellerons Ia et Ib. Leur intensité est presque la même, et celle de l'espace qui les sépare n'en diferre aussi que très peu. La figure 1 fait voir distinctement, toutefois, que cela n'a lieu que pour certains degrés de concentration bien déterminés. - Quand la concentration devient plus forte, les deux bandes se confondent en une seule; lorsqu'elle est plus faible, la bande Ia conserve toute son obscurité, tandis qu'à son côté le plus refrangible se place une zone dont l'intensité est égale à celle qu'on observe entre Ia et Ib.* (p.6.)

Ich habe mich, nachdem mir die beiden Angaben bekannt geworden, oft und immer wieder bemüht die Sache in der Weise zu sehen, wie es die beiden Vorgänger beschreiben. Das Resultat aber, das ich erhalten, stimmt nicht damit überein; es lässt sich in Folgendem zusammenfassen.

Bei völlig normalen Lösungen habe ich mitunter, durchaus nicht immer, bemerken können, dass der rechte Rand des Bandes I (der gegen die brechbarere Seite gelegene) etwas, aber nur sehr wenig, allmäliger abgeschattet ist als der linke, gegen das rothe Ende gelegene - ein Resultat, zu dem auch die genaue Untersuchung HagenBaCH's geführt hat. Da aber meines Erachtens GerLand und Rauwenhoff zersetztes Chlorophyll, nicht normales, in ihrer Fig. 1 - der massgebenden - untersuchten, so galt es bei diesem die Erscheinung näher 
in's Auge zu fassen. Bei diesem fand ich den rechten Rand noch mehr als bei normalem abgeschattet, wie es in unserer Fig. 7 auf Taf. I deutlich hervortritt, aber auch hier konnte ich eine wirkliche Trennung des Schattens bei keiner Concentration wahrnehmen. Am Deutlichsten endlich und ziemlich scharf abgesetzt, aber niemals getrennt, fand ich den rechtsseitigen Schatten bei dem Spcctrum lebender Blätter, auf den wir unten ausführlich werden zu sprechen kommen. Es ist aber ausdrücklich hervorzuheben, dass dieser Schatten in keinem Falle die Intensität des eigentlichen tief schwarzen Bandes annahm.

Gerade diese letztere Behauptung in den Angaben der beiden Forscher hat mir eine Vermuthung nahe gelegt, "wie vielleicht die Ansicht von der Duplicatur des Bandes auf andere Weise, als aus der objectiven Kenntniss des eben genannten Schattens entstanden sein mag. Es scheint mir nemlich, eine subjective Erscheinung bei der Betrachtung des Spectrums für objectiv gehalten worden zu sein. Beobachtet man den schwarzen Streifen, wenn er eine gewisse, ziemlich ansehnliche Breite erreicht hat, länger und fixirt ihn genauer mit dem Auge, so glaubt man plötzlich mitten durch denselben einen ziemlich hellen rothen Streifen gehen zu sehen und man gewahrt ein Bild, als ob der vorher einzige breite schwarze Streifen in zwei gleich breite Bänder zerfallen sei, zwischen denen das rothe Licht hindurch schimmert. Die Erscheinung verschwindet sofort, wenn man wegsieht, das Auge einen Moment ausruhen lässt und dann wieder beobachtet. Ich war keinen Moment im Zweifel, dass es sich hier um eine subjective Erscheinung handle. Mein verehrter College LommeL, ein genauer Kenner des Chlorophyllspectrums, erklärte die Erscheinung auf mein Befragen für eine Contrastwirkung.

Was mich besonders in der Meinung bestärkte, in dieser subjectiven Erscheinung den Grund für die Behauptung der Duplicatur zu finden, ist, einmal, dass die Beschreibung der Erscheinung, insbesondere Schöns's, so genau passt, andererseits die Erfahrung, dass diese Art Duplicatur in der That nur bei einer gewissen, beträchtlichen Breite des Streifens - ganz so wie von den Beobachtern verlangt wird eintritt.

Wenn das Band I vorhin das charakteristischste von Allen genannt wurde, so soll damit nur gesagt sein, dass es vermöge seiner Eigenschaften leichter als die anderen kenntlich ist; nicht allein, dass es durch Breite und Schwärze vor allen übrigen hervorsticht, es erscheint 
auch in den dünnsten Lösungen zuerst, und erhält sich bei Zersetzungen und beim Ausbleichen des Chlorophylls weitaus am längsten. Schon Brewster (Transact. Roy. Soc. Edinb. XII. 542) hatte gefunden, dass dieses Band noch in Chlorophylllösungen $\mathrm{zu}$ erkennen ist, die (fast) wasserhell geworden sind.

Dagegen müsste ich mit Entschiedenheit widersprechen, wenn man glauben wollte, die Bändel II-IV seien weniger constant, vielleicht nur gewissen Modificatiouen des Chlorophylls eigenthümlich oder fremden Beimengungen zuzuschreiben. Meines Wissens hat ausser Askenasi (a. a. O. S. 228) in letzterer Zeit Niemand diese Ansicht geäussert; GerLand und RaUwenhoff haben ihm gegenüber bereits die Zugehörigkeit dieser Bänder zum Chlorophyllfarbstoff vertheidigt (a. a. O. S. 16). Es wäre in der That sonst nicht abzusehen, wie ich bei allen unter angeführten Pflanzen und in jedem Lösungsmittel die Bänder als Begleiter des ersten hätte finden sollen. Wenn die Streifen, wie sogleich anzugeben, bei Zerstörungen des Chlorophylls durch Licht oder Säuren veränderlicher oder leichter verwischbar erscheinen, so darf man meines Erachtens daraus nur schliessen, dass die Atomgruppen, denen das Chlorophylhmolecül diese Absorptionen verdankt, beweglichere und leichter zerstörbare sind, als die, welche das schöne Band zwischen $\mathrm{B}$ und $\mathrm{C}$ hervorrufen. -

Das Band II, nach I weitaus das stärkste im ersten Theil, ist wie die folgenden ron jenem dadurch wesentlich unterschieden, dass die Absorption auch bei den stärksten Concentrationen, bei denen sie noch selbstständig erscheint, in der Mitte niemals tief schwarz und total erscheint, und dass die Ränder stets breit schattenartig nach beiden Seiten verlaufen. Es erleidet, wie wir später sehen werden, bei Zersetzungen des Chlorophylls nur geringe Veränderungen, indem es nur ein wenig gegen die brechbarere Seite hin verschoben wird und an Stärke ansehnlich abnimmt.

Anders dagegen der viel schwächere, sonst gleich gebaute hinter D liegende Streifen III. Er rückt bei Zersetzungen des Chlorophylls sofort sehr beträchtlich gegen das blaue Ende hin und nimmt dabei oft bis zur schattenartigen Verblassung an Stärke ab. Er ist überhaupt nicht selten von eigenthümlicher Verwaschenheit, mehr als Band IV, das freilich immer nur ein äusserst zarter, aber deutlich contourirter, feiner Streifen von grosser Constanz ist. Diese Eigenschaft, wie die Eigenheit desselben, bei zunehmender Concentration nur 
äusserst wenig zu wachsen, während das umgehende Grün selbst sich immer mehr verdüstert, haben viel dazu beigetragen, dass er in den Beschreibungen und Zeichnungen übersehen wurde. Bei Veränderungen des Chlorophylls verändert er sich weitaus am meisten von allen besprochenen: zwar bleibt er in Lage, aber er schwillt zu einem Bande an, das an Breite und. Stärke das normale II erheblich übertriffit. -

Es erübrigt zu betrachten, wie sich bei zunehmender Concentration oder Zunahme der Dicke der absorbirenden Flüssigkeitsschicht die Absorptionen gestalten.

Wie bemerkt, folgen sich der Breite wie der Stärke der Absorption nach die Bänder I-IV wie ihre Nummern selbst; und in gleicher Weise verhalten sich auch die Verdunkelungen der Strahlen zwischen ihnen. Die Verdunkelung zwischen I und II erscheint stärker als die zwischen II und III, und diese wiederum bedeutender als die zwischen III und IV, welch' letztere der zwischen IV und der totalen Endabsorption völlig gleich kommt. Es fliessen demnach auch bei zunehmender Concentration die Bänder I und II zuerst, damn II und III zusammen. Selbst wenn letztere Streifen völlig untereinander, wie mit I zu einer totalen Absorption zusammengeflossen, blickt zwischen III und IV einerund IV und der blauen Endabsorption andererseits das Grün noch ziemlich klar hindurch. Geht die Concentration noch weiter, so fliessen unter stetiger Verdunkelung des Grün, indem gleichsam die Finsterniss vom blauen Ende und von III her immer weiter gegen einander vorrückt, endlich die beiden grossen Absorptionen zu einer einzigen zusammen, die das ganze Spectrum bedeckt, mit Ausnahme des äussersten Roth von B bis zur Grenze der Sichtbarkeit. Am rothen (braunen) Ende habe ich niemals eine Verdunkelung oder eine Hinwegnahme der letzten Endigung bemerken können. Es muss dies desshalb hervorgehoben werden, weil eine solche Endabsorption am Roth wiederholt bis in die neueste Zeit verzeichnet worden ist. So zuerst von ANGSTRÖM, dann von HARTING und nachdem sie inzwischen von den Beobachtern nicht mehr angegeben worden war, in jüngster Zeit wiederum von Preyer (Die Blutkrystalle, 1871, Taf. II, Fig. 14-16). Vgl. das Nähere in der Literaturangabe.

b) Die Bänder der zweiten Spectrumhälfte.

Dass bei concentrirteren Lösungen, wie man sie gewöhnlich benutzt, die ganze zweite Hälfte des Spectrums - so nennen wir das 
Spectrum von $\mathrm{F}$ ab bis zum sichtbaren Ende hinter den beiden Linien $\mathrm{H}$ - total absorbirt wird, haben wir bereits gesehen, und darin stimmen auch alle Angaben einmüthig zusammen. In der That ist, wie oben bemerkt, schon von 440 an, also bald hinter b eine Verdunkelung des Blaugrün zu bemerken, die bei 480 (also vor F, welches auf 510 liegt) in eine totale Verfinsterung übergegangen ist (Taf. I, Fig. 3). Wie sich dagegen die Absorptionen bei schwachen Solutionen gestalten, darüber sind merkwürdiger Weise bis auf die neueste Zeit nur sehr spärliche Angaben gemacht. Merkwürdig besonders desshalb, weil schon in dem ersten Spectrum von Brewster (a. a. O. Pl. XII, Fig. 2) zwei sehr schöne und starke Bänder im Blau, das eine hinter F, das andere bei $\mathrm{G}$ gezeichnet worden sind. Dieselben werden nur noch von STOCKES vorübergehend (a. a. O. S. 248) erwähnt, dann verschwindet wenigstens das eine spurlos aus der Literatur, während das andere, hinter $\mathrm{F}$ gelegene, hin und wieder (z. B. von Angström, Askenasy u. A.) Erwähnung findet. Eine richtige Würdigung aber haben diese Bänder erst wiederum durch Hagenbach gefunden (a. a. 0. S. 267 f. u. 272), der dieselben zwar nicht in seiner Zeichnung (Fig. 8), wohl aber im Fluorescenzspectrum und im Texte richtig hervorhebt.

Es ist allerdings von ihm mit Recht bemerkt worden (S. 267), dass der Concentrationsgrad, bei dem man die Bänder gewahrt, schwer zu treffen sei. Bedient man sich aber, wie wir, einer ganz dünnen, nur gelbgrünen Lösung, und lässt man nach unserer Methode durch verschieden starkes Neigen des Probirröhrchens alle mögliche Dicken der Flüssigkeitsschicht vor dem Spectrum rasch vorbeipassiren, so findet man ausserordentlich rasch (fast momentan) die richtige Haltung, bei welcher die Bänder auf's Schönste hervortreten. Ein besonderes Erforderniss ist freilich auch noch, dass man directe Sonne oder wenigstens das Licht des besonnten Himmels anwende. Bewölkter Himmel ist zu dunkel, auch Lampenlicht (Gas) völlig ungeeignet, wenigstens um alle Bänder des blauen und violetten Theiles zu gewahren. Leichter ist das erste Band zu sehen; es wurde desshalb auch öfter als die übrigen gezeichnet.

Um die Bänder des zweiten Theiles sicher zu sehen, nimmt man eine ganz schwach grüne Chlorophylllösung, an der bei einer Dicke von 1 Centimeter nur die ersten Bänder des ersten Theiles stark hervortreten und bringt dieselbe vor den sonnebeleuchteten Apparat. Nach einer kurzen Probe, hinsichtlich des Neigens des Glases, wird man 
alsbald hinter $\mathrm{F}$ drei sehr schöne, im Bau ron einander wesentlich abweichende breite Absorptionsbänder, oder richtiger innerhalb einer schwachen continuirlichen Absorption des ganzen zweiten Theiles drei bandartige Anschwellungen gewahren. In dem lichtblauen Theile, gerade hinter $\mathrm{F}$ beginnend, liegt ein beiderseits schattenartig verlaufendes, in der Mitte fast schwarzes Band, das wir mit Bezug auf die bereits früher bezeichneten $\mathrm{V}$ nennen. Nicht minder auffallend und merkwürdig gebaut erscheint ein zweites - VI - etwas hinter der Mitte von F und G allmälig und schattenartig anhebend, kurz vor und auf G zu einer fast schwarzen Absorption anschwellend, hinter G rascher, als es begonnen, schattenartig 'endend. Gegen. das Ende des Spectrums tritt wiederum fast plötzlich eine totale Absorption ein, welche das ganze Ende hinwegnimmt und VII genannt werden soll.

Die genauere Lage des ersten Bandes, das wie bemerkt in der Mitte fast schwarz, nach beiden Rändern gleichmässig abgeschattet ist, ist folgende:

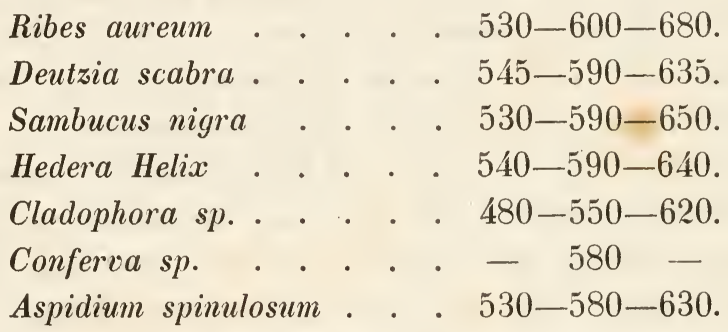

Man sieht, dass die Lage einigen, allerdings nicht sehr beträchtlichen Schwankungen unterworfen ist.

Dieses Band, von Brewster zuerst gesehen, wurde von den späteren Beobachtern gewöhnlich allein als eine gesonderte Absorption im zweiten Spectrumtheile genannt, während die folgenden Bänder übersehen wurden. Es gehört, wie wir später sehen werden, einem im „Chlorophyll* vorhandenen gelben Farbstoff an, der mit dem meisten Blumengelb und dem Farbstoff etiolirter Pflanzen identisch ist.

Das VI. Band, ebenfalls von Brewster entdeckt, dagegen später fast ausnahmslos übersehen, beginnt etwa im dritten Dritttheil zwischen $\mathrm{F}$ und $\mathrm{G}$ ziemlich allmälig, schwillt ziemlich rasch vor, auf und hinter der Linie $\mathrm{G}$ zu einer sehr intensiven Absorption an und endet oft - nicht immer - etwas rascher als es angeschwollen. Seine Intensität übertrifft die von V. Seine Lage ist constant und im Mittel: $765-820-880$. 
Der eben angeführte eigenthümliche Bau - das raschere Endigen, langsamere Anschwellen - rührt, wie wir später sehen werden, daher, dass es die Combination zweier, nahezu aufeinander fallender Bänder verschiedener Farbstoffe ist; der vordere schwächere Theil gehört demselben gelben Farbstoff an, der das Band $\mathrm{V}$ zu eigen hat, während der finstere und jäh endende Theil einem blangrünen Farbstoffe zugehört, demselben, der die vier Bänder des ersten Theils hervorruft.

Das Band VII, wie wir die totale Hinwegnahme des violetten Endes nennen wollen, beginnt unter den vorstehenden Umständen gewöhnlich um 960. -

Es ist schon kurz angedeutet worden, dass die gesammten sieben Bänder des Chlorophylls nicht alle zu gleicher Zeit sichtbar zu machen sind. Bei der schwachen Concentration, bei welcher die Bänder V-VII klar und individuell hervortreten, sind in der ersten Hälfte nur I, das als schmaler schwarzer Strich erscheint, und andeutungsweise II vorhanden, III und IV dagegen können, ihrer Schwachheit wegen, nicht gesehen werden. Andererseits fliessen die Bänder V-VII, jedenfalls aber VI und VII zusammen, wenn III und IV zum Vorschein kommen sollen. Nichtsdestoweniger darf man aber sagen, dass das richtige Chlorophyllspectrum aus sieben Absorptionsbändern zusammengesetzt ist, aus vier schmalen im ersten und drei breiten im zweiten Theile.

Uebrigens kann man sich nach der Methode, die wir bei der Untersuchung befolgt haben, eine dünne Chlorophylllösung vor dem Spectroskope stärker und schwächer zu neigen, leicht an derselben Lösung wenigstens nacheinander die sämmtlichen Bänder vorführen. Bei der stärksten Neigung des Glases, wo die Flüssigkeitsschicht am dünnsten, erscheint bloss der Streifen I, als dünner aber fast schwarzer Strich, der bei etwas weiterer Hebung des Glases bald als dicker schwarzer Balken auftritt, wobei alsbald auch das Band VI zum Vorschein kommt und gleichzeitig oder kurz nachher, - ich lasse es dahin gestellt - die Endabsorption VII gewahrt wird. V, das ich stets nach VI kommen sah, erscheint etwa gleichzeitig mit dem deutlich auftretenden II; III und IV folgen zuletzt und um diese Zeit ist VI und VII nicht mehr von einander getrennt, öfter sogar V und VI fast unkenntlich zusammengeflossen.

Umgekehrt kann man von dem Spectrum, wie es gewöhnlich gezeichnet wird, mit vier Streifen im vorderen und der continuirlichen Absorption im hinteren Theile ausgehen. Oefter sieht man dann, bei 
einger Neigung des Glases, während die Bänder III und IV noch deutlich zu erkennen sind, V bereits vou der dahinter liegenden Endabsorption (die VI und VII zugleich enthält) sich ablösen. Dann verschwinden III und IV, II wird sehr schmal und VI beginnt von VII sich abzuheben. Die scharfe Distinction zwischen VI und VII kommt (in directer Sonne) erst dann zum Vorschein, wenn im ersten Theile nur die Absorption I als ein schmaler schwarzer Streifen übrig ist.

c) Identität des Chlorophyllspectrums bei den höheren Pflanzen und einem Theile der niederen.

Bei der Besprechung des Chlorophyllspectrums im Vorhergehenden wurde gewöhnlich keine Pflanze namhaft gemacht, von welcher die Lösung speciell bereitet worden, und es war das insofern unnöthig, als bei allen vorgenommenen genau dasselbe Spectrum gefunden wurde, was Zahl, Lage und Bau der Streifen anlangt, selbstverständlich, nachdem für alle eine einheitliche Behandlung festgehalten worden war: es wurden stets kleine Stücke der Blätter in einem Probirröhrchen mit Wasser ausgekocht, dann sofort mit kochendem $(95 \%)$ Alcohol extrahirt und der Untersuchung unterzogen.

Es gehören aber die untersuchten Pflanzen sehr verschiedenen Gruppen an.

Von Mono- und Dicotylen wurden untersucht: Deutzia scabra und gracilis, Philadelphus coronarius, Saxifraga ligulata, Primula offcinalis, Funkia cordata, Sanguisorba officinalis, Caltha palustris, Prunus Padus, Hedera Helix, Hablitzia tamnoides, Rhododendron maximum, Betonica officinalis, Lolium perenne, Paeonia officinalis, Ribes aureum, Camellia, Pittosporum undulatum, Pyrus Malus, Lappa major, Pastinaca sativa, Sambucus nigra, Ampelopsis hederacea, Vitis vinifera, Mercurialis perennis, Ulmus, Tilia, Hydrangea arborescens *.

Von Gefässkryptogamen: Onoclea sensibilis, Aspidiuin spinulosum, Thelypteris, Struthiopteris germanica, Aspidium Filix mas, Scolopendrium und Selaginella hortensis.

Von Moosen: Marchantia, Ceratodon, Funaria und Bryum.

Von Chlorophyllalgen: Cladophora, Zygnema stellinum, Conferva sp. und Spirogyra (kleine Art).

* Anschliessend an die schöne Entdeckung Wiesner's, Chlorophyll in Neottia nidus betreffend (Bot. Ztg. 1871, S. 619), kann ich bemerken, dass ich aus alten Herbarienexemplaren einen Auszug erhalten habe, der deutlich die Bänder I, sowie IVa und b gezeigt hat. 
Nimmt man, was wohl von Niemand bezweifelt wird, an. dass gleichen Spectren auch gleiche Stoffe entsprechen; so ergibt sich aus dem Vorstehenden, dass der Chlorophyll farbst off bei allen höheren Pflanzen, bei Gefässkryptogamen bis auf die Moose herab, und selbst bei den sogenannten nChlorophyllalgen" identisch ist.

Für die bunten Algen (nebst Flechten) - wie wir kurz alle nicht èhlorophy,llgrünen Thallophyten nennen wollen - z. B. Florideen, Fucaceen, Phycochromaceen, Diatomaceen - wird die Frage noch zu entscheiden sein. Eine Untersuchung über Oscillaria, die unten angeführt werden soll, lässt vermuthen, dass hier $\mathrm{MI}$ od i f icationen des Chlorophylls auftreten.

In der Folge werden wir freilich sehen, dass von einem (einzigen) "Chlorophyllfarbstoff" nicht die Rede sein kann," dass vielmehr "das Chlorophyl1“, „der Chlorophyllfarbstoff“ eine Mischung mehrerer (wenigstens zweier) Farbstoffe, und das ,Chlorophyllspectrum" die Combination (Uebereinanderlagerung) zweier Spectra ist, wornach wir, streng genommen, nicht von einer Identität des Chlorophyllfarbstoff's, sondern der Farbstoffmischung zu sprechen hätten. -

Es lag nicht in meiner Absicht, die Schicksale des Chlorophylls von der Zeit seines Entstehens im Frühling bis zu seiner Zerstörung im Herbste zu verfolgen; es wurde aber soviel nebenbei beobachtet, dass das Spectrum des Chlorophylls ganz junger Blätter (Prumus Padus. Piltosporum undulatum) und das der herbstlichen (noch nicht verfärbten) z. B. von Tilia, Ulmus, Populus, ebenso das mehr als einjähriger von Hedera und Camellia mit dem der gewöhnlichen ausgewachsenen heurigen übereinstimmt.

\section{d) Historisches und Kritisches.}

Ich habe bisher auf die Literatur nur dann Rücksicht genommen, wenn es die Sache unmittelbar forderte oder eine Bemerkung sich zwanglos anschliessen liess. Es soll jetzt die Literatur ausführlich besprochen werden, besonders um auf die Ursachen hinzuweisen, die es mit sich brachten, dass die verzeichneten Spectra nicht unter sich, noch mit dem oben beschriebenen Spectrum übereinstimmen; denn vielleicht dürfte es auffallend erscheinen, dass in einer scheinbar so einfachen Beobachtungssache so ausserordentlich abweichende Ångaben gemacht worden sind. 
Freilich wird sich nicht immer die Fehlerquelle der verschiedenen Beobachtungen angeben lassen, zumal da vielfach über die Darstellungsoder Beobachtungsmethode Nichts oder nur ganz kurz berichtet worden ist; wo aber diese angeführt ist, lässt sich mitunter schon daraus mit voller Sicherheit erweisen, dass durch sie ein richtiges Spectrum unmöglich erhalten werden konnte.

So ist insbesondere, was die Darstellungsmethoden der Chlorophylllösung anlangt, von vornherein anzunehmen, dass alle jene Präparationen, die einen längeren, mit Abdampfen, Fällen oder längerem Verweilen an Luft, Licht u. s. w., längerer Berührung mit den getödteten Blättern verbundenen Weg wählen, fast absolut zur Darstellung von zersetztem Chlorophyll führen. Während z. B. die kurze Operation, die Hagenbach (a. a. O. S. 247) anwendet, zur Darstellung eines ganz normalen Chlorophylls führte, hat Askenasy (a. a. 0. S. 225), wie mir scheint, einzig und allein durch seine Präparationsmethode angegriffenes Chlorophyll erhalten.

Andererseits ist nicht zu vergessen, dass gewisse Blätter zur Darstellung unveränderten Chlorophylls nur schwer verwendbar sind, mindestens, wenn man sie vorher mit Wasser auskochen will. Einen solchen Fall, über den ich unten berichten werde, habe ich bei Ampelopsis und Vitis* kennen gelernt.

Für's Zweite kommt aber auch die Beobachtungsmethode und das Instrument in Betracht.

Es kann meines Erachtens nicht genug betont werden, wie viel es auf die Lichtstärke des Apparates, besonders bei Beobachtung der Streifen III und IV, dann der Bänder im Blau und Violett ankommt. Der Mikrospectralapparat, der so ausserordentlich lichtstark ist gegenüber den gewöhnlichen Instrumenten, erforderte mitunter grosse Aufmerksamkeit um das schattenschwache Band IV zu erkennen, und ich bin überzeugt, dass es in manchen Zeichnungen bloss desshalb fehlt, weil es der lichtschwache Apparat nicht erkenuen liess.

Es darf ferner nicht Wunder nehmen, wenn Harting bis auf einen einzigen Fall das (an zersetzten Lösungen, wie er sie vor sich hatte) sehr schwache Band III nicht gesehen hat, da er das Spectrum, wie er selbst angibt (a. a. O. S. 544) auf Schirmen aufgefangen, objectiv wiedergegeben hat, eine Methode, bei welcher das Spectrum

* Vgl. Pfeffer in Arbeiten des bot. Instituts in Würzburg. Heft 1. S. 27 und 28 . 
jedenfalls lichtschwächer und die Grenzen der Streifen undeutlicher erscheinen müssen.

Endlich muss hervorgehoben werden, dass die Lichtquelle von Bedeutung ist, besonders für die Untersuchung der Absorptionen des blauen und violetten Theiles. Letzterer erscheint bei Lampenlicht kürzer und so dunkel, dass es schwer wird, Absorptionen darin zu gewahren. Schon aus diesem Grunde wird z. B. erklärlich, warum ANgström und Askevasy die Bänder des zweiten Spectraltheiles nicht sahen.

Nach diesen allgemeinen Bemerkungen möge eine Besprechung der bisherigen Chlorophyllspectra folgen.

Brewster, On the colours of natural bodies (Transact. of the Royal Society of Edinburgh. 1834. T. XII, p. 5̌38 ff. u. Plate XII, Fig. 2), der Entdecker der Fluorescenz und des Absorptionsspectrums des Chlorophylls, hat von dem weingeistigen Auszug aus den Blättern von Prunus Lanrocerasus ein Spectrum gegeben, welches, besonders im zweiten Theile, viel richtiger als die meisten späteren ist. Freilich ist zu bemerken, dass sein Spectrum weder den Bau der Bänder, noch die Verdunkelungen zwischen denselben berücksichtigt, - ein Mangel, den es allerdings mit den meisten nachfolgenden theilt - auch wohl nicht das Spectrum einer einzigen Lösung sein kann, sondern offenbar eine Combination aus zwei Lösungen darstellt, da man die beiden Streifen im Blau und Violett, die er zeichnet, nicht sehen kann, wenn die Streifen im ersten Theile in solcher Intensität und Breite, wie sie bei ihm vorhanden sind, auftreten.

'Sein Spectrum gibt fünf Bänder' an, die alle etwa gleich, also schematisch, angedeutet sind. I ist an seiner Stelle gezeichnet, ebenso II, diess jedoch gewiss zu breit; unser Band III (hinter D zu suchen) ist nicht vorhanden. Dieser Umstand einerseits, andererseits die Zeichnung von IV, welches viel zu stark wiedergegeben, weisen mit Sicherheit darauf hin, dass er das Bild einer veränderten Chlorophylllösung wiedergibt, von einer Veränderung, die allerdings nicht sehr beträchtlich gewesen sein kann, einmal weil die Bänder des blanen Theiles noch sehr gut erhalten, dann weil er stark veränderte Chlorophyllösung selbst schon gekannt hat. ANGSTRör (a. a. O. S. 478) hat, wie schon Hagenbach (a. a. O. S. 266) bemerkt, Unrecht, wenn er den eben als IV angesprochenen Streifen BREwster's für seinen Streifen III erklärt, da letzterer nach seiner eigenen Angabe bei E liegt. Unser Band V zeichnet er gleich hinter $\mathrm{F}$ in ansehnlicher Breite; HAGEN- 
BACH scheint diesen Streifen (a. a. 0. S. 265) anders zu interpretiren, da er meint, sein Band VI (unser V) sei noch "von keinem früheren Autor angegeben" worden. Endlich gibt er unser VI vor G; dagegen hat er eine Endabsorption nicht angedeutet.

Die Beschreibung, die er von dem Wechsel des Spectrums bei zunehmender Dicke der absorbirenden Schichte gibt*, scheint mir vielmehr für zersetztes, als normales Chlorophyll zu passen und zu bestätigen, dass er in der That vorwiegend ersteres untersucht hat.

Stockes, Pogg. Ann. Erg.-Bd. IV, S. 218 ff., welcher Chlorophylllösung besonders von Nesselblättern studirte, machte insofern einen Fortschritt in der Kenntniss des Chlorophyllspectrums, als er, wie aus seinen Auseinandersetzungen (S. 218 und 219) über „frisches“ und „modificirtes“ Chlorophyll hervorgeht - Abbildungen gibt derselbe nicht - die vier ersten Bänder nach Zahl, Lage und Stärke wohl erkannt hat; denn er sagt (S. 218): "die dunkeln Streifen Nr. 1 und 2 liegen im Roth, Nr. 3 liegt etwa.im Gelb oder Gelbgrün, Nr. 4 im Grün und Nr. 5 erst im Blau." Die Beschreibung der Lage und Stärke bei der Auseinandersetzung der Veränderungen an „modificirten" Lösungen ist ganz richtig. Er kennt besonders auch die Unveränderlichkeit von I, und die Veränderungen, die III und IV erfahrt.

Im zweiten Theile freilich kam er über die BREwsteR'schen Beobachtungen nicht hinaus; es war auch wohl nicht möglich, da er bei Kerzenlicht arbeitete.

Angström's Zeichnungen (Pogg. Ann. Bd. 93. 1854. Taf. IV, Fig. 10 und 11) sind hauptsächlich desshalb interessant, weil sie zum ersten Male eine graphische Darstellung der Absorption bei zunehmender Schichtendicke geben, und ein Versuch gemacht wird den $\mathrm{Bau}$ der Streifen anzudeuten. Man sieht z. B. deutlich Band I beiderseits scharf begrenzt, die übrigen schattig auslaufen; ferner wie das Band I bei zunehmender Absorption auf der brechbareren Seite fast allein wächst, während die übrigen gleichmässig auf beiden Seiten

* "At a certain thickness of the green fluid there are three red bands. By increasing the thickness, the violet and blue spaces are absorbed, and the two inner red bands. An absorption then begins near the middle of the green space, and after destroying the more refrangible portion of that space, three bands are left; vize on e faint band of the extreme red, one band almoste white, corresponding with the luminous spectrum, and on e green band contiguous to the white one." 
anwachsen. Allerdings tritt bei ihm auch zum ersten Male die, meines Erachtens nicht vorhandene, Absorption am äussersten rothen Ende in der Zeichnung auf.

Im Uebrigen stimmen die beiden Spectra, die er Fig. 10 von einem Auszug von Trifolium pratense, und richtiger in Fig. 11 von Euglena viridis gibt, nicht überein, wohl, wie es scheint, weil der Auszug aus dem Klee bereits zersetzt war.

Beim Euglenen-Auszug sind die Streifen I--III auch in ihrer Lage ganz richtig angegeben, IV, wahrscheinlich schwach vorhanden, ist übersehen. Unerklärlich ist, wie er zu einem auf E fallenden Streifen gelangte. Im zweiten Theile ist nur eine totale Absorption gezeichnet.

Der Auszug aus den Kleeblättern gibt den Streifen III nicht; dieser Umstand wie die sehr starke Wiedergabe von IV weisen darauf hin, dass die Lösung zersetzt war. Hinter $\mathrm{F}$ ist eine Andeutung von $\mathrm{V}$, weiterhin nur eine totale Absorption gegeben.

Das Spectrum von Blättern des Potamogeton perfoliatum und Taxus baccata findet er mit dem letzteren übereinstimmend.

Schon aus dem eben Gesagten lässt sich entrehmen, das die Ungleichheit der Spectra nicht berechtigt, auf ungleiche Farbstoffe bei Algen und Phanerogamen zu schliessen, wie ANGSTRöm gethan.

Dies hat auch Harting in seiner Arbeit über das „reine und unreine Chlorophyll- (Pogg. Ann. Bd. 96. 1855. S. 543 ff.) gethan, in welcher zum ersten Male die Chlorophyllspectra von sech s vers chi edenen Pflanzen (Syringa vulgaris, Fraxinus excelsior, Senecio Doria, Vitis vinifera, Vaucheria clavata und Spirogyra maxima), Taf. IV, Fig. $12-16$ und 19 nebeneinander gestellt und ihre Identität darzuthun gesucht wird. Freilich konnte die Art und Weise der Darstellung der Spectra - Auffangen derselben auf weissen Schirmen - die Umrisse und Intensität der Bänder und somit ihren Bau nur undeutlich wiedergeben. Es kommt auf diese Weise, dass selbst das Band I wenig scharf begrenzt erscheint, dass feinere Streifen nothwendig übersehen wurden.

Dies Uebersehen trifft hier unser Band III, das bei zersetzten Lösungen undeutlich und sehr schwach wird. Dass er aber schwach zersetzte Lösung vor sich hatte, geht nicht allein daraus hervor; er zeichnet auch - typisch für zersetztes Chlorophyll - Band II etwas zu nah an die Linie D, und IV zu stark. Im zweiten Theile gibt er, weniger genau als seine Vorgänger, nur eine continuirliche Absorption. 
In der einzigen Fig. 17 hat er, wie es scheint, eine unveränderte Lösung vor sich gehabt; denn er gibt die Bänder III und IV in der Lage richtig, allerdings von gleicher Stärke wie II an. Es ist bemerkenswerth, dass die Lösung eine ätherische war, die sich nach meinen Beobachtungen überhaupt besser hält als weingeistige. Dass seine ain rothen Ende gezeichnete Absorption von mir nie gesehen wurde, ist bereits erwähnt worden.

Das Spectrum, das er von reinem, nach der BerzeLius'schen Methode hergestellten Chlorophyll gibt (Fig. 20), trägt, wie wir später auszuführen haben, alle Merkmale des von Säuren zersetzten Chlorophylls.

Eine Reihe von Spectren, die nach diesen eben angeführten den Gegenstand speciell tendirenden Untersuchungen, gelegentlich geliefert wurden, lehnen sich an diese an und bringen nichts Neues, oft Falsches. So das von Weiss (Sitzb. Wien. Ac. 1861. II. 210) gegebene Schema; das von rersetztem Chlorophyll herrührende, ebenfalls ganz schematische, das Sinmler gegeben (Pogg. Ann. 1862. Bd. 115, S. 612. Taf. VII, Fig. 12) und das von Valentin (Gebr. des Spectroscops. 1863. S. 70, Fig. 13), welches Confervengrün darstellen soll, und ein Band zwischen $A$ und $B$ und ein noch stärkeres auf $C$ liegend, gibt:

In dem Spectrum CoHN's (M. Schultze, Arch. f. mikr. Anat. Bd. III, 186, Taf. 1 und S. 14) ist weder Band II an seiner richtigen Stelle, noch IV gezeichnet; auch beginnt die continuirliche Absorption erst hinter $\mathrm{F}$ und offenbar zu spät.

Ein richtiges Chlorophyllspectrum, was Zahl, Lage und Stärke der ersten vier Bänder anlangt, ist in Schellen's Spectralanalyse, 2. Aufl., auf der Farbentafel Fig. 10 abgebildet; die Endabsorption ist hier, wie in dem offenbar nach zersetztem Chlorophyll entworfenen Bilde Fig. 71, n. 2 (S. 184), zu spät begonnen. In Roscoe's Spectralanalyse, deutsche Ausg., p. 120, Fig. 43 (nicht 41 wie im Text steht) ist das Spectrum gänzlich verfehlt.

Die Zeichnungen, welche Thudichum (Tenth report of the med. off. of the privy council 1867. London 1868, p. 217. Pl. III, Fig. 9 bis 10) gegeben, sind gleichfalls unvollkommen. Sehen wir ab von dem Spectrum, das aus einer rothen auf Menschenknochen gefundenen Alge stammt (Figuren auf S. 216), so zeichnet er Pl. III, Fig. 9 und auf p. 217 das Spectrum von dem Auszug einer grünen Alge, in einer gewiss ganz ungenauen Art. Es werden drei Bänder - unser IV fehlt 
- schematisch als totale Absorptionen des Lichts in einer Lage gezeichnet, wie sie kein genauerer Beobachter gesehen: er setzt Band I zwischen A und $\mathrm{B}$; das II stärker als I ausgedrückt, unmittelbar neben $\mathrm{C}$ und das III vor D! Die totale Absorption des zweiten Theiles beginnt er vor $\mathrm{E}$.

Viel richtiger ist (Fig. 10, P]. III und p. 217) das Spectrum durch Säure veränderten Graschlorophylls, das wir später zu erörtern haben.

Endlich ist unter den gelegentlich gegebenen Chlorophyllspectren auch noch eines von Sorby (Proc. Roy. Soc. of London. Vol. XV. 1867, p. 438, n. 11) zu erwähnen. Eı nennt nur drei Bänder, von denen das erste schon vor A beginnt, das zweite sehr nahe an und vor D, das dritte zwischen D und E mitten innen liegt - die continuirliche Endabsorption beginnt vor F. - Bandzahl wie Lagerungsverhältnisse machen es sehr unwahrscheinlich, dass er wirklich "normal chlorophyll" untersucht hat.

Neben diesen, wie bemerkt, mehr gelegentlich gegebenen Spectren sind in neuerer Zeit zwei ausführliche Abhandlungen über das Chlorophyllspectrum erschienen, von denen besonders die letzte unsere Kenntniss desselben um ein Wesentliches weiter geführt hat.

In der Abhandlung von Askenasy, „Beiträge zur Kenntniss des Chlorophylls und einiger dasselbe begleitenden Farbstoffe", Bot. Ztg. 1867, 19. Juli, S. 225 ff. mit Taf. V, wird zum ersten Male eine genaue, nach der Messungsmethode mit feststehender Skala vorgenommene Lagebestimmung der Absorptionsstreifen des Chloropliylls vorgenommen. Das Spectrum, welches Taf. V, Fig. 1 von einer ätherischen Chlorophylllösung aus .Hercurialis annua gezeichnet ist, stellt freilich nicht das Spectrum normalen, sondern zersetzten Chlorophylls dar, wie (nach der Darstellungsmethode der Lösung schon wahrscheinlich) sicher wird sowohl durch das Fehlen des Bandes III, das an normalen Lösungen stets klar vorhanden ist*, als aus der Stärke des Bandes IV. Im Uebrigen sind die Streifen der ersten Hälfte nach Lage und in Hinsicht auf das Anwachsen bei zunehmender Absorption zum ersten Vale genau dargestellt; im brechbareren Theile dagegen wie bei den meisten früheren nur eine continuirliche totale Absorption ge-

* Ich habe zu mehrmalen ätherische Lösungen von Mercurialis und der unten genannten von ihm untersuchten Pflanzen geprüft und stets das gewöhn. liche von mir oben beschriebene Spectrum gefunden. 
zeichnet*. (In Fig. 2 von zersetztem Chlorophyll tritt Band V deutlich hervor.) - Ausserdem vergleicht er auch Pinus sylvestris, Hedera Helix, Camellia, Iris und Cladophora fracta. ist jedoch im Unrechte, wenn er die Bänder II und III als ,nicht dem Chlorophyll wesentlich“ betrachtet wissen möchte; denn diese Bänder fehlen bei genannten Pflanzen nicht, sondern sind, so gut wie bei anderen Pflanzen, in jeder richtig bereiteten Lösung, und an den Blättern selbst zu sehen.

Bemerkenswerthe andere Beobachtungen, die in dieser Arbeit niedergelegt sind, haben wir später gelegentlich anzuführen.

Die Untersuchung, welche E. HagenbaCH (1870) gemacht hat**, enthält unter allen vorhandenen weitaus die richtigste Darstellung des Chlorophyllspectrums. Die Taf. II, Fig. 8 a. a. 0. gibt ein Spectrum, das im ersten Theile die Bänder I-IV nach Lage, Stärke und Bau auf's getreueste wiedergibt, vielleicht nur, dass die Verdunkelungen zwischen den Bändern noch lätten angedeutet werden können. Der zweite Theil ist allerdings bei einer Concentration gezeichnet, bei welcher die Bänder nur höchst unvollkommen hervortreten konnten; zwar ist unser Band $V$ an der Senkung zwischen F und G zu erkennen, aber VI und VII von einander nicht zu unterscheiden. Dass er aber diese letzteren Bänder, wenn nicht gezeichnet, wohl gekannt hat, geht aus der Abbildung des Fluorescenzspectrums wie ans der Beschreibung S. 268-270 und 272 hervor, welche das getreue Abbild des Spectrums wesentlich vervollständigt.

Seine genauen Angaben über die Veränderungen, welche das Chlorophyll bei der "Modification" erleidet, werden später zu betrachten sein.

Mit diesen und meinen eigenen Angaben stimmen auch die Beobachtungen überein, die mein College, Herr Prof. Lownel, anlässlich seiner Fluorescenzarbeit gemacht hat***.

Es ist bedauerlich, dass in einer neuesten Abhandlung von E. GERLand und W. P. RauWenhoff, Recherches sur la chlorophylle et quelque-uns des ses derivés, Arch. Néerland. T. VI. 1871 †, in welcher die Fremy- und Filhol'schen Chlorophyllderivate untersucht und abgebildet

* Nach Askenasy ist auch das schematische Chlorophyllspectrum von Pfeffer in "Arbeiten des bot. phys. Instituts zu Würzburg," Heft I, S. 27 entworfen.

** Untersuchung über die optischen Eigenschaften des Blattgrüns von Eduard Hagenbach. Pogg. Ann. Bd. 141, Stück 2, 1870, n. 10, S. 245 ff.

*** Carl's Repertor. f. Physik. Bd. VII, 1871, S. 73.

† Auch in Pogg. Ann. 1871. 
worden sind, wieder ein Schritt rückwärts geschieht und (Fig. 1 der Tafel) ein Spectrum als von normalem Chlorophyll aufgeführt wird, das nach meinen und den eben genannten Untersuchungen nicht als naturgetreu bezeichnet werden kann. Wir haben oben schon der vermeintlichen Duplicatur des Bandes I gedacht; die Betrachtung der Bänder III und IV, die in umgekehrter Stärke, als sie normales Chlorophyll erheischt, gezeichnet sind*, weist deutlich, dass ihr Chlorophyll zersetzt war. Dass im brechbareren Theil nur ein Band andeutungsweise wahrgenommen wurde, von den übrigen aber Nichts, ist allerdings durch die Untersuchung bei Lampenlicht begreiflich (a. a. 0. p. 4).

Zum Schlusse möge noch das Historische über die Frage nach der Identität des Chlorophyllspectrums bei den verschiedene $\mathrm{n} \mathrm{Pflanzen} \mathrm{angefügt} \mathrm{werden.}$

Schon Brewster hatte (a. a. O. S. 541) 20 Pflanzen auf ihr Chlorophyll untersucht; es sind Gymnospermen, Mono- und Dicotylen der verschiedensten Familien darunter, und nicht allein die Blätter, auch z. B. grüne Früchte untersucht worden. Er sagt nicht, dass er einen Unterschied der Spectra gefunden habe.

ANGSTRöm (a. a. O. S. 478, wollte zwar einen Unterschied zwischen Phanerogamen- und Algenchlorophyll gefunden haben; allein schon HARTING (a. a. O. S. 549) hat die Identität der beregten Farbstoffe dargethan und durch Abbildungen gezeigt, „dass kein Unterschied zwischen dem grünen Farbstoff der Phanerogamen und dem der Algen * bestehe.

Askenasy (a. a. 0. S. 228) wollte bei seinen oben angeführten Pflanzen ein „etwas differirendes Spectrum“ erhalten haben; und auch Gerland und Rauwenhoff (a. a. 0. p. 7) lassen die Frage, ob verschiedene Chlorophyllsorten vorkämen, noch offen.

Dem gegenüber habe ich im Obigen gezeigt, disss bei allen untersuchten „Chlorophyllpflanzen“ das Spectrum völlig gleich, mithin „der Chlorophyllfarbstoff“, oder wie wir nach dem Späteren richtiger zu sagen

* Uebrigens scheint Gerland die Unrichtigkeit dieser Darstellung nachträglich selbst eingesehen zu haben; da in einer Arbeit, die nach dem Niederschreiben obiger Zeilen in meine Hände gelangte (Pogg. Ann. 1871), die umgekehrte Stärke der Bänder bei normalem Chlorophyll angegeben wird (a. a. 0. S. 588). 
haben, die Mischung von Farbstoffen, die man als Chlorophyll althergebracht zu bezeichnen pflegt, eine gleiche ist.

\section{Das Spectrum lebender Blätter.}

Es ist eine Frage von unschätzbarer Wichtigkeit für die Physiologie, ob das Spectrum der Chlorophyll ös ung, welches wir bisher untersucht haben, in der That auch das Spectrum lebenden Chlorophylls, d. h. das Spectrum sei, wie man es erhält, wenn man frische Blätter unmittelbar vor den Apparat bringt. Nur wenn diese Identität wirklich festgestellt wäre, hat das Spectrum der Lösung physiologisches Interesse, indem es uns dann thatsächlich ein Bild der Strahlen gäbe, welche die Pflanze zurückhält und verwendet.

Die Frage nach dieser Identität hat aber auch in unserem speciellen Falle besonderes Interesse. Durch ihre Bejahung würde entschieden, dass das Lösungsmittel, dass die vermuthlichen Beimengungen von fremden Stoffen auf das Spectrum keinen Einfluss haben, und dass die an Lösungen gemachter. Erfahrungen direct auf das Chlorophyll der lebenden Pflanzen übertragen werden dürfen.

Aus diesem Grunde muss hier auch das Spectrum lebender Blätter etwas näher in's Auge gefasst werden.

Die Feststellung desselben ist der natürlichen Undurchsichtigkeit des Materials wegen mit grösserer Schwierigkeit verknüpft, als bei der pelluciden Lösung. Es ist klar, dass das Licht, wenn es durch die Zellwände, festen und flüssigen Zellinhalte, und insbesondere lufterfüllte Intercellularräume vielmal wechselnd hindurch geht, auf die mannigfachste Weise gebrochen, absorbirt und zerstreut werden muss. Durch die Wahl dünner und mehr gleichmässig gebauter Blätter lässt sich diesem Uebelstand nur wenig abhelfen. Wenn man die Blätter mit Wasser - von Weingeist gar nicht zu reden -- injicirt und die lufterfüllten Intercellularräume mit Wasser füllt, welches das Licht etwa dem Zellinhalt gleich bricht* (Valentin, Gebr. d. Spectroscops. 1863, S. 70) oder, wie SchöNn gethan (a. a. 0.), das Blatt welken lässt, wodurch die Zellen und Intercellularräume zusammenfallen und die letz-

* Ich habe, gleich V alentin, gefunden, dass die Blätter, weil durch Injection mit Wasser durchscheinender, vor dem Spectroskop brauchbarer werden, und ein deutlicheres Spectrum geben. Auffallender Weise geben Gerland und Rauwenhoff (a. a. O. S. 9-10) das Gegentheil an, und versuchen sogar eine Erklärung der Erscheinung. 
teren von ihrem Inhalt befreit werden -- ist keine Garantie mehr vorhanden, dass die Zellen wirklich noch lebendig und das Chlorophyll intact sei.

Unter diesen Umständen bleibt nur übrig, die Untersuchung bei möglichst reicher Lichtquelle (Sonne) und mit sehr lichtstarken Spectren anzustellen. Und hier erweist sich nun das klare, lichtvolle Spectrum des Mikrospectralapparats ausserordentlich brauchbar. Nicht allein bei Sonnenlicht, selbst bei bewölktem Himmel und Gaslicht gewahrt man mit ihm fast an jedem Blatte sofort die drei, oft sogleich die vier ersten Bänder des Chlorophylls. Es ist mir völlig unerklärlich, wie VALENTIN (Max Schultze, Arch. f. mikr. Anat. VII. 227) bei der Untersuchung lebender Blätter mit dem Mikrospectralapparat nur "negative Resultate" erhalten konnte, da selbst für den Ungeübten an den von ihm untersuchten Blättern so gut als an allen andern die genannten Bänder prächtig zu sehen sind. Dagegen sind allerdings bei der Untersuchung mit den gewöhnlichen, z. B. Steinheil'schen grossen Spectralapparaten die Bänder sehr schwer zu sehen, und ein Uebersehen derselben leicht möglich. -

Legt man ein frisches Blatt, zunächst vielleicht ein dünneres von Quercus, oder ein mässig fleischiges von Deutsia oder Philadelphus auf den Mikroskoptisch und schiebt den Tubus, an welchem eine schwache Objectivlinse angeschraubt ist, bis auf dasselbe heran, so gewahrt man im Sonnenlicht ohne alle Schwierigkeit und ganz klar mit dem BRowning'schen Spectralocular ein sehr schönes aus Bändern gebildetes Chlorophyllspectrum.

Nehmen wir zunächst ein Blatt von Deutzia in einfacher Lag e. (Taf. I, Fig. 5.)

Die Grenze des sichtbaren Roth ist wie gewöhnlich die Linie A. Im Roth selbst erscheint zwischen B und C das Band I als ein starker, wie in der Lösung tief schwarzer Streifen, der nach A hin scharf begrenzt ist, gegen $\mathrm{C}$ dagegen sieht man an demselben einen grauen Anhang, etwa ron der Breite wie das schwarze Band. Es sieht aus, als ob das Band I aus zwei combinirt sei, dem gewöhnlichen tief schwarzen und einem schwächeren grau erscheinenden. Eine Trennung dieses Bandes von dem schwarzen ist so wenig wahrzunehmen, als etwa eine tiefere Schwärze in der Mitte desselben oder Abnahme derselben gegen den linken Rand hin. 
Lässt man stärkeres Licht auf dasselbe fallen, so verschwindet der graue Theil und der schwarze bleibt allein übrig.

Im weiteren Raume sind klar, und deutlich die Bänder II, III und IV vorhanden, aber auffallend schwächer als bei einer Lösung der Fall scheint, die etwa Band I und die Endabsorption in der gleichen Stärke gäbe. II erseheint stärker als III und dieses wieder als IV; doch sind die gegenseitigen Unterschiede nicht so auffallend.

Im zweiten Theile gewahrt man sehr deutlich vor und auf $\mathrm{F}$ ein Band, das unserem V entspricht, hinter diesem eine schwache Erhellung mit Durchschimmerung von Blau, darauf ist das Ende des Spectrums total absorbirt.

Legt man zwei Blätter übereinander vor den Apparat, Taf. I, Fig. 6, so erscheint Band I schwarz und so breit-als im ersten Falle sammit dem grauen Anhang; letzterer fehlt. Zwischen ihm und dem stark hervortretenden zweiten ist das Licht ziemlich verdunkelt; zwischen II und III einerseits, diesem und IV andererseits ist stark erleuchtet, dagegen hinter IV auffallend düster, zwischen $\mathrm{E}$ und $\mathrm{b}$ tritt allmälig totale Absorption ein.

Bei vier Lagen Blätter bleibt nur das Roth vor dem Bande-I und das Grün zwischen III und IV sichtbar.

Fassen wir nur das bisher Gesagte in's Auge, so kann man sagen, dass das Spectrum des lebenden Blattes im Wesentlichen mit dem der Lösung übereinstimmt. Die Bänder I- V sind ihrer relativen Lage und in ihren wesentlichen Eigenschaften wieder gefunden; dass die Bänder VI und VII nicht zu sehen seien, war zu erwarten; es müssten dazu Blätter von grösserer Dünnheit untersucht werden. Freilich treten im Bau der vorhandenen Bänder einige Verschiedenheiten hervor. von denen die eigenthümliche schattenartige Hälfte des Bandes I besonders auffällt und unerklärlich bleibt. Doch werden wir bei zersetzten Chlorophylllösungen später ein ähnliches kennen lernen.

Es bleibt aber noch eine andere, noch nicht erwähnte Verschiedenheit übrig, die der absoluten Lage der Bänder.

Ein Lageunterschied, wenigstens des Bandes I und des Anfangs der continuirlichen Endabsorption, war schon den genaueu Beobachtungen HagenbaCH's nicht entgangen. Er hatte schon gefunden, dass der Streifen I ,um eine sehr merkliche Grösse nach der weniger brechbaren Seite gerückt" ist; ferner bemerkte er, dass die totale Endabsorption 
weiter nach dem rothen Ende, als in der Lösung gerückt sei (a. a. 0 . S. 272).

Aus den Zeichnunger Taf. I, Fig. 5 und 6, ist sichtbar, dass alle Bänder etwas gegen das Roth hin verschoben sind; und die Untersuchung zahlreicher Blätter hat ganz allgemein gezeigt, dass im lebenden Blatt die Bänder im Verhältniss zu denen der Lösung gleichsinnig gegen das rothe Ende verschoben sind. Die Messungen wurden besonders an den im ersten Theil gelegenen, schmalen und desshalb sicherer messbaren Bändern gemacht. Ich führe unter denselben auch ausdrücklich von denjenigen Blättern auf, an denen VALENTIN keinen Streifen bemerken konnte:

\begin{tabular}{|c|c|c|c|c|}
\hline & I & II & III & IV \\
\hline Deutzia scabra & $25-75$ & $100 *$ & 180 & 290 \\
\hline Chloranthus inconspicuus & 40 & 100 & 180 & 280 \\
\hline Agapanthus umbellatus & 50 & 100 & 180 & 280 \\
\hline Sedum macrophyllum & 50 & 100 & 180 & 280 \\
\hline Sempervivum tectorum . & ǰ & 100 & - & - \\
\hline
\end{tabular}

Ferner wurden untersucht: Paeonia, Colchicum, Buxus, Fritillaria, Lilium candidum, Melanoselinum decipiens, Saxifraga ligulata. Rosa, Parietaria, Phyllis nobla, Hydrangea, Phytolacca dioica, Prunus Laurocerasus, Begonia, Evonymus japonicus.

Bei einigen Blättern wurden zugleich die frisch bereiteten Lösungen daneben verglichen:

1. Phrynium setosum.

$\begin{array}{rcc} & \text { a. Blatt. } & \text { b. Weingeistige L } \\ \text { I } & 20-40-65 & 35-80 \\ \text { II } & 100 & 120 \\ \text { III } & 180 & 190 \\ \text { IV } & 275 & 300 \\ \text { V } & 450 & 570\end{array}$

2. Mercurialis perennis.

$\begin{array}{rcc} & \text { a. Blatt. } & \text { b. Aetherische Lösung. } \\ \text { I } & 10-30-50 & 45-80 \\ \text { II } & 80-90 & 115 \\ \text { III } & 180 & 190 \\ \text { IV } & 280 & 310\end{array}$

* Die angegebenen Zahlen bedeuten die Lage der Mitte des Bandes. 
Ein Blatt von Mercurialis in Aether gelegt, zeigte nach kurzer Zeit die Streifen fast wie die ätherische Iösung; die mikroskopische Untersuchung zeigte, dass in den Zcllen der Chlorophyllfarbstoff aus den Körnern in den eingedrungenen Aether getreten und gelöst war.

3. Sambucus nigra.

$\begin{array}{rcc} & \text { a. Blatt. } & \text { b. Weingeistige Lösing. } \\ \text { I } & 25-j 5 & 30-75 \\ \text { II } & 90 & 95-135 \\ \text { III } & 180 & 175-210 \\ \text { IV } & 285 & 300\end{array}$

Die Angaben, die wir in der Literatur über das Spectrum lebender Blätter besitzen, laufen einander in der neuesten Zeit zuwider. Nach den meisten, freilich stets ganz allgemein gehaltenen, ist das Spectrum der Blätter mit dem einer Chlorophylllösung identisch (Stokes, Sachs, Askenasy, Schönn, Gerland und Rauwenhoff). Dem gegenüber geben Andere (Simmler, Valentin) nur den Streifen I im Roth mit Sicherheit an, und in jüngster Zeit behauptet ein genauer Beobachter (HAGENBACH), dass bei ,festem Chlorophyll *, wie er das der Blätter (gleich dem aus einer Lösung niedergeschlagenen) nennt, nur Band I und die Endabsorption zu sehen sei (a. a. 0. S. 272).

Wir wollen der Vollständigkeit halber auch hier die Literatur ausführlich zusammenstellen:

Schon STokEs hatte sich bekanntlich (a. a. O. S. 220) kurz dahin geäussert, dass , ein grünes Blatt die Hauptkennzeichen “ der Chlorophylllösung gibt. Der Erste aber, welcher ausführlich und richtiger, als die meisten folgenden Beobachter die Absorption der Blätter beschrieben hat, ist Sachs. In seiner für die Chlorophyllphysiologie epochemachenden Arbeit „Ueber Durchleuchtung der Pflanzentheile“ (Sitzgsb. der Wien. Ac. 1861, Bd. 43, II, S. 277) beschreibt er das Bild der Absorption eines Pflanzenblattes folgendermassen:

„Wenn man in das Objectiv des analysirenden Diaphanoscops nur ein Blatt von Kirsche, Kürbis, Runkelrübe, Chenopodien, Plantago, Polygonum u. s. w. einschaltet und die Oeffinung gegen die Sonne richtet, so zeigt das Spectrum des Spaltes alle Farben, nämlich Roth, 
Orange, Gelb, Grün, Blau, Violet; die beiden letztern aber geschwächt, und im Roth erscheint ein ziemlich schmaler schwarzer Streifen, der dem charakteristischen Absorptionsstreifen der Chlorophylllösung völlig entspricht; im Gelb bemerkt man eine Verdunkelung, die aber wegen der Divergenz des durchscheinenden Lichts nicht als schwarze Linie auftritt. Im Allgemeinen gleicht das Spectrum demjenigen, welches von dem durch eine verdünnte Chlorophylllösung gegangenen Licht herrührt. Schaltet man zwei bis drei Blätter ein, so wird der Absorptionsstreif im Roth viel breiter, es bleibt aber oberhalb desselben ein schmaler Streifen sehr dunkles Roth übrig, so dunkel, dass man es leicht übersieht; der dunkle Streif im Gelb ist auch jetzt nicht scharf begrenzt; das Blau ist beinahe völlig vernichtet, das Violet fehlt ganz. Zwei bis drei Lagen grüner Blätter verhalten sich also in Bezug auf das durchgehende Licht so, wie eine dickere Schichte von Chlorophyllextrakt oder wie eine dünnere Schichte der concentrirten Lösung. Das so erhaltene Spectrum besteht dann aus: Dunkelroth, schwarzem Streif, Hellroth und Orange, Gelb mit dunklem Streifen, Grün und Spur von Blau".

Anders wird etwas später (1863) das Spectrum der Blätter von Simuler beschrieben (PoGg. Ann., Bd. 115, S. 605-606): „Hält man ein grünes Blatt (ich benutzte welche von Ficus elastica und Gladiolus) vor die lichtgebende Spalte, so erscheint diese natürlich grün; das Spectrum dieses Lichtes zeigt aber einen Absorptionsstreif, etwa den Raum im Roth zwischen B und C einnehmend; das äusserste Roth war sichtbar bis zu B, ebenso Gelb und alle Töne im Grün und Blau, aber das Violet war von $\mathrm{G}$ ab gänzlich verschwunden". (S. 605.) So im Sonnenlicht. Im gedämpften Licht dagegen ist das Spectrum reducirt , auf einen Streifen im Orange und Grün mit Gelb in der Mitte, alle continuirlich verbunden" (Taf. VII, Fig. 11). „Ganz junge, dünne, gelbgrüne Blätter liessen etwas mehr Orange und Grün sehen, selbst noch die ersten Anfänge von Blau“. (S. 606). - Ihm gleich äussert sich Valentin (Gebr. des Spectroscops 1863, S. 70).

In neuerer Zeit haben Askevasy (Bot. Ztg. 1867, S. 226) und SchöNs (a. а. O. S. 327 ) kurz angegeben, dass die Spectra völlig übereinstimmen. Ersterer sagt: „Das Chlorophyll in den grünen Blättern zeigt dieselben Absorptionsstreifen, wie in der Lösung “. Letzterer findet den Streifen im Roth "genau an der entsprechenden Stelle", 
die übrigen Streifen erst dann sichtbar, wenn die Blätter in Folge der Hitze der beleuchtenden Flamme gelb-grün geworden waren *.*

HAGENBACH ist es, wie bemerikt, nicht gelungen, an Blättern mehr zu sehen, als das Band I und die Endabsorption, wahrscheinlich in Folge eines lichtschwachen Apparates; dagegen ist ein wesentlicher Fortschritt in der Kenntniss des Spectrums lebender Blätter dadurch gegeben worden, dass er die geänderte Lage des Bandes I wahrgenommen; er sah zuerst, dass dasselbe ,um eine sehr merkliche Grösse nach der weniger brechbaren Seite.gerückt" ist; in Gleichem bemerkte er, dass die Gränze der Endabsorption , in dem festen Chlorophyll weiter nach dem rothen Ende zuliegt, als in der Lösung “. Ob dagegen die Vermuthung desselben, dass in dieser Endabsorption überhaupt keine Bänder versteckt liegen (a. a. 0. S. 2i2), richtig ist, möchte ich bezweifeln. **

Endlich hat in jüngster Zeit eine Untersuchung des Gegenstandes durch Gerland und Rauwenhoff (Arch. Néerland., T. VI, 1871) das Spectrum lebender Blätter zum Gegenstande gehabt. Die Autoren sprechen sich zwar, indem sie die Bänder I-IV an den Blättern unterscheiden, gegen Hagenbach, der nur das Band I sah, aus und erklären (pag. 10), wie es kam, dass Letzterer die übrigen Bänder bei „festem Chlorophyll * *** nicht gewahrte; aber sie übersahen

* Massgebend wird dabei wohl gewesen sein, dass die Blätter in Folge der Einwirkung der Hitze d urchs che inender wurden.

** Den Ansichten $\mathrm{Hage} \mathrm{n} \mathrm{bachs}$ conform hatte sich auch mein College Lommel ausgesprochen (Zöller, Oekonomische Fortschritte 1871, n. 6 und Carls Repert. f. Physik, Bd. VII., 75). An erst citirtem Orte hat derselbe auch die „befremdlichen“ Angaben J. J. Mü 1 le r s (Pogg. Ann., Bd. 142, S. 615) erklärt.

*** Ich muss hier hinsichtlich des Ausdrucks "festes Chlorophyll" eine Bemerkung beifügen, um ein Missverständniss zu heben. Es ist seit Hagenbachs Untersuchung, von Gerland und Rauwenhoff, wie von Andern vielfach der Ausdruck festes Chlorophyll von dem in den Blättern befindlichen Chlorophyll als identisch mit dem festen Chlorophyll, welches man erhält, wenn man z. B. eine weingeistige Lösung desselben verdunstet, gebraucht worden. Eine solche Identificirung ist aber nach den in der Botanik, massgebenden Anschauungen durchaus unerlaubt.

Das aus der weingeistigen Lösung zurückbleibende Chlorophyll ist (wahrscheinlich) ein fester Körper im gewöhnlichen physikalischen Sinn, d. h. die kleinsten Theile, zwischen denen in der Lösung Alkoholmolecüle u. s. w. in unbestimmter Zahl zwischengelagert waren, liegen unmittelbar aneinander, ohne andere Substanzen zwischen sich zu haben, als den hypothetischen Lichtäther.

Anders im lebenden Blatt. Die Chlorophyll kö rn er sind, wie jedem Botaniker 
das Wichtigste an der ganzen Sache, die Verschiebung der Bänder gänzlich. *

\section{Einfluss des Lösungsmittels und der Temperatur auf Lage und Stärke der Absorptionsbänder.}

Die merkwürdige Lageverschiedenheit, welche wir zwischen den Bändern der Lösung und denen des Blattes bei sonstiger Conformität wahrgenommen haben, schien mir von rornherein nicht als ein wesentlicher Unterschied zwischen beiden Spectren angesehen werden zu dürfen, etwa der Art, dass in beiden Fällen wesentliche chemische Unterschiede statuirt werden könnten. Vielmehr schien es mir denklich, dieselbe äussern Ursachen zuzuschreiben, ähnlich, wie man weiss, dass die Spectra der Gase mit ihrer Dichtigkeit, die der Metalle mit der Temperatur sich ändern (Roscoe Spectralanalyse, S. 114), oder höchstens in die Kategorie von Aenderungen zu gehören, die z. B. Bunsen bei den Didymsalzen wahrgenommen hat (PoGg. Ann., Bd. 128, 1866, S. 107$)$.

Um so mehr, als in der Literatur auch hinsichtlich der Ab-

bekannt ist, nicht Ballen von festem Chlorophyllfarbstoff, sondern solche von einer festweichen Eiweissubstanz, in welche, soweit man bis jetzt weiss, der "Chlorophyllfarbstoff" eingelagert ist, $d$. h. die Chlorophyllmolecüle liegen hier nicht aneinander, sondern ähnlich, wie in der Lösung getrennt, durch Theile fremder Substanz. In dieser Hinsicht ist ein Chlorophyllkorn seiner innern Anordnung der Theile nach einer Lösung viel eher als einem festen Körper zu vergleichen.

Es kommt noch ein Umstand hinzu, der die Chlorophyllkörner dem Lösungszustande noch ähnlicher macht. Die protoplasmatische Grundlage der Chlorophyllkörner ist nämlich stets in hohem Maasse von Wasser (Flüssigkeit) durchdrungen. Nach der jetzt herrschenden Nägeli'schen Theorie über den Bau organisirter Gebilde, zu denen man das Protoplasma rechnen muss, hat man sich vorzustellen, dass Gruppen von Eiweissmolecülen von zahlreichen Wassermolecülen (Flüssig: keitsmolecülen) in begrenzter Anzahl umluüllt werden, und selbst individuell (als „Molecüle“ Nägeli) auftreten und in ihrer Zusammenlagerung die Eiweisssubstanz darstellen. Mag man sich nun in einer der Art gebauten Substanz wie immer die Chlorophylltheilchen vertheilt denken, gewiss ist, dass sie sich in einem Zustande befinden, der vielmehr der einer Lösung als eines festen Körpers ist.

* In jüngster Zeit hat Gerland ( $\mathrm{P} 0 \cong \mathrm{g}$. Ann. 1871, S. 603-606) die Verschiebung gesehen, und sie in einen Zusammenhang mit der $\mathrm{Tr}$ übung der Lösungen gebracht. Die unten mitgetheilten Beobachtungen über Einfluss des Lösungsmittels, deren Resultate schon am 10. Juli in der Sitzung der Erlanger phys.-med. Societät publicirt sind, zeigen, dass Verschiebungen ganz unabhängig von Trübungen, in ganz klaren Lösungen auftreten. 
sorptionsspectra von Flüssigkeiten einige Andeutungen zerstreut liegen, welche darauf hindeuten, dass zwar nicht Zahl und Bau der Bänder wie dort, wohl aber die Lage derselben mit dem Lösungsmittel abändern.

In unserm speciellen Falle hat schon Askenusy (a. a. O. S. 228) eine Verschiebung des Streifens I im Roth bei Verschiedenheit des Lösungsmittels bemerkt, wobei er, wie aus dem Ganzen hervorgeht, nicht an chemische Aenderungen des Farbstoffs gedacht hat. „Die Lösung des Chlorophylls in Terpentinöl schien eine sehr geringe Verschiebung dieses Maximums (des Streifens I) nach dem rothen Spectrumende zu zeigen; eine stärkere war in Schwefelkohlenstoff zu bemerken. Hier war das Maximum um 2 Theilstriche verschoben und fiel genau mit Li. a zusammen". Er erwähnt auch einer Verschiebung in einer Lösung mittelst fettem Oele beim Kochen.

Hagenbach (a. a. O. S. 272) hatte bei festem, d. h. aus einer Lösung niedergeschlagenem Chlorophyll die gleiche Lageänderung, wie beim Chlorophyll des Blattes bemerkt. Hinsichtlich eines andern, später zu besprechenden Farbstoffs, den Thunichus Lutein genannt hat, hat dieser * ebenfalls bemerkt, dass dessen im Blau und Violett gelegene Bänder in Alcohol und Aether nịcht gleiche Lage haben.

Endlich hat auch Preyer (Blutkrystalle 1871, S. 50) vermuthungsweise auf eine Verschiedenheit der Lage nach dem Lösungsmittel hingewiesen.

Freilich über den Zusammenhang der Lage mit einer bestimmten Eigenschaft des Menstruums hat meines Wissens Niemand eine Aeusserung gethan.

Die Versuche, die ich angestellt und im Folgenden mittheile, haben mich zu der Ansicht geführt, dass die absolute Lage der Absorptionsbänder mit dem specifischen Gewichte-der Dichtigkeit - des Lösungsmittels im Zusammenhange steht, dass die Absorptionsstreifen um so weiter gegen das rothe Ende - die Strahlen langsamerer Schwingung rücken, je schwerer - dichter — das lösende Medium ist

* Proceed. R. Soc. of London 1869, Vol. VII., p. 253 und Centralbl. f. med. Wiss. 1869, S. 2 . 
und umgekehrt, den violetten Strahlen - denen rascherer Schwingung - in leichteren Lösungsmitteln sich nähern.*

Die Vorführung der Versuche wird die Sache am klarsten darlegen.

\section{Versuchsreihe.}

Aus den Blättern von Sambucus Ebulus wurde mit Alcohol von 0,816 spec. Gewicht eine concentrirte Chlorophyllösung gemacht und von dieser je $1 \mathrm{Cub}$.Ctm. in 4 gleiche Probirröhrchen gebracht. Jede Lösung wird dann mit der doppelten Menge eines andern Lösungsmittels von verschiedenem Gewichte versetzt. Zu I wird die doppelte Menge des gleichen Alcohols, zu II ebenso von Aether, dessen spec. Gewicht 0,75, zu III Glycerin von 1,23 spec. Gewicht und IV wird mit Schwefelkohlenstoff geschüttelt (1,29 spec. Gewicht) ganz in diesen aufgenommen.

Die 4 ersten, schmalen und desshalb zur Messung geeigneteren Absorptionsbänder wurden wiederholt genau gemessen und gaben folgende Lagen:

I. Alcohol. II. Aether. III. Glycerin. IV. Schwefelkohlenstoff.

$\begin{array}{rcccc}\text { I } & 40-60-80 & 55-70-85 & 35-55-75 & 40-55-75 \\ \text { II } & 125 & 135 & 120 & 115 \\ \text { III } & 195 & 220 & 190 & 180 \\ \text { IV } & 310 & 315 & 300 & 285\end{array}$

Ein gleicher Versuch:

I. Aether. II. Alcohol. III. Glycerin.

$\begin{array}{rccc}\text { I } & 55-70-100 & 50-70-90 & - \\ \text { II } & 130 & 120 & 120 \\ \text { III } & 225 & 210 & 200 \\ \text { IV } & 310 & 300 & 290\end{array}$

Mit den gleichen Flüssigkeiten und Chlorophyll von Hydrangea arborescens :

$\begin{array}{lccc}\text { I. Glycerin. } & \text { II. Alcohol. } & \text { III. Aether. } \\ \text { III } & 120 & 130 & 140 \\ \text { IV } & 300 & 310 & 320\end{array}$

* Diese Ansicht hatte ich schon gewonnen, als ich die oben angefûhrte Literatur und insbesondere die Ansicht Bunsens kennen lernte, der bei der Lageänderung der Didymabsorptionen an deren Atomgewichte erinnerte. 
Ein gleicher Versuch, mit Gerstenchlorophyll. Die gleiche Menge (1 Cub.-Ctm.) der erwähnten Flüssigkeiten zugesetzt.

\begin{tabular}{lccc} 
& I. Aether. & II. Weingeist. & III. Glycerin. \\
I (Ende) & 90 & 80 & 75 \\
II & 140 & 125 & 120 \\
III & 210 & 200 & - \\
IV & 310 & 300 & 290 \\
Desgleichen & I. Weingeist. & II. Aether. \\
\multicolumn{2}{c}{ I (endet) } & 75 & 85 \\
\multicolumn{2}{c}{ II } & 120 & 130 \\
\multicolumn{2}{c}{ III } & 190 & 200 \\
IV & & 300 & 320
\end{tabular}

II. Versuchsreihe.

Aetherischer Auszug aus Mentha piperita zu gleichen Theilen I mit Aether, II mit Chloroform versetzt.

$\begin{array}{ccc} & \text { I. Aether. } & \text { II. Chloroform. } \\ \text { I (Mitte) } & 60 & 55 \\ \text { II } & 135 & 125 \\ \text { IV } & 320 & 310\end{array}$

Aus derselben Lösung durch Schütteln mit Benzol den blaugrünen Farbstoff des „Chlorophylls" aufgenommen, und diese Benzollösung I mit Benzol, II mit Chloroform versetzt.

$\begin{array}{ccc} & \text { I. Benzol. } & \text { II. Chloroform. } \\ \text { I } & 50-65-80 & 40-60-80 \\ \text { II } & 130 & 120 \\ \text { III } & 310 & 300 \\ \text { Band 6 (Mitte) } & 655 & 645\end{array}$

III. Versuchsleihe.

Getrocknete Blätter von Mentha piperita, welche "zersetztes“ Chlorophyll enthielten, mit Alcohol ausgezogen, dann gleiche Mengen I Aether, II Alcohol, III Glycerin zugesetzt.

$\begin{array}{cccc} & \text { I. Aether. } & \text { II. Alcohol. } & \text { III. Glycerin. } \\ \text { I } & 50-65-75 & 45-60-80 & \text { Mitte } 50 \\ \text { II } & 135 & 130 & 110 \\ \text { IV a } & 305-320-340 & 300-315-325 & \text { Mitte } 295 \\ \text { IV b } & 400-435-470 & 400-435-470 & , \quad 415\end{array}$




\section{Versuchsreihe.}

Blätter von Sambucus Ebulus mit Wasser ausgekocht, zwischen Filtrirpapier stark abgepresst und in absoluten Alcohol (0,79 spec. Gewicht) und absoluten Aether $(0,73)$ gebracht, den sie augenblicklich stark färbten. Die Lösungen verkorkt untersucht.

$\begin{array}{rcc} & \text { I. Abs. Alcohol. } & \text { Il. Abs. Aether. } \\ \text { I } & 35-80 & 45-85 \\ \text { II } & 120 & 130 \\ \text { III } & 180 & 195 \\ \text { IV } & 300 & 310\end{array}$

Die ätherische Lösung auf einem Uhrglas verdunsten lassen, ergibt

$$
\text { I } 35-65
$$

II 110

V. Versuchsreihe.

Von derselben Pflanze untersucht mit Alcohol (0,816 spec. Gew.) und Schwefelkohlenstoff' (1,29 spec. Gewicht.; Alcohol.

$\begin{array}{rc}\text { I } & 45-80 \\ \text { II } & 120 \\ \text { III } & 185 \\ \text { IV } & 300\end{array}$

Schwefelkohlenstoff.

$$
\begin{gathered}
30-70 \\
110 \\
180 \\
280
\end{gathered}
$$

\section{V e rsuchs reihe.}

Feste ,Chlorophyllgelatine*, d. h. Gelatineblättchen, die mit alcoholischem Chlorophyll getränkt wurden, und die ich der freundlichen Mittheilung meines Collegen Lonvel verdanke*, gab folgende Lage (Mitte der Bänder):

$\begin{array}{rr}\text { I } & 45 \\ \text { II } & 95 \\ \text { III } & 175 \\ \text { IV } & 280\end{array}$

Ein damit verglichenes Eichenblatt gab ganz dieselbe Lage.

Die angeführten Beispiele zeigen klar, dass die Lage der Bänder mit dem Lösungsmittel in 'der oben angegebenen Beziehung wechselt. Ich lasse dahin gestellt, ob alle Bänder in gleichem Maasse verschoben

* Vgl. über die Darstellungsmethode solcher gefärbten Gelatineblättchen L o m mel in Sitzb. Erlanger phys. med. Soc., 26. Juli 1871. 
werden. Der Bau derselben ward meiner Beobachtung nach nirgends sichtlich geändert. Nach diesen Erfahrungen, wie nach der Natur der lösenden Medien selbst, ist in allen. Fällen an eine chemische Aenderung der absorbirenden Substanz im gewöhnlichen Sinne des Wortes nicht zu denken. Es bleibt demnach nụr übrig an Aenderung der physikalischen Zustände zu denken. Eine andere Beziehung der Lageänderung als die zu dem specifischen Gewichte der Flüssigkeiten ist nicht erkemntlich.

Ist es num richtig, dass die Bänder um so mehr gegen Roth rücken, je dichter die Lösungsflüssigkeit und umgekehrt, so ist klar, dass auns der bckannten Lage der Bänder auf die unbekannte Dichtigkeit des tragenden Mediums des Farbstoff's geschlossen werden kann, wenn man anders in der Lage ist, eine Flüssigkeit von bekanntem Gewicht zu finden, welche die gleiche Bänderlage gibt, wie man sie bei einem Träger umbekannter Dichtigkeit gefunden hat. Es wäre somit ein Mittel gegeben, dur ch genauen Vergleich der Lage der Absorptionsbänder des lebenden Blat tes, wo der Chlorophyllfarbstoff in eine Eiweisssubstanz unbekannter Dichtigkeit eingeschlossen is t, mit der Lage der Bänder in Nedien bekannter Dichtigkeit, die Dichtigkeit der Chlorophyllkörner selbst zu bestimmen*.

Ich halte die gemachten Untersuchungen für diese Zwecke noch nicht hinreichend.

Aus dem Vorstehenden ergeben sich zwei wichtige praktische Folgerungen :

Einmal, dass die Angaben über die absolute Lage der Absorptionsbänder von Flüssigkeiten nur dann von Werth sind, wenn die Lösungsmittel und ihr spec. Gewicht angegeben sind, und dass alle diese Angaben nicht absoluten, sondern nur relativen Werth haben; und es ergibt sich daraus die Nothwendigkeit bei der Vergleichung der absoluten Lage der Absorptionsbänder von gleichen oder verschiedenen Stoffen immer genau die gleiche Flüssigkeit zu wählen. In dieser Beziehung sei hier ausdrücklich bemerkt, dass überall wo in meinen Untersuchungen nicht das Gegentheil angegeben ist, die Spectra sich stets auf alcoholische Lösung und auf Alcohol von 0,816 spec. Gew. (92\% dem Gewichte, $95 \%$ dem Volum nach) beziehen.

* Dagegen halte ich es z. B. nicht für erlault, ans solcher Lagegleichheit etwa auf den Aggregatzustand selbst schliessen zu wollen. 
Für's Zweite ist durch die Anwendung dichterer oder lockerer Menstrua ein Mittel gegeben, den Bau solcher Spectra genauer darzustellen und zu studiren, deren charakteristische Bänder dem einen oder andern Spectrumende nahe liegen. So war es mir, bevor ich noch über die genauere Lage der Absorptionsbänder in verschiedenen Medien unterrichtet war, aufgefallen, dass der erste Absorptionsstreif des Chlorophylls viel leichter in seiner ätherischen und alcoholischen Lösung als im Blatte zu sehen, ganz abgesehen von der. grösseren Undurchsichtigkeit des letztern: weil er in den Lösungen weiter in das Roth hereingerïckt ist. Umgekehrt sind \%. B. die drei im Blau und Violett gelegenen charakteristischen Absorptionsbänder des gelben Farbstoff's etiolirter Pflanzen u. s. w. in Schwefelkohlenstoff* auffallend besser zu gewahren als in Alcohol: weil sie in dieser schwereren Flüssigkeit dem Grün näher gerückt werden. Ein Gleiches gilt von den im Blau und Violett gelegenen Bändern des blangrünen Bestandtheils des Chlorophylls; ein Beispiel von dem letztern genommen zeigt, in Benzol und Schwefelkohlenstofl' folgende Lage zweier Bänder (Mitte gemessen):

Benzol.

665

850
Schwefelkohlenstoff.

800

Es schien mir, dassunter Umständen durch Anwendung geigneter Lösungsmittel sogar neue Absorptionsbänder zum Vorschein kommen, d. h. aus dem unsichtbaren in den sichtbarenSpectraltheil gerückt werden könnten, Bänder die vorher im Ultraviolett oder Ultraroth gelegen, unsichtbar waren. Ich habe diese Erfahrung bei dem orangegelben Farbstoff aus den Fruchtkelchen von Physalis Alkekengi gemacht. Derselbe zeigt in weingeistiger Lösung 3 Bänder, resp. 2 und die Endabsorption (Taf. III, Fig. 3), mit folgender Lage:
1. $460-\ddot{v} 30-610$.
2. $645-720-785$.
3. von 960 ab.

Uebergiesst man frische Fruchtkelche mit Chloroform, so erhält

* Schon S o r b y hat auf Schwefelkohlenstoff als ein vorzügliches Untersuchungsmittel für gelbe Farbst off e ü berhaupt hingewiesen (Quat. Journ. of Science, Jan. 1871, p. 66); es ist aber nicht klar. ob der Lage oder eines andern gleich anzuführenden Grundes wegen. 
man eine Lösung, die dunkler Gelb erscheint* und folgende 4 Bänder resp. 3 Bänder mit Endabsorption gibt. (Taf. III, Fig. 4).
1. $430-480-530=$ dem obigen 1 .
2. $580-650-720=\pi, \quad 2$.
3. eine kleine Anschwellung bei 835 .
4. Endabsorption von 1000 an.

Es scheint mir offenbar, dass die unter 3 genannte schwache Absorption in der alcoholischen Lösung nicht gesehen wurde, weil sie zu sehr gegen das Ende des an sich düstern Violetts gelagert ist.

Erst nachträglich ersah ich, dass PreYer (Blutkrystalle 1871, S. 50 und 236) bei der Untersuchung des gelben Farbstoff's der Eier hinsichtlich einer ätherischen und Chloroformlösung die gleiche Erfahrung geinacht hat. Er fand bei der Anwendung von Chloroform dort 3, bei der von Aether mur? Bänder. Die Frage aber nach der Ursache der Erscheinung lässt er unentschieden. -Ich kann nicht entscheiden, ob eher eine Zersetzung durch den Sauerstoff im Aether, als ein Einfluss des Lösungsmittels selbst angenommen werden muss." (a. a. O. S. 50).

Uebrigens kommt, wie mir scheint, bei dieser Wirkung des Lösungsmittels hinsichtlich der Sichtbarkeit auch noch eine andere Seite in Betracht. Ich meine die ungleiche Schärfe, in welcher die Absorptionsbänder bei verschiedenen Lösungsmitteln auftreten. Es ist auffallend, mit welch' grösserer Klarheit die Umrisse, welch' grösserer Schwärze der Körper der Bänder des Chlorophylls sowohl, wie des genannten gelben Farbstoff's in 'Schwefelkohlenstoff und Chloroform d. h. einem dichten Medium, gegenüber der Alcohollösung hervortreten. Preyer hat auch (a. a. O. S. 51) darauf hingewiesen, dass Blutkrystalle ein viel schärferes Spectrum geben als Lösungen derselben.

Im Zusammenhange steht wohl diese Erscheinung mit einer ihr entgegengesetzten, riämlich mit dem undeutlich werden und gänzlichen Verschwinden gewisser Absorptionen bei hoher Temperatur und Wiedererscheinen derselben in der Kälte.

* Es ist eine allgemeine Thatsache, dass die F a r b e n n ü an c e n bei Chlorophyll wie bei den später zu betrachtenden Farbstoffen nach dem Lösungsmittel le is e wec h s el n, dassz. B. gelbe Farbstoffe in Chloroform und Schwefelkohlenstoff einen Stich in's Orange, ja geradezu eine Orangefarbe bekommen. Die 'Thatsache erklärt sich durch die Lageänderung der Bänder, die in letzteren Flürssigkeiten die blauen und grünen Strahlen vollständiger hinwegnehmen als z. B. in Alcohol oder Aether. 
Beror ich Kenntniss davon hatte, dass Prerer (a. a. O. S. 50) beim Hämatin die Bänder bei höherer Temperatur der Lösung verschwinden såh, hatte ich die sehr auffallende Beobachtung gemacht, dass bei dem mehr erwähnten gelben Farbstoff der etiolirten Pflanzen oder gelben Blumenblätter die drei schönen Absorptionsbänder im Blau und Violett nach dem Erhitzen der Lösung zum Kochen — sie bleibt dabei ganz klar - undeutlich, ja in den meisten Fällen gänzlich geschwuuden sind und einer schwächeren continuirlichen Absorption dieser Strahlen Platz gemacht haben; und dass dieselben in dem Maasse wieder erscheinen, als die Flüssigkeit abkühlt, endlich aber in ungeschwächter Schärfe wieder vorhanden sind. - Bei Chlorophylllösungen habe ich ein ähnliches Verhalten bei Band V - das dem gleichen gelben Farbstoff zugehört - bei den übrigen keine Veränderung wahrgenommen.

Preyer hat (a. a. 0.) in seinem Falle eine Erklärung der Erscheinung versucht. Meines Erachtens verdient das ganze Thema einer ausführlichen und allgemeinen Behandlung, da nach der einzigen mir bekainten Abhandlung über diesen Gegenstand * die absorbirenden Substanzen ein ungleiches Verlalten zeigen, und bei steigender Temperatur sowohl Verschwinden vorhandener als Auftreten neuer Absorptionen wahrgegenommen wurde.

\section{Zur Kenntniss der Verïnderungen des Chlorophyllspectrums.}

Unter diesem Titel sollen einige der Veränderugen besprochen werden, die das Chlorophyllspectrum erleidet, einmal die, welche eintreten, wenn die Lösung, sich selbst überlassen, eine freiwillige Zersetzung eingeht, dann die durch organische oder anorganische Säuren bewirkten Modificationen. Die wenn auch nur fragmentarische Behandlung der Frage scheint mir desshalb nothwendig, weil das zersetzte Chlorophyll in der Literatur mehr als billig die Rolle des normalen spielt; wir haben das schon angedeutet und die specielle Betrachtung desselben wird den Beweis dafür liefern.

a. Das zersetzte Chlorophyll.

Bewahrt man eine alcoholische Chlorophylllösung längere Zeit auf, so verliert dieselbe bald ihre schön grüne Farbe und wird schmutrig braungrün, gleichzeitig ändert sich das normale Spectrum in ganz bestimmter Weise.

* F e u s s n e r in Sitzb. Berl. Acad. (12. März) 1865, S. 144-147. 
Der Vorgang, bald als "Zersetzung" bald als „Modification" bezeichnet, ist schon dem ersten spectralanalytischen Beobachter des Chlorophylls aufgefallen und von ihm, wie von spätern Beobachtern, wiederholt Gegenstand der Untersuchung gewesen.

Wir sehen ab von den chemischen Vorgängen die dabei statt haben und die zur Zeit noch Gegenstand der Controverse sind*; anch von der allmähligen Genese dieses Zustandes und betrachten das Spectrum einer zersetzten Lösung, wie man sie erhält, wenn man eine in der gewöhnlichen Weise präparirte alcoholische Lösung wochen- ader monatelang aufbewahrt (Taf. I, 7), und sehen wiederum ab von den Weiterveränderungen die eine solche Lösung erfährt, insbesondere dam, wenn sie dem Lichte ausgesetzt wird und schliesslich farblos wird.

Was die Physiognomie des Spectrums einer solchen Solution auffallend ändert, das ist das Auftreten zwe i e r breiten Absorptionsbänder im Grün, von denen das vordere im Lichtgrün gelegene nur das stark verbreiterte schon in der Normallösung vorhandene Band IV ist, während das im Reingrün gelegene zweite zwischen b und F neu hinzutritt; ihrem Dasein verdankt die Lösung, wie schon Hagenbach (a. a. 0. S. 270) bemerkt, ihre schmutzig grüne Farbe, indem das Grün durch dieselben zum grossen Theil vernichtet wird. Die auffallendste Veränderung erfahren ausserdem das Band III im Gelb, welches sehr stark nach rechts (Violett) hin verschoben ist und oft fast bis zum Verschwinden an Stärke abgenommen hat und die Bänder im zweiten Theile des Spectrums, die (V-VII) völlig vernichtet sind und einer continuirlichen Absorption des ganzen Blau und Violett Platz gemacht haben, die, erst hinter $\mathrm{F}$ beginnend, unter gleichen Verhältnissen einen grössern Theil des Spectrums durchgehen lässt als eine normale Lösung **.

Doch betrachten wir die einzelnen Streifen des neuen Spectrums für sich. Sie lassen sich vielleicht zweckmässig in drei Gruppen zusammenfassen, in die des rothen bis gelben, die des grün- und blangrünen und endlich die des blauen und violetten Spectraltheiles.

* Vgl. darüber J odin, Compt. rend. 1864, T. 59, p. 859. - Sa c h s, Exp. Phys., S. 14. - N. Müll e r, Pringsh. Jahrb. VI. S. 204 ff. - Micheli, Bibl. univ. de Génève, Mai 1867, p. 19 d. Separatabdr. - Timiriaseff, Bot. Ztg. 1869, S. 885 und neuerlichst Ger land, Pogg. Ann. 1871; S. 593 ff.

** Wie schon Harting a. a. 0., S. 549 richtig bemerkte. 
In der ersten Gruppe, von Roth bis Gelb, liegen 3, mitunter nur 2 Absorptionsbänder. die den Bändern I-III des normalen Chlorophylls entsprechen. Das Band I ist auch hier im ganzen Spectrum, wenn nicht das breiteste, so doch intensirste, es ist kohlschwarz, auf der Seite gegen das rothe Ende ziemlich scharf alogeschnitten, a u $\mathrm{f}$ der brechbareren dagegen stärker schattenartig verlaufend als im Normalzustande (vgl. Abbildung I, 7). Eine wesentliche Aenderung besteht darin, dass es, wie alle genaueren Beobachter gesehen haben, mit der Normallösung verglichen etwas weiter gegen das rothe Ende hin gerückt ist. Der Grad der Verschiebung wird aus der Tafel und den später anzuführenden Zahlen sichtbar werden. Uebrigens ist diese Verschiebung mach den Erfahrungen, die ich gemacht habe, nur eine scheinbare: Das Band hat nämlich, gegen das normale gehalten, an Breite etwas abgenommen und diese Abnahme ist hauptsäehlich da geschehen, wo auch die Zunahme im Normalfalle bei zunehmender Absorption hauptsächlich statt hat, auf der brechbareren, in Folge dessen ist die Mitte des Bandes scheinbar weiter gegen das rothe Ende gerückt. Diese Abnahme an Breite ist übrigens nichts ihm eigenthümliches, gehört vielmehr der ganzen ersten Gruppe an, die sich dadurch wesentlich ronder Mittelgruppe, in welcher die Bänder an Breite zunehmen, unterscheidet.

Demn auch Band II und III haben an Breite verloren; doch ist noch auffallender an ihnen, dass sie, im Gegensatz zu vorigem, beide gegen das brechbarere Ende verschoben sind; im Uebrigen verhalten sich beide etwas ungleich; Band III nimmt viel stärker $a b$, ja verschwindet mitunter fast völlig und rückt, vorher D nahe, jetzt näher an $\mathrm{E}$.

Die 3. Gruppe der Absorptionen, in Blau und Violett, die sich hier zweckmässig anschliesst, ist eine continuirliche Absorption des ganzen brechbareren Theiles. Je nach der Concentration beginnt dieselbe früher oder später; bei einer solchen, wo alle ‘Bänder getrennt sichtbar sind, beginnt sie schwach schattenartig gleich hinter F, so dass ein Theil des Blau zwischen dem 2. Streifen im Grün und der Endabsorption hervorsieht, und wächst rasch zu einer totalen Absorption alles übrigen Blau und Violett. - Bei schwächeren Concentrationen wird nur mehr vom Blau sichtbar, Bänder gelangen nicht zum Vorschein.

Die mittlere, dem Grün angehörige Bandgruppe aus 2 breiten 
Streifen, die der Intensität nach den 2. Rang einnehmen, bestehend, ist weitaus die interessanteste und charakteristischste bei der ganzen Erscheinung.

Das Band, das wir als Band IV a bezeichnen, von den beiden das vordere und schmälere, ist nichts Anderes als das Band IV des normalen Chlorophylls, das mitunter etwas seine Lage geändert, gewöhnlich aber auf seiner Stelle liegen bleibend an Stärke und Breite colossal zugenommen. Es hat eine Intensität die das Band II übertrifft, seine Breite gewöhnlich von 295-315-335, bei grösserer Concentration $290-320-350$.

Ihm an Intensität ganz gleich, nur noch etwa ein Drittheil breiter, ist ein zweites Band im Grün neu entstanden. Auf der einen Seite gewölnnlich von der Linie b begrenzt, andrerseits etwa auf der Hälfte zwischen dieser Linie und $\mathrm{F}$ endend.

Seine Lage war gewöhnlich $400-450-500$.

$$
\begin{aligned}
& \text { oder } 400-440-480 . \\
& \text { oder } 380-450-520 .
\end{aligned}
$$

Einige Beispiele aus der Reihe von Beobachtungen, aus denen die vorliegenden Angaben abgezogen sind, werden die Lage der Bänder kennen lehren.

1. Die gleiche weingeistige Lösung aus den frischen Blättern von Mentha piperita frisch und nach mehreren Monaten untersucht gibt folgende Lagen:

frisch :

$\begin{array}{lc}\text { I } & 30-60-80 \\ \text { II } & 120 \text { (Mitte) } \\ \text { III } & 185 c \\ \text { IV } & 300 \quad\end{array}$

zersetzt:

$\begin{array}{lc}\text { I } & 35-55-75 \\ \text { II } & 125-135-155 \\ \text { III } & 235 \\ \text { IV a } & 295-315-335 \\ \text { IV b } & 400-450--500\end{array}$

2. Eine frische Lösung auf dem Sandbade bei mittlerer Temperatur abgedampft, zeigt sich wiedergelöst zersetzt und gibt:

I Mitte 55

$\begin{array}{lll}\text { II } & * & 135 \\ \text { III } & * & 225 \\ \text { IV a } & \text { » } & 305 \\ \text { IV b } & \text {, } & 430\end{array}$

3. Aus den Blittern von Deutzia scabra, die mit Alcohol ausge- 
zogen, mit dem Extract noch einige Tage in Berührung gestanden, ergab sich eine zersetzte Lösung.

Lage der Bänder: I Mitte 60

$\begin{array}{ccc}\text { II } & & 150 \\ \text { III } & 0 & \\ \text { IV a } & 325 & \\ \text { IV b } & 445 .\end{array}$

4. Eine einen Monat alte Lösung von Pittosporum undulatum:

IV a $295-305-315$

IV b $400-450-500$.

5. Eine. Lösung aus Sambucus nigra, 14 Tage alt:

$$
\begin{aligned}
& \text { I } 45-60-75 \\
& \text { II } 125 \\
& \text { III } 0 \\
& \text { IV a Mitte } 295 \\
& \text { IV b , } 440 .
\end{aligned}
$$

Wir haben bis jetzt eine Lösung mittlerer Concentration betrachtet, bei welcher alle überhaupt möglichen Bänder individualisirt erscheinen; es erübrigt nun nachzuholen, in welcher Weise die Absorptionen von der geringsten Concentration bis zur stärksten, oder, wie wir betrachten wollen, bei zunehmender Dicke der Flüssigkeitsschicht allmählig erscheinen und sich ändern.

Bei ganz dünnen Schichten erscheint anch hier, wie in der Normallösung zuerst Band I, dann ziemlich deutlich Band IV b allein, unmittelbar darauf auch IV a und am violetten Ende eine theilweise Hinwegnahme der Strahlen, endlich bei weiterer Zunahme der Schichtendicke die Bänder II und zuletzt III, zugleich mit einer immer weiteren Fortnahme von Blau und Violett.

Bei weiterer Verdickung der Schicht fliessen nun IV b und die Endabsorption zusammen, so dass von 400 ab eine totale Verdunkelung statt hat. Es bleibt dann noch übrig Band I, II, III, und IV a. Die Lichtstreifen zwischen diesen Bändern sind: ein rothes Band vor B, ein zweites zwischen I und II, ein gelbes zwischen II und III und 2 grüne, zwischen III und IV a einerseits und dann IV a und IV b andrerseits. Letzteres ist sehr stark verdunkelt und im weiteren Verlauf fliesst auch IV a völlig mit der ganzen Endabsorption zusammen, so dass nur noch ein grünes Band übrig ist. - Zuletzt blieb mir noch deutlich sichtbar das Roth zwischen I und II und Gelb zwischen II 
und III, welch' letyteres am klarsten war. Das Roth jenseits B und das Grün zwischen III und IV a waren schon vorher unsichtbar geworden.

Mani sieht, dass sich das zersetzte Chlorophyll auch in der Art und Weise, wie bei zunehmender Concentration die Lichtstrahlen verschwinden. sehr wesentlich von dem normalen unterscheidet, während dort zuletzt Grün und Roth, schliesslich nur Roth jenseits B übrig bleibt, scheint mir hier das Roth zwischen B und C und das um D gelegene Gelb länger zu beharren. Uebrigens ist schon an Lösungen mittlerer Concentration leicht bemerklich, dass in normalem Chlorophyll der Raum zwischen Streifen I und II stark verdunkelt, in zersetztem sehr hell erscheint.

Aus dem Vorstehenden ergeben sich zugleich auch die Grade der Verdunkelungen, die jedesmal in dem Spectrum zwischen den Bändern vorhanden sind.

Fassen wir nach dem Vorgange von Hagenbach (a. a. O. S. 268) die Veränderungen, die das Spectrum bei Zersetzungen des Chlorophylls erleidet, in allgemeine Kategorien kurz zusammen, so bestehen diese:

1) In einer A enderung des Baues der Bänder: I-III nehmen an Stärke ab, IV zu.

2) In einer Lageänderung: I rückt scheinbar gegen das rothe Ende, II-III (mitunter IV) in der That gegen das violette. Die Aenderung geschieht nicht bei allen Bändern in gleichem Maasse.

3) Verschwinden von Bändern und Auftreten neuer. Die Bänder V-VII, offenbar auch an Stärke abnehmend, schmelzen zu einer Absorption zusammen. - Hinzutreten des neuen Bandes IV b.

H i s t o r i s ches. Dass das „zersetzte" Chlorophyll schon BrewSTER bekannt war, ist bereits oben angeführt worden; die Stelle, aus der insbesondere auch hervorgeht, dass er die 2 charakteristischen Bänder im Grün erkannt hatte, lautet (a. a. 0. p. 541-542): „When the green fluid obtained from these plants has stood for three or four days, it loses its high green colour and becomes of an olive-green, which grows more and more of a brownish-yellow, till it becomes almost colourless. During these various changes, the specific action of the fluid upon the spectrum changes also. - When the fluid has become almost colourless like water, it still exercises a powerful action upon the middle of the red space, and a faint, but still perceptible action, at two points of the green band." 
STOckes, der die zersetzte Lösung wohl unterscheidet und zuerst für dieselbe den Namen „modificirtes * Chlorophyll eingeführt hat, kennt (a. a.0. S. 219), wie wir bereits oben angeführt, einige wesentliche Eigenschaften (die beiden grünen Bänder und das „Verschwinden“ von III, sowie endlich die geringere Absorption im Blau).

Durch Askenasy (a. a. O. S. 228) wird meines Wissens zuerst bekannt, dass das Band I im Roth bei der Zersetzung „namentlich auf seiner brechbareren Seite sehr abnimmt", er sagt ferner, dass die „andern Streifen schwächer" werden und im Blau die Absorptionen in 2 getheilt sind. Aus seinen Zeichnungen lässt sich aber (Fig. 2 mit 1 und zwar die Dicken a und e verglichen) viel Wichtigeres, als das von ihm Gesagte, herauslesen: dass das Band II etwas verschoben ist.

Die präciseste und bis auf ein Geringes correcte Darstellung der Veränderungen, die das Spectrum an „modificirtem Chlorophyll“ erleidet, hat Hagenbach (a. a. O. S. 268) gegeben. Er hebt klar hervor, dass die Veränderungen betreffen: 1) das Verschwinden vorhandener Streifen und das Auftreten neuer, 2) die Aenderung in der Reihenfolge in Bezug auf Intensität und 3) die Verschiebung von Streifen. - Mit den Einzelausführungen in den drei Puncten stimmen meine Erfahrungen ganz überein, hinzuzufügen war wesentlich nur die Verschiebung des Bandes II.

Die Zeichnung und Untersuchung von Gertand und Rauwenhoff (a. a. 0. p. 8 und Fig. 2) hat den von Hagenbach eruirten Thatsachen nichts hinzugefügt, als dass sich eine solche Lösung und ihr Spectrum unter Umständen über 5 Jahre intact erhalten kann; denn die Beobachtung über Duplicatur des Bandes I halte ich auch hier für nicht in der Natur selbst begründet*.

Endlich hat Preyer (a. a. O. Fig. 14) von ätherischem mehrjährigem Extract eine bis auf die Anfangsabsorption im Roth richtige Zeichnung gegeben*.

* In der inzwischen schon mehrmals noch anmerkungsweise berücksichtigten neuesten Arbeit Gerlands (Pogg. Ann. 1871, S. 585) sind verschiedene Entwicklungsstadien der Zersetzung unterschieden, auch insbes., was ich für richtig halte, Zersetzung als verschieden von Verbleichen des Chlorophylls betont; die schon niedergeschriebenen Resultate meiner Arbeit werden dadurch nicht alterirt. 


\section{Einwirkung von Säuren und sauren Salzen auf das Chlorophyll und sein Spectrum.}

Zum Verständniss der im Vorstehenden geschilderten „Zersetzung * des Chlorophylls und Beurtheilung der FilhoL'schen Chlorophyllderivate schien es mir nothwendig einige Versuche über die Einwirkung organischer Säuren und ihrer sauren Salze auf das Chlorophyll und sein Spectrum anzustellen; andererseits zur richtigen Würdigung des Spectrums des sog. reinen Chlorophylls und der Frewr'schen Chlorophyllfarbstoffe die Wirkung anorganischer Säuren, bes. der Salzsäure, etwas näher ins Auge zu fassen.

Auch hier genügte es bestimmte, gerade intentirte Veränderungen der Lösung zu studiren und ein näheres Eingehen auf die Genese oder das schliessliche Ende eines solchen Vorgangs speciellen Untersuchungen vorzubehalten.

\section{Einwirkung organischer Säuren.}

Setzt man zu einer kleinen in einem Reagirglas befindlichen Menge alcoholischen normalen Chlorophylls (etwa 0,5 Cubctm.) einige Tropfen Essigsäure, so verfärbt sich die Lösung sofort g elbgrün, und damit ist auch das normale Spectrum geändert. Die Veränderungen sind aus folgender Lageangabe erkenntlich:

a) normale Lösung.

I $40 \div 60-80$

II 120

III 190

IV 300

V 520-580-640

VI $760-820-880$ b) mit Essigsäure versetzte.

$40-70$

130

0

$-300-310$

IV b $380-430-480$

$$
\text { V } \quad 520-580-640
$$

0

Nach 24 Stunden hatte sich in der mehr gelb gewordenen Lösung ein schwärzlicher Niederschlag gebildet, der beim Erwärmen sich wieder löste und die gelb- oder braungrüne ursprüngliche Färbung wieder erzeugte. Das Spectrum ergab nun:

I $40-70$

II 135

III 0 (220)

IV a $290-300-310$

IV b $380-430-480$

$\mathrm{V} \quad 0 \quad$ statt dessen eine continuirliche Absorption des 
Blau und Violett, die bei 600 schattenartig begann und bei 700 total war.

Aus dem Vorstehenden ist ersichtlich, dass bei Einwirkung der Essigsäure sofort folgende Aenderungen eintreten:

a) Band I wird schmäler und damit scheinbar weiter gegen das rothe Ende hingerückt.

b) Band II rückt gegen Violett weiter.

c) Band III verschwindet, mitunter ist es sehr schwach in der Lage $220 \mathrm{zu}$ sehen, also wie II gegen das violette Ende verschoben.

d). Band IV a und b treten wie bei dem ,zersetzten“ Chlorophyll auf.

e) Band $V$ bleibt zunächst, rerschwindet aber nach einiger Zeit.

f) Band VI verschwindet sogleich und an Stelle desselben tritt eine continuirliche Absorption des Blau und Violett. -

Eine ganz gleiche Wirkung habe ich von der Einwirkung anderer organischer Säuren gesehen. Beispiele:

a) normale Lösung.

I $40-80$

II 125

III 180

IV 305

$$
\text { V } 510-580-650
$$

VI wie gewöhnlich b) versetzt mit $A$ pfelsäure.

$$
40-80
$$

$145^{\circ}$

$0(220)$

IV a $285-300-315$

IV b $380-430-480$

$\mathrm{V}$ geblieben

VI verschwunden

Nach 24 Stunden: I $35-70$

$$
\begin{array}{cc}
\text { II } & 140 \\
\text { III } & 0 \\
\text { IV a } & \text { geblieben } \\
\text { IV b } & \text { gerschwunden. } \\
\text { V } & \text { versch }
\end{array}
$$

Derselbe Versuch mit Wéinsäure:

\section{Normal.}

$$
\text { I } 40-80
$$

II 120
Mit Weinsäure.

$40--75$

140
Nach 24 Stunden*.

$50-75$

$120-135-150$

* Wie Filhol (s. unten) richtig bemerkt, entsteht durch Einwirkung organischer Säuren alsbald eine Fällung in Form schwärzlichen Gerinnsels; allein man kann dies jederzeit durch Erwärmen des Alcohols wieder lösen und die getrübte Lösung klar machen. 
Normal.

III 190

IV 300

V
VI wie gewöhnlich

Mit Weinsäure.

220

IV a $280-300-320$

IV b $370-440-510$

Derselbe Versuch mit $0 \mathrm{xals} a ̈$ ure.

Normal.

$$
\text { I } 40-80
$$

II 125

III 190

IV 300

$\mathrm{V}$
$\mathrm{VI}$ \} wie gewöhnlich
Mit einem Krystall erwärmt.

$$
40-75
$$

$125-140-160$

220 kaum sichtbar

IV a $275-300-330$

IV b $360-430-500$

sichtbar

verschwunden.

2. Einwirkung pflanzensaurer Salze.

Versetzt man eine normale Chlorophylllösung mit einigen Tropfen einer concentrirten Lösung sauren weinsauren Kal is, so erfolgt zunächst keine Veränderung, oft stundenlang nicht; erwärmt man, so erhält man häufig eine Zersetzung; stets aber tritt sie ein, wenn die Lösung etwa 24 Stdn. sich selbst (dunkel) überlassen wird. Ein Beispiel des Spectrums:

Das Spectrum der normalen Lösung genau wie oben; das des zersetzten :

I $\quad 30-70$

II 135

III sehr schwach 215

IV a $290-305-320$

IV b $370-435-500$

V Mitte 570. - VI u. s. w. verschwunden.

Nach 2 Tagen ist auch Band $\mathrm{V}$ verschwunden und am blauen Ende wie gewöhnlich eine continuirliche Absorption vorhanden.

Ein gleiches Resultat ergab ein Versuch mit saurem äpfelsaurem Kalk.

Experimente mit neutralem und saurem weinsaurem $\mathrm{Kali}$, die in gleichen Mengen der gleichen Menge Chlorophylllösung zugesetzt wurden, ergaben, dass mit ersterem sich die Lösung auch nach 48 Stunden noch völlig normal erhalten, mit letzterem nach einigen Minuten in der angegebenen Weise zersetzt hatte. 
Fassen wir die Resultate über die Wirkung der Pflanzensäuren und sauren Salze derselben kurz zusammen, so sieht man, dass das Endresultat eine totale Zersetzung ist, die sich von der oben als freiwillige Zersetzung betrachteten nicht unterscheidet. Vorher allerdings tritt ein Zwischenstadium auf, in welchem zum Unterschied von jener Band $\mathrm{V}$ noch erhalten ist *; in dieser Zeit ist IV b nicht so scharf zu sehen als später, weil es unmittelbar an das dunkle Band $\mathrm{V}$ anstösst, während später hinter ihm das Blau deutlich hervortritt. -

Im Anschluss an diese Versuche mögen einige Erscheinungen besprochen werden, die zum Theil sicher, zum Theil wahrscheinlich mit einer Säure- oder Salzwirkung zusammenhängen.

Eigenthümliches Verhalten der Blätter von Ampelopsis beim Kochen mit Wasser.

Unter allen Pflanzen, die ich auf Chlorophyll untersucht und zu diesem Behufe vorher mit Wasser ausgekocht, bot Ampelopsis hederacea ${ }^{* *}$ allein die abweichende Erscheinung dar, dass die Blätter nicht wie die übrigen beim Kochen schön grün blieben, sondern stets eine stark gelbraune oder braungrüne Farbe annahmen, ähnlich der Farbe zersetzten Chlorophylls. Die Extraction mit Weingeist zeigte auf den ersten Blick eine der Farbe und der spectralanalytischen Reaction nach zersetzte Lösung, die im ersten Theile die oben genannten Bänder, im zweiten auch noch Band $\mathrm{V}$ wahrnehmen liess.

Bei der Extraction mit Alcohol war auch noch eine andere auffallende Erscheinung walızunehmen. Uebergoss man nämlich die abgekochten Blätter mit Alcohol und erhitzte, so zog dieser zunächst eine rein goldgelbe Lösung aus, die alle Claraktere des gelben Chlorophyllbestandtheils hatte. Nach weiterem Kochen erhielt man eine braungrüne Lösung, in welcher der obengenannte gelbe und der zweite aber zersetzte blaugrüne Bestandtheil des Chlorophylls sich befand. Die Erscheinung beweist, dass die Löslichkeit des gelben Bestandtheils in Alcohol im Verhältniss zum zweiten grösser geworden war als bei nor-

* Die ganze Wirkung der Säuren wird leicht begriffen, wenn man die Wirkung derselben auf die beiden Componenten des "Chlorophylls", die wir später auseinander zu setzen haben, kennt. Durch die Säturen wird zunächst nur der blaugrüne Bestandtheil zersetzt (d. h. die Bänder I-IV' umgeändert, IV b hervorgerufen, die im Blau und Violett liegenden Bänder zerstört) der gelbe Bestandtheil bleibt zuerst intact und dessen Bänder treten im Blau und Violett allein hervor. Nach Verfluss von 24 Stunden ist auch er zersetzt.

** Wie ich nachträglich sah auch Vitis vinifera; wahrscheinlich auch noch andere. 
malem Chlorophyll, aus welchem durch Alcohol stets beide Bestandtheile zugleich ausgezogen worden.

Bei einem Erklärungsversuch dieser Zersetzungserscheinung beim Kochen mit destillirtem Wasser war von vornherein nur an die Einwirkung gewisser Blattbestandtheile auf das Chlorophyll selbst zu denken, da das Chlorophyll gegen Kochen mit Wasser unempfindlich ist. Einen Fingerzeig für die Erklärung gab die Thatsache, dass das Kochwasser stark sauer reagirt. Nach Rochlener (Phytochemie S. 57) ist in den Blättern "Weinsäure* vorhanden. Um jedoch hinsichtlich der Blattbestandtheile noch sicherer zu sein, bat ich meinen Collegen Prof. von GoRup um eine Untersuchung des ausgepressten Saftes der Blätter. Die Analyse*, welche derselbe auszuführen die Güte hatte und die auch in anderer Hinsicht sehr interessante Resultate geliefert hat, ergab untes anderm in Blättern aus dem Monate Juni reichliche Mengen von saurem weinsaurem Kali und freie Weinsäure, in solchen vom September freie A epfelsäure.

Man hat offenbar anzunehmen, dass die nachgewiesenen Stoffe im Zellinhalt in Lösung rorhanden sind. So lange das protoplasmatische Chlorophyllkorn selbst lebt, hat es, ähnlich wie das Protoplasma überhaupt gewissen Farbstoffen gegenüber, die Fähigkeit, diese Salze und Säuren, die den Chlorophyllfarbstoff zersetzen, nicht eindringen zu lassen. Wird das Chlorophyllkorn durch Kochen mit Wasser oder Hitze getödtet, so treten in die Masse desselben die Säuren und Salze ungehindert (vielleicht sogar gespeichert) ein und bewirken dort die Zersetzung.

Die Erscheinung, dass zunächst aus solchen Blättern nur ein gelber Farbstoff ausgezogen wird, erklärt "sich aus der Wirkung der Säuren auf die beiden Chlorophyllfarbstoffe, die wir später näher zu betrachten haben. Einstweilen sei nur so viel bemerkt, dass durch sie eine Fällung des blaugrünen Farbstoffs wohl auch in den Chlorophyllkörnern stattfindet, und dass der Niederschlag desselben offenbar schwieriger in Alcohol zu lösen ist, als der unverändert bleibende gelbe Farbstoff; wesshalb dieser zuerst, jener erst später in Alcohol übertritt. -

Es gibt eine Reihe anderer Zersetzungs-Erscheinungen, die wahrscheinlich mit der Einwirkung von Säuren oder sauren Salzen zusammenhängen.

Vor Allem möchte ich bemerken, dass es nicht unmöglich

* Sie ist besprochen in Sitzb. phys.-med. Soc. zu Erlangen 5. Dec. 1871 und in Ber. deutsch. chem. Gesellsch. 1871. 
ist, dass die freiwillige Zersetzung des Chlorophylls, die eintritt, wenn man die auf gewöhnliche Weise bereitete Chlorophylllösung sich selbst überlässt, hä ufig durch Salze oder Säuren bewirkt werde, die aus dem Blatte mit in die alcoholische Lösung übergehen. Mehrere Gründe sprechen dafür. Einmal, die schon von STockes (a. a. 0.) beobachtete Thatsache, dass die Chlorophyllösung, die aus vorher ausgekochten, d. h. zum grossen Theil von löslichen Salzen befreiten Blättern bereitet wurde, haltbarer ist als andere; ferner die Beobachtung, dass Lösungen in absolutem Alcohol oder Aether - in welche nur minimale Quantitäten zersetzender Körper übergehen, gleichfalls dauerhafter sind.

Wahrscheinlich längt mit der Einwirkung von Säuren auf die getödteten Chlorophyllkörner auch die im Herbste überall wahrnehmbare Erscheinung zusammen, dass gewisse Blätter nach dem ersten Froste (der sie getödtet) sofort ihre grüne Farbe verlieren und die zersetzten Chlorophylls annehmen.

Endlich sei auch darauf hingewiesen, dass ein in den Küchen üblicher Kunstgriff, gekochte Gemüse schön grün zu erhalten, wie mir scheint, darauf schliessen lässt, dass die nicht seltene Braungrünfärbung grüner Küchenpflanzen beim Kochen mit der Wirkung von Säuren zusanmenhängt. Man pflegt, um die Farbe der grünen Gemüse rein zu bewahren, beim Kochen etwas Soda zuzusetzen; möglich, dass dadurch Säuren oder saure Salze gesättigt und Einwirkungen derselben auf das Chlorophyll verhütet werden.

Das Historische über die Wirkung organischer Säuren auf das Chlorophyll und sein Spectrum können wir hier übergehen, da es unten bei der Zerlegung des Chlorophyllfarbstoffs näher in's Auge zu fassen sein wird.

3. Einwirkung von Salzsäure.

Setzt man zu einer Chlorophylllösung eine Spur Salzsäure, so verfärbt sich dieselbe augenblicklich (Mıchel a. a. 0. S. 12); ein Gleiches geschieht, weun man einen oder mehrere Tropfen hinzubringt. Die Färbung ist anfünglich ganz die ,zersetzten " oder mit organischen Säuren versetzten Chlorophylls; wirkt die zugesetzte Säure mehrere Stunden oder länger, so färbt sich die Flüssigkeit allmälig bla ugrü̈n.

Das Spectrum dieser veränderten Lösung ist, wie sich denken 
lässt, in dem einen und andern Falle ein etwas verschiedenes; man überzeugt sich bald, dass nicht allein das Spectrum zu Anfang (bei der braungrünen oder braungelben Färbung) und zu Ende (bei der blaugrünen Farbe) verschieden ist, und in den Zwischenzeiten allmälig wechselt, sondern, dass je nach der Menge der zugesetzten Säure, der Stärke der Einwirkung ein ziemlich verschiedenes Spectrum .zum Vorschein kommt.

Eines steht unter allen Umständen fest, dass durch die geringsten Spuren von Salzsäure - Schwefelsäure wirkt, soweit ich gesehen, gerade so; Phosphorsäure dagegen im Anfange mehr wie die organischen Säuren - das Spectrum des Chlorophylls und der darin enthaltenen Farbstoffe unwiederbringlich zerstört wird. Diese Thatsache zu kennen, reichte eigentlich für meine Zwecke völlig aus, und ich unterliess es daher, das complicirte Phänomen eingehender zu studiren; doch möge zum Belege des Gesagten in Kurzem berichtet werden, was ich nebenbei wahrgenommen habe.

1) Versetzt man etwa 1 Cub.-Ctm. reiner Chlorophylllösung mit einem Tropfen conc. Salzsäure, so färbt sich dieselbe sofort braungelb; etwaige Trübungen schwinden beim Erwärmen.

Das Spectrum dieser Flüssigkeit stimmt mit dem zersetzten Chlorophylls in der Hauptsache überein, insbesondere ist an den Bändern I, II, IV a kein nennenswerther Unterschied gegen jenes wahrzunehmen. Hinsichtlich III habe ich Verschiedenes gesehen, entweder war dies schwach geworden und in der gewöhnlichen Weise verschoben; immer jedoch beträchtlich deutlicher, als bei der Wirkung von organischen Säuren, bei deren Einwirkung es fast völlig verschwindet; oder in andern Fällen - näher präcisiren konnte ich dieselben nicht - blieb es von beträchtlicher Stärke, etwa der von II gleich, jedoch ebenfalls verschoben.

IV b erschien in den meisten Fällen seln schwach, so dass es leicht übersehen werden konnte, besonders im ersten Anfange der Wirkung. In der zweiten Hälfte des Spectrums waren -von Anfang an sofort V und VI verschwunden, und statt dessen eine continuirliche Absorption vorhanden, die aber erst etwa in der Hälfte zwischen F und $G$ total wurde, so dass ein grosser Theil des vordern Blau durchging. Sehr merkwürdig war, dass im ersten Anfang der Wirkung a uf oder hinter der Linie $\mathrm{F}$ eine Verdunkelung vorhanden war, die sich etwa in der Breite des Bandes $\mathrm{V}$ beiderseits von der Linie er- 
streckte und den Eindruck machte, als ob das Band V gegen die Linie F hin vorgerückt sei. - Ein solches Spectrum ist in Fig. 7, Taf. III abgebildet.

2) Wirken mehrere Tropfen Säure etwa 12 oder 24 Stunden auf die Lösung, so ist dieselbe ausgesprochen blangrün. Das Spectrum ist damit ebenfalls geändert.

An den Streifen I und II konnte ich höchstens die weitere Veränderung constatiren, dass sie noch schmäler geworden. III fehlte mitunter, in den meisten Fällen war es aber stark und deutlich vorhanden und fast IVb gleich, die Verschiebung desselben etwas geringer, als in der zersetzten braungelben Lösung. IV b erschien mir auffallend schwach; im zweiten Theile des Spectrums die continuirliche Absorption noch später beginnend als anfänglich.

Für diesen wie für den ersten Fall sei noch ausdrücklich darauf hingewiesen, dass die Verdunkelungen zwischen den Bändern ganz anders, als bei normalem Chlorophyll sind, dass insbesondere das vor B gelegene Roth sehr verdüstert ist, das zwischen I und II gelegene sehr klar hervortritt. - Bei der blaugrünen Lösung ist daș Gelb sehr gedämpft.

Kritisches. Die vorstehenden Beobachtungen genügen, um einige Spectra von Chlorophyll, das mit Salzsäure behandelt wurde, zu verstehen.

HaRTiNa hat von sog. reinem Chlorophyllfarbstoff, den er nach Berzeius' Vorgang durch Abdampfen 1. s. w. einer gewöhnlichen Chlorophylllösung und schliessliches Aufnehmen in "rauchender Salzsäure* erhalten wird, ein Spectrum gegeben (a. a. O. Taf. IV, Fig. 20) und schon selbst darauf hingewiesen (a. a. O. S. 549 f.), dass zwischen den Spectren gewöhnlichen Chlorophylls und diesem des "reinen" wesentliche Unterschiede bestehen, freilich - in der Meinung, dass sein Salzsäure-Chlorophyll rein, und die Verschiedenheiten des gewöhnlichen , auf Rechnung der mit dem Chlorophyll vermischten fremdartigen Substanzen gesetzt werden müssen ".

Betrachtet man nun das Spectrum desselben näher, so sieht man, dass es mit unsern Angaben über das Spectrum der blaugrünen Veränderung (und so war das seinige nach seiner Angabe, S. 549 oben, ja auch gefärbt) ganz wohl übereinstimmt. Er zeichnet ganz richtig eine Verschiebung von I und II, auch das Band IV a an seiner Stelle, freilich übersieht er III und das allerdings leichter übersehbare IV $b$; 
richtig gibt er wieder den späten Beginn der totalen Absorption am Ende an.

Da in unsern Versuchen das Chlorophyll nicht gereinigt, sondern nur mit $\mathrm{HCl}$ versetzt war; so können selbstverständlich die Veränderungen des Spectrums nur auf Rechnung der Säurewirkung und nicht, wie Hartivg will, auf den'Ausschluss fremder Beimengungen gesetzt werden.

Die obigen Angaben setzen uns auch in den Stand, die Spectra des Freny'schen Phylloxanthine's und Phyllocyanine's, wie sie von Askenasy und Gerland-Rauwenhoff gegeben worden sind, zu verstehen.

Vergleicht man zunächst die ältern Angaben Askenasy's, so sieht man sofort, dass das Spectrum des Phylloxauthine's (a. a. 0., Fig. 5) ganz wohl mit dem Spectrum übereinstimmt, das wir oben für die erste Wirkung von Salzsäure auf Chlorophyll beschrieben haben. die Verschiebungen von I und II sind freilich nicht zu erkemen, auch für III der seltenere Fall des Fehlens angegeben, dagegen ist IV a und IVb und die Remission hinter IVb sehr deutlich gezeichnet. Noch viel schöner stimmt aber das Spectrum des Phyllocy a nine's (Fig. 6) mit unserm für die Endwirkung der Salzsäure angegebenen Spectrum. Das charakteristische breite Band III ist besonders gut hervorgehoben. Dass Band IV b nicht gezeichnet ist, erklärt sich aus der ausserordentlichen Schwäche und leichten Uebersehbarkeit desselben. Dis Vortreten des Blau ist richtig angegeben.

Auch die Spectra GerLand-Rauwenhoff's über die beiden Fremy'schen Chlorophyllderivate lassen den angegebenen Ursprung erkennen, doch weniger klar als bei Askenasy. In den Fig. 4 und 5 (a. a. 0.) zeigt das Phylloxanthine den Charakter zersetzten Chlorophylls, besonders in dem Band IV a und $b$, freilich sind auch hier die Verschiebungen der 3 ersten Bänder, wenigstens gegen das Normalspectrum dieser Autoren gehalten, nicht erkenntlich; aber das starke Band IV des Normalspectrum zeigt eben deutlich, dasș hier in Zersetzung begriffenes Chlorophyll für normal genommen wurde.

An dem Spectrum des Phyllocyanine's tritt (Fig. 3) die Stärke des Bandes III und der Durchtritt des Blau hinter IV b sofort in die Augen. Das Spectrum Fig. 6, Phyllocyanine nach Kromayers Methode präparirt, beweist durch seine fast völlige Gleichheit mit dem vorigen, dass ein ganz gleiches Zersetzungsprodukt durch $\mathrm{HCl}$ vorliegt. 
Dass an diesem Spectrum IV b fehlt, kann, nach dem oben Bemerkten, nicht Wunder nehmen.

Wurden in den vorangehenden Fällen Salzsäure-Spectra nur gelegentlich und öfter ohne Kenntniss ihrer Natur als solche gegeben, so mögen hier auch noch einige Spectra mit Säure behandelten Chlorophylls erwähnt werden, die als solche erkannt und bezeichnet worden sind.

Ein Spectrum durch Salzsäure zersetzten Chlorophylls hat Thudichum (a. a. O. S. 217, Pl. III, Fig. 10) gegeben. Es sind die Bänder IV a und b richtig angegeben, auch III tritt stark hervor, . dagegen sind die Verschiebungen, wie der spätere Anfang der Endabsorption übersehen.

Sorby's Spectrum (a. a. 0. p. 12) zeigt sowohl die Bänder im Grün, als die Verschiebungen der 3 ersten Streifen.

Das Spectrum von Chlorophyll, in saurer Lösung“ (mit conc. Schwefelsäure), das Preyer (a. a. 0. Taf. 4, Fig. 16) gegeben, stimmt mit dem Spectrum des Salzsäure-Chlorophylls nicht wohl überein: es fehlt demselben das Band IVb; es ist ferner eine Verschiebung des Bandes I gegen das violette Ende hin angegeben, dagegen zeichnet er im Gelb das Band III sehr stark, was mit unsern Erfahrungen an Salzsäure-Chlorophyll zusammentrifft; unzukömmlich aber dürfte es sein, dieses Band geradezu als ein „Säureband " zu bezeichnen, da es bei Mineralsäuren nur in einem gewissen Stadium der Wirkung, bei organischen Säuren, soweit meine Erfahrungen reichen, niemals auftritt. 


\section{Entmischung des Chlorophylls.}

\section{Kritische Betrachtung der bisherigen Versuche.}

Die Versuche, den Chlorophyllfarbstoff, oder wie man gewöhnlich sagt, das Chlorophyll als eine Mischung mehrerer Farbstoffe darzustellen, datiren von den bekannten Arbeiten Fremy's über diesen Gegenstand. Allerdings hatte schon Marquart (Die Farben der Blüthen, Bonn 1835, S. 41) Versuche gemacht, ,das Blattgrün in Blau und Gelb zu zerlegen ", allein es handelte sich dabei nach dessen eigener Aussage streng genommen nicht um eine Entmischung in präexistirende Farbstoffe, sondern um „Zerlegung “ des Blattgrüns in Blumenblau und Blumengelb.

Ueber Fremy's Experimente, soweit sie Säurewirkungen betreffen, können wir uns, da sie nach den einstimmigen Anssagen aller späteren Untersucher nicht zum Ziele, sondern zu „Zersetzungen“ des Chlorophylls geführt haben, kurz fassen, zumal, da wir selbst oben schon aus spectralanalytischen Gründen die Natur seiner Chlorophyllderivate erkannt haben.

In seiner ersten Abhandlung * zeigte er bekanntlich, dass weingeistige Chlorophylllösung mit Salzsäure und Aether (Verhältniss 1: 2) geschüttelt in ersterer eine schön indigblane, in letzterem eine gelbe Farbe zurücklässt. Die beiden Farbstoffe bezeichnet er als Phyllocyanine und Phylloxanthine. Er lässt unentschieden, ob diese im Chlorophyll präexistiren oder nicht **.

* Recherches sur la matière colorante verte des feuilles. Compt. rend. L. 1860, p. 405-412 und Ann. scienc. nat., S. IV, T. Xlll, 1860, p. 45-53.

** „Je me propose également de rechercher si la phyllocyanine et la phylloxanthine - - existent réellement dans les végétaux", p. 411 od. 52. 
In einer zweiten Arbeit* charakterisirt er zunächst die beiden Säureproducte näher, den gelben als neutralen krystallisirbaren, aber verschieden vom Blumengelb, den blauen als eine Säure, ist dagegen zur Ueberzeugung gelangt, dass die beiden Körper nicht als Componenten des grünen Chlorophylls - als Mischung - anzusehen seien. Ich führe die Stelle, in welcher er letztere Meinung ausspricht, wörtlich an, weil, wie mir scheint, ganz allgemein die Ansicht verbreitet ist, FrEMY habe seine Körper als unmittelbare Componenten des Chlorophyllfarbstoffs angesehen. - - „Faut-il admettre que la chlorophylle est un simple mélange d'une substance bleue et d'un corps jaune? Je ne le pense pas. - Pour moi, la chlorophylle est un principe immédiat vert". - 1. c., p. 191.

Wichtiger aber ist, dass er in dieser Arbeit versucht durch Einwirkung von Basen das Chlorophyll zu entmischen. Sẹine Resultate in dieser Richtung klar zu stellen, wird Aufgabe specieller chemischer Untersuchungen sein. Für mich genügte die Wiederholung eines Versuches, um zu sehen, ob er durch Einwirkung der Körper, die er anwendete, die reinen Farbstoffe (Componenten) des Chlorophylls erhält oder nicht. Ich habe den Versuch mit reinem Thonerdehydrat - das mir mein College von Gorup zur Disposition stellte - wiederholt.

Schüttelt man eine reine Chlorophyllösung mit viel Thonerdehydrat und filtrirt, so bleibt auf dem Filter die Thonerde rein chloroply llgrün gefürbt zurück, die filtrirte Flüssigkeit ist schwach, aber rein goldgelb; sie zeigt das Spectrum des unveränderten gelben Farbstoffs. Kocht man die gefärbte Thonerde mit Alcohol aus, so erhält man eine chlorophyllgrüne Lösung, die das Spectrum des normalen Chlorophylls gibt.

Schüttelt man die Lösung mit wenig Thonerdehydrat, so erhält man eine grüne filtrirte Flüssigkeit, die einfach das Spectrum des Chlorophylls gibt; die ausgekochte Thonerde ebenfalls.

Die Versuche wurden mehrmals mit gleichem Erfolge wiederholt. Man ersieht aus denselben:

1) Dass durch Einwirkung von Thonerdehydrat die Chlorophylllösung nicht zersetzt wird.

2) Dass aber auch die Trennung in einen gelben und blaugrünen Farbstoff gewöhnlich nur unvollständig erfolgt. Möglich, dass durch

* Recherches chimiques sur la matière verte des feuilles. Compt. rend. 1865 , T. LXI, p. $180-192$. 
genaues Ausprobiren der Quantitäten von Chlorophyll und Hydrat eine Trennung zu bewerkstelligen ist. Möglich auch, dass Barythydrat, das Fremy noch besser wirkend gefunden hat, eine reine Trennung hervorbringt, und in diesem Falle hätte Fremy die beiden Farbstoffe des Chlorophylls wirklich getrennt.

Es ist demnach möglich und wahrscheinlich, dass der Körper, den er in der zweiten Arbeit (p. 190) als Phylloxanthine beschreibt, ganz der Farbstoff war, den wir unten ebenfalls herstellen. Er ist aber dann im Irrthum, wenn er diesen (a. a. 0.) mit dem gelben, resp. gelbbraunen Product identificirt, das er bei Salzsäure- und Aethereinwirkung in letzterem erhalten.

Was sein Phyllocyanine anlangt, so ist gewiss, dass es auch in diesem Falle ein Zersetzungsproduct ist, nicht als ob er dasselbe dưrch die Fällung mit Thonerde- oder Barythydrat verändert hätte, aber er nimmt (a. a. 0., S. 190) dasselbe aus dem Baryte mittelst Schwefelsäure auf, was jedenfalls eine Zersetzung des Farbstoffs lerbeiführt. - Bliebe noch ein Zweifel, dass er ein Zersetzungsproduct vor sich gehabt, so würde er vollständig gelöst durch seine Bemerkung (S. 191), dass die Lösungen der Phyllocyansäure in Alcohol und Aether "olivenfarben" sind.

Es genügt hier noch, darauf hinzuweisen, dass sowohl von chemischer Seite durch Michei. *, Filmor **, Millardet und mich***, Müluer $\dagger$ und Timiriaseff $\dagger \dagger$ dargethan wurde, dass die Fremy'schen Operationen mit Säuren zu "Zersetzungsproducten“ führen, als auch die spectralanalytischen Untersuchungen von Simuler (a. a. 0. S. 615), Askenasy (a. a. 0. S. 230), GerLand und Rauwenhoff (a.a. 0. S. 18), SchöNn (a. a. O. S. 327) und Stockes (Proc. Roy. Soc. Lond. 1864, p. 144) dasselbe Resultat ergeben haben.

Dass die von Kromayer $\dagger+\dagger$ angegebene, von Fremy's Methode

* Marc Micheli, Quelques observations sur la matière colorante de la chlorophylle.

** Ann. Chim. et Phys. S. IV, T. XIV, 1868, p. 335 et $336-37$.

*** Mem. d. l. Soc. d. scienc. nat. de Strasbourg, T. Vl. 1867.

† Pringsh. Jahrb., Bd. Vll., S. 202.

†† Bot. Ztg. 1869, S. 884.

†† Arch. Pharm. von Bley, Bd. CVl. 1861, S. 164-169. Auszüge in Chem. Centr.-B1. 1861, S. 393; Jahrb. für Fortschr. d. Chem. von Will und Kорp 1861. 
etwas abweichende, aber ebenfalls mit Salzsäurewirkung verknüpfte Darstellungsweise von Phyllocyanine und Phylloxanthine gleichfalls nur zu Zersetzungen des Chlorophylls führen könne, ist nach dem oben Angeführten selbstverständlich; übrigens geht es schon aus den Angaben von Simmler (a. a. O. S. 615 f.), wie aus den Spectren (Fig. 6 und 7) von Gerland und Rauwenhoff hervor.

Obwohl jetzt, der Zeitfolge nach, der Angaben von Jobrs und StockEs über die Composition des Chlorophylls zu gedenken wäre, so wollen wir diese doch lieber im Verein mit andern kurzen Notizen über Chlorophyllbestandtheile zusammen erwähnen, und uns sogleich zu einem zweiten ausführlichen Versuch, mittelst Säuren das Chlorophyll $\mathrm{zu}$ entmischen, wenden.

E. Firнor hat unter dem Titel, Recherches sur la matière colorante verte des plantes" in den Ann. Phys. et Chim. IV S. XIV T. p. 332-348 eine Anzahl früherer Arbeiten zusammengefasst, in denen er das Chlorophyll durch Anwendung von organischen Säuren zu zerlegen strebt.

Indem er die Anwendung von Mineralsäuren als tiefgreifende Zersetzungen hervorrufend verwirft (p. 335), studirte er die Wirkung organischer Säuren, besonders der Wein- und Oxalsäure, und findet, dass diese theils Zersetzungsproducte liefern, theils solche Körper, die in der Chlorophylllösung und dem Blatt schon präexistiren (p. 338).

Giesst man nämlich nach ihm eine Lösung von Wein- oder Oxalsäure in eine weingeistige Chlorophyllösung, so wird die Lösung sofort braungelb, nach kurzer Zeit setzen sich aber schwarze Flocken nieder und die Flüssigkeit erscheint hübsch gelb.

Was zunächst diese gelbe Solution anlangt, so hält er dafür, dass der darin befindliche Körper nicht ein Zersetzungsproduct sei, sondern präexistire; einmal, weil man denselben auch durch blosse Filtration der Chlorophylllösung mit Knochenkohle erhalten kömne (p. 338) andrerseits, weil er in einzelnen Pflanzen (Gold-Varietät von Evonymus, p. 338) für sich in den Laubblättern vorkomme. Er fluorescirt nach ihm nicht (p. 347. 8) und wird durch Salzsäure zunächst grün gefärbt, setzt aber bald gelbe Flocken nieder und ẹrscheint dann schön blau (p. 336).

Der gelbe Niederschlag lässt sich in Alcohol lösen, wird aber von Salzsäure nicht wieder gebläut, kann jedoch dazu durch Aufnahme von Sauerstoff gebracht werden (p. 339). Anderseits kann die in Lösung 
gebliebene blaue Substanz durch Sättigung der Säure in, Gelb verwandelt werden. Er behauptet nun (p. 346 und 347), dass auch diese letztere gelbe Substanz neben dem Chlorophyll frei in der Pflanze existire. Ich kann aber bei ihm keinen Beweis dafür finden; im Gegentheil genügt die Thatsache, dass diese Substanz durch Anwendung von Salzsäure dargestellt wird, sie als Zersetzungsproduct des ursprünglichen gelben Farbstoffs zu kennzeichnen.

Der Körper, welcher in schwärzlichen Flocken bei der Behandlung der Chlorophylllösung mit einer organischen Säure niederfällı̣t, ist nach ihm ein Gemisch von Fett mit einem braunen Körper, der sich durch Anwendung von conc. Salzsäure trennen lässt. Diese löst - ob mit oder ohne Veränderung, lässt er dahingestellt - denselben mit grüner Farbe; durch Sättigung der Säure mit Kreide kann man denselben als braunes Präcipitat und dieses in Alcohol gelöst rein erhalten. Dieser nach ihm stickstoffhaltige und fluorescirende Körper ist es, den Mulder und Morot als reines Chlorophyll angesprochen (p. 341). Fılhor hält diesen braunen Körper zwar nicht für das Chlorophyll selbst, aber doch für einen, der die wesentlichen Eigenschaften desselben constituirt (p. 343).

In neuerer Zeit wurden die Spectra der Filhol'schen Farbstoffe von Gerland und Rauwenhoff (a. a. 0. p. 15 und Fig. 8) untersucht. Dieselben sprachen sich dahin aus, dass sie die ächten Constituenten des Chlorophylls und zwar desshalb seien, weil die Spectra der beiden Farbstoffe zusammengenommen das Chlorophyllspectrum darstellen*. -

Die oben angeführten Untersuchungen über die Wirkung organischer Säuren auf das Chlorophyllspectrum einerseits, eine directe Wiederholung der FiLHoL'schen Versuche andrerseits haben mir folgendes Resultat ergeben.

Die Angaben, dass durch organische Säuren - man kann ebenso gut Aepfelsäure, Citronsäure als Wein- oder Oxalsäure nehmen -- das Chlorophyll in einen gelöst bleibenden gelben und alsbald (nicht sogleich) niederfallenden braungrünen Farbstoff geschieden werde, kann man ohne alle Schwierigkeit bestätigt finden. Trennt man durch Filtration den Niederschlag von dem gelösten gelben Farbstoff, so überzeugt man sich, dass der letztere einen unserer Farbstoffe - den gelben - vor-

* „Les matières jaune et verte de Filhol paraissent devoir être regardées comme les principes constituants de la chlorophylle, qui doit sa couleur au mélange de celles de ces deux matières". A. a. O. p. 18. 
läufig unverändert, darstellt; man erhält spectralanalytisch die unten zu besprechenden charakteristischen drei Bänder in Blau und Violett. Freilich darf dabei nicht ein zu grosser Ueberschuss ron Säure zugesetat, jedenfalls dieselbe mit dem Farbstoffe nicht lange in Berührung gelassen werden, sonst zersetzt sich der gelbe Farbstoff, was man nicht sowohl an einem Farbenwechsel, als an dem Verschwinden der Absorptionsstreifen gewahrt.

Filtrirt man Chlorophyll mit Knochenkohle, so wird man allerdings mitunter ein rein gelbes gelöstes Filtrat erhalten, das sich spectralanalytisch durch die genannten Bänder als unser gelber Farbstoff ausweist; ohne grössere Uebung dagegen wird man leicht zu viel Kohle nehmen, und dann ein wasserhelles Filtrat erhalten - wobei beide Farbstoffe in der Kohle zurückbleiben; oder aber man nimmt zu wenig Kohle und es geht eine grüne Lösung durch, die mehr oder weniger die Charaktere des Chlorophylls zeigt. Hat doch auch schon FilhoL zugegeben, dass zur Darstellung mit Knochenkohle „quelques tâtonnements " gehören.

Es ist demnach gewiss, dass man durch FilHol's Methode mitunter den gelben Farbstoff, den wir unten als einen Bestandtheil des Chlorophylls werden kennen lernen, erhält, dass aber jedenfalls die Methode nicht besonders sicher ist.

Wenn nun Gerland und Rauwenhoff (a. a. 0. Fig. 8) das Spectrum des gelben Farbstoff als eine continuirliche Absorption des Blau und Violett darstellen, so geht daraus hervor, entweder, dass sie eine zu concentrirte Lösung nahmen, um das typische Spectrum zu sehen, oder aber, dass sie bereits ein Zersetzungsproduct desselben, das nur eine continuirliche Absorption gibt, und das man in der That leicht erhält, vor sich hatten.

Ganz anders verhält es sich init dem braunen, beziehungsweise braungrünen Farbstoff, der bei der Säurebehandlung zunächst in schwärzlichen Flocken niederfällt. Mag man denselben rom Filter sofort aufnehmen, oder nach dem Auswaschen mit Kreide neutralisiren, immer erhielt ich eine Lösung, die bräunlich von Farbe von vornherein auf die Zersetzung hinwies, und die spectralanalytisch sich unzweifelhaft als ein Säurezersetzungsproduct kund gab. Wir haben oben schon gesehen, dass die geringste Spur von Säure, besonders anorganischer, eine totale Zersetzung des Chlorophylls herbeiführte. Es sei hier einstweilen nur so viel bemerkt, dass das Spectrum dieser Lösung stets die charakteristi- 
schen Verschiebungen von I-III, die Anschwellung von IV a und das Auftreten von IVb, gleichwie eine totale Zerstörung der Bänder hinter F, mit andern Worten alle Zeichen der Zersetzung zeigte, wie wir sie später bei unserm blaugrünen Bestandtheil des Chlorophylls bei Einwirkung von Säuren sehen werden.

Wemn dagegen Gerlano und Rauwenhoff fanden, dass diese Lösung die Charaktere des normalen Chlorophyllspectrums zeige, so genügt es einfach darauf hinzuweisen, dass eben das, was die beiden Untersucher für normales Chlorophyll hielten, zersetztes war, und dass demnach deren Angaben ganz für mich sprechen.

Es ergibt sich daher, dass FilHoL den zweiten Chlorophyllbestandtheil stets nur in Zersetzung dargestellt hat.

Ein dritter Versuch „die Zusammensetzung des grünen Farbstoffs aus mehreren verschiedenfarbigen " $\mathrm{zu}$ finden, wurde von N. MúluER gemacht (Pringsh. Jahrb. VII., p. 200). Derselbe zeigte, dass beim Verdunsten von Chlorophyll (in Weingeist) auf einer Porcellanschale „ sich die Lösung in mehrere Ringe differenzirt, an welchen verschiedene Pigmente ablagern. Die reinste Abscheidung gewahrt man an einem äussern schmalen gelben Ring, auf diesen folgt ein blaugrüner, endlich eine rein grüne Kreisfläche" (S. 203). Diese Zerlegung, die sich auch beim Verdunsten eines Tropfens Chlorophylllösung auf Papier zeigt (S. 204), ist, wie er zeigt, unabhängig von Licht und von der Einwirkung atmosphärischer Gase und er kommt daher zu der Ueberzeugung, „dass die auf die genannte Weise gesonderten verschiedenen Pigmente (ein gelbes, blangrünes und grünes) in der Lösung existiren müssen".

Die Erscheinumg, die Mullardet und mir schon bei unseren Untersuchungen über Algenfarbstoffe an dem Papierfilter beim Filtriren der Farbstoffe aufgefallen war, lässt sich leicht in all' den von MüLLER genannten Weisen constatiren. Führt man den Verdunstungsprozess in einer Uhrschale aus, so kann man mit dem Nikrospectralapparat die Spectren der „3 Pigmente" untersuchen. Eine solche hat aber gelehrt, dass der äussere gelbe Kreis von dem gelben Farbstoff herrührt, den wir unten als einen wahren Bestandtheil des Chlorophylls werden kennen lernen. Der zweite, blaugrüne Ring stellt den zweiten unten zu betrachtenden Farbstoff des Chlorophylls dar. Dagegen zeigt die Spectralanalyse der, „innern rein grünen Kreisfläche“, dass diese nichts Anderes ist, als das unentmischte Chlorophyll selbst, 
d. h. die beiden aussen als Ringe befindlichen Farbstoffe zusammen. Mit andern Worten: Beim Verdunsten eines Tropfens Chlorophylllösung findet am Rande der Lösung eine Trennung (Dialyse) der beiden Mischungsbestandtheile statt*, im Centrum bleiben dieselben vermischt.

Trennt man nach unserer Methode die beiden Chlorophyllbestandtheile und lässt jeden derselben für sich verdunsten, so erhält man bloss einen dem Centrum gleichfarbigen Ring am Rande.

Müller hat demnach die 2 Pigmente (Bestandtheile) des Chlorophylls in den beiden Farbenringen richtig, aber unrichtiger Weise in dem centralen grünen Fleck einen dritten Farbstoff gesehen.

Neben diesen ausführlichen Angaben über Chlorophyllzusammensetzung existiren noch eimige kurze Notizen über den gleichen Gegenstand, die aber bei rölligem Mangel alles Details, insbesondere anch der Darstellungsmethode, eine weitere Erörterung nicht zulassen.

Aus dem Jahre 1864 stammen 2 Angaben:

JonIs bemerkt in seiner Arbeit, Action chimique de la lumière sur quelques principes immediats des végétaux", (Compt. rend. 1864 T. LIX, p. 859). "La chlorophylle pure est une substance solide, noire, à reflets bleuâtres, de constitution résinoide, très facilement pulvérisable. Elle est soluble d'alcool, l'éther, l'acide chlorhydrique, les alcalis, etc. Les solutions neutres dans l'alcool ont une teinte jaune-brunâtre, mais il suffit d'une goutte d'acide chlorhydrique pour leur communiquer une belle teinte bleue".

Ferner: „La chlorophylle paraît toujours accompagnée dans les tissus végétaux d'une matière grasse de couleur jaune" etc.

Diese Worte genügen, um zu zeigen, dass JoDrs als grünen Farbstoff nur ein Zersetzungsproduct kannte, und in dieser Hinsicht von Fremy's und Filhor's Anschauungen kaum differirt. Hinsichtlich des gelben Farbstoffs ist aus seinen Angabeu kaum etwas zu entnehmen; el scheint darin eher mit Filhol als mit Freur überein zu kommen.

Eine zweite sehr bemerkenswerthe Mittheilung aus demselben Jahre ist von STockes; leider ist dieselbe so kurz, dass sich daraus über die nähere Natur der Pigmente gar Nichts entnehmen lässt. Er hat im Chlorophyll 2 grüne und 2 gelbe Farbstoffe gefunden.**

* Die Andeutung einer Erklärung dieser Scheidung hat Mülle r selbst versucht (a. a. O. S. 204).

** On the supposed Identity of Biliverdin with chlorophyll, with remarks on the constitution of chlorophyll. By G. G. Stockes. Proc. R. Soc. of London Vol. XIII, p. $144-145$. 
„I find the chlorophyll of land-plants to be a mixture of four substances, two green and two yellow, all possessing highly distinctive optical properties. The green substances yield solutions exhibiting a strong red fluorescence; the yellow substances do not. The four substances are soluble in the same solvents, and three of them are extremely easely decomposed by acids or even acid salts, such as binoxalate of potash; but by proper treatment each may be obtained in a state of very approximate isolation, so far at least as coloured substances are concerned".

Es ist sehr zu bedauern, dass Sтоскеs zur Zeit nicht mehr über seine Untersuchungen publicirt hat, da dieselben, wie es scheint, zu völlig reinen Darstellungen der Farbstoffe geführt haben.

Endlich ist auch noch die kurze Mittheilung über TimiriasefF's Spectralanalyse des Chlorophylls zu erwähnen, die in Bot. Ztg. 1869, S. 884 f. gegeben ist, als Referat über einen Vortrag desselben in der zweiten russischen Naturforscherversammlung zu Moskau vom September 1869. Auch daraus ist wenig zu entnehmen. Es heisst dort: „Die näheren Bestandtheile des Chlorophylls sind nicht Phylloxanthin und Phyllocyansäure (FreNr), sondern Phylloxanthin und die Ammoniakverbindung eines intensiv grünen Körpers, den TrmiriasefF Chlorophyllin nennt".

„Die charakteristischen Absorptionsstreifen des Chlorophylls verdankt dasselbe dieser Ammoniakverbindung. Ausserdem hat die letztere einen solchen Streifen in dem blanen Theil des Spectrums, aber dieser Streifen wird im Chlorophyll durch's Phylloxanthin verdeckt, welches eine continuirliche Absorption der blauen und violetten Strahlen zeigt".

Meines Wissens hat sich zur Zeit über diese Arbeit ausser GERLand und Rauwexhoff (a. a. 0. p. 16) Niemand geäussert. Sie halten die grüne Materie von Filhor für identisch mit Timiriseff's Chlorophyllin orler mit der ammoniakalischen Verbindung desselben; das Phylloxanthin desselben für gleich mit dem gelben Farbstoff Fruhol's. Ich bin der Ansicht, dass sich das bei dem Mrangel aller Detailangaben nicht entscheiden lässt. Soviel lässt sich aber aus den Angaben ersehen, dass Tumiriaseff's Farbstoffe mit den unsrigen nicht identisch sind, oder aber, wenn dies, dass seine Angaben über das Spectrum nicht richtig sind; er müsste in letzterm Falle beim ,Chlorophyllin" die Bänder des zweiten Theiles unrichtig beschrieben, beim "Phylloxanthin“ die charakteristischen Absorntionen desselben ganz überselien haben. 
Die vorliegend besprochenen Versuche waren es, die mir zur Zeit meiner eigenen Arbeiten über die Bestandtheile des Chlorophyllfarbstoffs bekannt waren, und die ich in einer Mittheilung über diesen Gegenstand (Sitzb. Erlanger phys.-med. Soc. 1871, 7. Juni) bereits berücksichtigt habe. Erst kurz nachher erhielt ich aus SkLaRek's „Naturforscher" N. 23 ausgegeben 10. Juni 1871, Kenntniss von den umfangreichen Untersuchungen H. C. SoRBY's über die Farbstoffe herbstlicher Blätter; die Einsicht in die Originalarbeit „On' the various tints of autumnal foliage“ in Quat. Journ. of Science 1871 n. XXIX. Januar, p. 64-7i, - war mir erst durch die Zuvorkommenheit des Vorstandes der Kgl. Universitätsbibliothek zu Göttingen möglich. Die Resultate dieser wichtigen Arbeit, die übrigens ohne alle Beziehung auf die einschlägige deutsche und französische Literatur gemacht ist, hat Resultate gegeben, die den meinigen ähnlicher sind, als es auf den ersten Blick erscheint.

Uebrigens wird man aus der ganzen Fassung meiner Arbeit sehen, dass sie unabhängig von jener entstanden, aus andern Gesichtspuncten, als die englische, gearbeitet, und insbesondere auch auf der bisherigen Literatur über den Gegenstand fusst, den Millardet und ich bereits früher in den Untersuchungen über Algenfarbstoffe berührt haben.

Ich werde desshalb dieselbe hier nicht weiter besprechen, sondern anhangsweise mit meinen Untersuchungen im Zusammenhang vergleichen, was jedoch nicht hindert, dass im folgenden Texte überall auf dieselbe speciell Rücksicht genommen wird.

\section{Trenung der Chlorophyllfarbstoffe.}

a) Allgemeines - Methode.

Die Idee, das Chlorophyll als eine Mischung verschiedener Farbstoffe aufzufassen, ist mir im Gegensatz zu all' den angeführten Versuchen, wo sich auf chemischem Wege der Gedanke aufgedrängt hatte, durch rein spectralanalytische Betrachtungen gekommen. Es war mir nämlich, nachdem ich bereits an einzelnen Zellen, an Blättern und Lösungen das Spectrum des gelben Farbstoffs der etiolirten Pflanzen und des Anthoxanthins kennen gelernt hatte (Sitzb. Erlanger phys.med. Soc. 1871, 13. März), das sich durch ein in der Gegend der Frauenhofer'schen Linie F gelegenes breites und starkes Absorptionsband besonders auszeichnet, an mehreren, dünneren Chlorophylllösungen, 
die ich untersuchte, ein gleiches Band an derselben Stelle aufgefallen und der Gedanke gekommen, ob nicht vielleicht dieser Streifen sein Dasein einem gleichen Farbstoff im Chlorophyll verdanke, der aber hier durch einen andern verdeckt erscheine. Der Gedanke empfahl sich ohnehin auch vom physiologischen Standpunct, da es eine allbekannte Thatsache ist, dass gelbe etiolirte Blätter am Licht ergrünen, und grüne (7. B. junge Blumenblätter) später gelb werden, wobei sich daran denken liess, dies einfach durch Hinzutreten oder Verschwinden eines andern (grünen, blauen n. s. w.) Farbstoffs zu erklären.

Ein Mittel, diesen auf spectraTanalytischem Wege erschlossenen gelben Farbstofl von einem vermuthlichen zweiten u. s. w. zu trennen, bot sich in dem von Muluardet und mir* bei einer Untersuchung über Algenfarbstoffe mit gutem Erfolge angewendeten Benzol. In der That genïgt es, eine Portion alcoholischer Chlorophylllösung mit einer beliebigen Menge Benzol zu schütteln, um sofort eine Trennung der ursprünglich grasgrünen Lösung in 2 verschiedenfarbige Schichten zu veranlassen.

Fast augenblicklich sondert sich nach tüchtigem Schütteln die Mischung in eine unten stehende alcoholische goldgelbe Lösung, und eine darüber stehende Benzollösung von einem Grün, das einen deutlichen Stich in's Blaue hat. - Dies ist die sehr einfache Methode, durch welche das „Chlorophyll" als eine Mischung zweier Farbstoffe, eines goldgelben und blaugrünen, erwiesen wurde.

Zur Rechtfertigung dieser Methode zunächst Folgendes:

So wenig als bis jetzt Jemand behauptet hat, dass das Chlorophyll durch Aufnahme in Alcohol oder Aether eine wesentliche (chemische) Aenderung erleide; ebenso wenig kann man glauben, dass durch Behandlung der ätherisch und alcoholischen Lösung des Chlorophylls mit dem gänzlich indifferenten Benzol die Lösıng eine chemische Aenderung erfahre. Der Vorgang, welcher durch Zusatz von Benzol zu dem Farbstoffgemisch, das wir Chlorophyll nennen, hervorgerufen wird, ist offenbar ein rein dialytischer. Die beiden eben erwähnten, in ihrer Mischung „Chlorophyll * darstellenden Farbstoffe verhalten sich offenbar zu Weingeist und Benzol in verschiedener Weise. Der blaugrüne Farbstoff, wie der gelbe in Alcohol löslich, ist

* Bulletin de la Soc. de scienc. nat. de Strasbourg 1868 n. 2, p. 22 und ausführlich in den "Mémoires" ders. Ges., Vol. VI. 
leichter löslich in Benzol. Bringt man daher zu „Chlorophylllösung“ diese Flüssigkeit, so diffundirt der blaugrüne Farbstoff in dieses und im Weingeist bleibt der gelbe Farbstoff für sich zurück. Umgekehrt ist der gelbe Farbstoff, der in Benzol, wie der blaugrüne, ebenfalls löslich ist, in Alcohol leichter löslich und wird, wenn man zu einer Chlorophyllsolution in Benzol Weingeist zusetzt, in diesen übertreten.

Es ist daher auch nicht nothwendig, die weingeistige Lösung mit Benzol zu schütteln; es genügt eine einfache Uebereinanderschichtung der beiden Flüssigkeiten, um den Trennungsvorgang zu bewirken. Giesst man auf eine in einem Standgefäss befindliche alcoholische Chlorophylllösung vorsichtig und ohne Erschütterung etwa die gleiche Menge Benzol und überläšst die Flüssigkeiten an einem dunkeln Orte sich selbst, so ist schon nach wenigen Stunden der Eintritt einer Dialyse deutlich erkennbar; da wo die grüne Lösung an das wasserhelle Benzol grenzt, ist dieselbe merklich gelbgrün, ja an der ‘üussersten Grenze deutlich goldgelb geworden, das angrenzende Benzol dagegen tief grün. Mit der Zeit nimmt die blaugrüne Färbung des Benzols immer mehr zu und in demselben Maasse wird der Weingeist goldgelb. Nach Tagen oder Wochen, je nach der Menge der diffundirenden Flüssigkeit, ist der Vorgang vollständig beendet und beiderseits eine reine Farbstofflösung vorhanden.

Uebrigens vollzieht sich dieser dialytische Vorgang bei jeder Filtration alcoholischer Chlorophylllösung auf dem Filtrirpapier selbst, da wo die Benetzung des Papiers aufhört und wo man stets zu äusserst einen goldgelben und darauf einen blaugrünen Farbering sieht, wie wir oben bereits bemerkt haben.

Es gibt sogar einen directen Beweis dafür, dass die beiden erhaltenen Farbstofflösungen unveränderte Componenten sind: durch Zusammenmischen der getrennten Flüssigkeiten erhält man wieder das ursprüngliche Chlorophyllspectrum. Es ist zu diesem Behufe nöthig, die beiden Farbștoffe in ein und demselben Lösungsmittel zu haben, was man leicht bewerkstelligen kann, wenn man z. B. die Benzollösung im Finstern und bei gewöhnlicher Temperatur eintrocknen lässt, und den trockenen Farbstoff in Alcohol aufnimmt, oder, was leichter geht, umgekehrt den gelben Farbstoff abdampft und den Rückstand in Benzol löst. Die wiedergemischten Farbstoffe geben eine Lösung, deren Spectrum das des Chlorophylls ist. 
Ueber die Darstellungsmethode und ihre Resultate im Speciellen sei noch Folgendes bemerkt:

Auch diesmal sind die Blätter zunächst mit destillirtem Wasser ausgekocht. Es hat den oben angeführten Vortheil haben sollen, dass sich die Blätter leichter mit Alcohol ausziehen. - In manchen, aber nach meinen Beobachtungen seltenen Fällen wird durch das Kochen reichlich ein in Wasser löslicher Farbstoff (s. unten) hinweggenommen. Nur in einem Falle habe ich gefunden, dass das Kochen unanwendbar ist. Es ist nämlich eine constante Erscheinung bei Farnen (die untersuchten sind weiter unten angeführ't), dass sich bei ihnen, nachdem die Blätter ausgekocht sind, die beiden Farbstoffe aus der weingeistigen Lösung nicht tremnen lassen, während es an sofort aus frischen Blättern gemacliter weingeistiger Lösung wie immer leicht gelingt. Ich habe nicht näher nachgeforscht, worauf die merkwürdige Erscheinung beruhen mag.

Die Chlorophylllösung wird gewöhnlich mit der etwa doppelten Menge Benzol in einem Reagirglas stark geschüttelt und dann genügen ein paar Minuten, dass sich die beiden Flüssigkeiten, mit den betreffenden Farbstoffen beladen, von einander trennten. Hin und wieder kommt es vor, dass bei dem erstmaligen Schütteln die Lösungen sich nicht von einander trenmen, und das Benzol nicht aus dem Weingeiste weichen will, wobei der letztere eine trübe Flüssigkeit darstellt. Es genügt dann der Zusatz einiger Tropfen Alcohol, um eine sofortige Klärung herbeizuführen.

Die auf die genannte Weise erhaltene Benzollösung, grün mit einem Stich in's Blane, wird abgegossen und sofort zur spectralanalytischen Untersuchung genommen. Dass die gelbe Weingeistlösung völlig rein sei, muss dieselbe mehrmals mit Benzol, geschüttelt werden. Wie schon bemerkt, ist die Behandlung nur in seltenen Fällen mehr als 2-3 Mäl nöthig gewesen. Die vollständige Reinheit erkennt man einerseits an der rein goldgelben Farbe, die auch nicht die geringste Spur von Grün und Fluorescenz, spectralanalytisch keine Spur des Bandes I des Chlorophyllfarbstoffs, zeigt, andrerseits daran, dass das ïberstehende Benzol selbst vollständig wasserhell, ohne Fluorescenz und ohne Bänder des Chlorophylls erscheint. - In einigen Fällen war die gelbe Lösung nicht rein ru bekommen; das stete Abnehmen des Bandes I, wie das allmählige Schwächerwerden der Fluorescenz und grünlichen Färbung zeigte hinreichend, dass es sich auch in diesem Falle nicht um einen besonderen Farbstoff handle, 
sondern um ein ungewöhnlich festes Inhäriren des blaugrünen Farbstoffes in dem Gelben. -

Mit diesen Operationen habe ich mich vorläufig hinsichtlich der Darstellung der Farbstoffe begnügt. Es schien mir bei der grossen Veränderlichkeit der Farbstoffe überhaupt und insbesondere des blaugrünen Farbstoffes, welche dieser ganz mit dem „Chlorophyll* theilt, richtiger, welchem dieses seine Veränderlichkeit rerdankt, räthlich, die Farbstoffe zunächst einmal in dieser Weise zu untersuchen und von weiteren Proceduren abzustehen, insbes. die Reindarstellung weiteren Untersuchungen zu überlassen.

Man hätte ror Allem versucht sein können die in einer solchen Lösung unvermeidlich vorhandenen Fette und Salze zu entfernen, oder auch zu versuchen, ob sich die erlangten Farbstoffe nicht selbst noch als Gemische erkennen liessen.

Was die erstere Frage anlangt, so hätte hiezu wiederholtes Abdampfen und Wiederaufnehmen in geeigneten Mitteln führen können. Einige Versuche in dieser Richtung überzeugten mich bald, dass man hiebei grosse Gefahr läuft veränderte Körper zu erhalten; denn öfter war das einfache Eindampfen bei sehr gelinder Temperatur hinreichend den blauen Farbstoff zu zersetzen, wogegen allerdings der gelbe Farbstoff ziemlich unempfindlich erscheint. Es sei bemerkt, dass man beim Abdampfen die Farbstoffe in den amorphen klebrigen Massen erhält, die wir (Mulardet und ich)* bei Darstellung unseres Phycoxanthins kennen gelernt haben.

Hinsichtlich der Frage, ob die beiden erhaltenen Flüssigkeiten nicht selbst noch Farbstoffgemische darstellen, habe ich allerdings einige Versuche gemacht, durch Einwirkung anderer Lösungsmittel, wie Aether, Schwefelkohlenstoff, Chloroform u. s. w. ein Resultat zu erhalten; es ist mir jedoch nicht gelungen einen andern Erfolg zu erzielen, als dass der Farbstoff ganz oder zimm Theil in die zugesetzte Flüssigkeit übergieng, ohne dass er seine Charaktere wesentlich geändert hätte.

Uebrigens ist von den beiden erhaltenen Farbstoffen der gelbe an sich hinreichend interessant genug, mag el num ein chemisches Individuum darstellen oder selbst noch eine Mischung sein, da er, um mich so auszudrücken, wenigstens morphologisch individuell ist d. h. für sich mit ganz gleichen Charakteren in zahlreichen gelben Blüthen und in etiolirten Pflanzen vorkommt. - Nach den später an- 
zuführenden Untersuchungen Thunichuss scheint es möglich, dass derselbe in krystallisirtem Zustande erhalten werde.

Was die blaugrüne Lösung anlangt, so ist schwer zu sagen, ob sie ein einziger Farbstoff oder ein Gemisch ist. Möglich, dass sie in mehrere Farbstoffe zerlegt werden kann, wenigstens hat STockes, wie wir oben gesehen, zwei grüne Farbstoffe im Chlorophyll angegeben. -

Die Farbstoffe wurden in den genannten Lösungen unmittelbar und stets frisch zur spectralanalytischen Reaction genommen und durch diese hauptsächlich charakterisirt; nebenbei wurden sie auch dem Einfluss einiger chenischer Mittel unterworfen, solchen, deren Einwirkung an sich interessant oder zur schärferen Charakteristik beizutragen schien, doch ist die Haupt-Charakteristik eine spectralanalytische geblieben. -

Ist nun unter diesen Verhältnissen gar nicht zu läugnen, dass den Farbstoffen stets eine Anzahl fremder Körper (Salze, Fette) beigemengt war, ja bleibt es sogar noch unerwiesen, ob diese als reine Farbstoffe angesprochenen Körper nicht Gemische sind: so glaube ich doch soviel annehmen zu köunen, dass die angegebenen Eigenschaften der Lösungen hauptsächlich, wo nicht ausschliesslich zur Diagnose eines Farbstoffs gehören und es läge nahe, den gelben und blaugrünen Bestandtheil des Clorophylls mit eigenen Namen zu belegen; jedenfalls würden sich diese mit mehr Gründen verantworten lassen als die bisher in diesem Capitel ansgetheilten Namen. Aber die Erfahrungen, die man über die nicht geringe Anzahl von Namen für angebliche Chlorophyllbestandtheile hat machen müssen, haben mich abgehalten definitive Namen für meine Farbstoffe einzuführen. Es ist nachgerade schwer geworden noch einen Namen wenigstens für einen gelben Farbstoff zu finden. Nachdem von Berzelius der Name $\mathrm{X}$ anthopyll für ein Gemisch von Farbstoffen, der Name Phylloxanthine von Fremy für ein Zersetzungsprodukt des Chlorophylls, endlich die Bezeichnung L ut ein von Thudıchum (vgl. unten) für eine Anzahl wahrscheinlich heterogener gelber Farbstoffe verbraucht worden ist, ist es schwer noch ein lateinisches oder griechisches passendes Wort aufzutreiben; die Bezeichnung Chrysophyll die wegen der goldgelben Farbe des neuen Bestandtheils für diesen sehr passend wäre und von mir bereits in Aussicht genommen war, ist, wie ich erst nachträglich sah, von SoRBY (vgl. unten) für die in Wasser löslichen gelben Farbstoffe ebenfalls vergeben; und so bleibt nichts übrig als den von SoRby wieder aufgenommenen Namen X antho- 
phyll für unseren Farbstoff anzunehmen, wenn es nöthig erscheint denselben zu benennen.

Für den blaugrünen Farbstoff ist die Calamität beim Namengeben geringer; Fremr's Bezeichnung Phyllocyanine ist jedenfalls zurückzuweisen; SoRby hat für einen Farbstoff, der offenbar mit dem unsrigen identisch ist, den Namen "Chlorophyll" gebraucht. Ich glaube aber nicht, dass es zweckmässig ist, diesen Namen, der in der Chemie, Morphologie und Physiologie immer für das bekannte F a r bstoffgem isch gebraucht worden ist, wie es die Protoplasmakörner durchdringt und wie man es durch Extrahiren der Pflanzentheile mit Alcohol erhält, auf den neuen Farbstoff zu übertragen. Es ist allerdings gewiss, dass el die meisten Eigenschaften, die man dem „Chlorophyll* beilegt, selbst besitzt und insofern wäre der Name für ihn nicht unpassend. Allein wir würden uns dann in der Lage befinden, für das überall natürlich vorkommende Farbstoffgemisch, das wir bisher „Chlorophyll “ genannt haben einen neuen Namen bilden zu müssen, da dieses doch wohl unter keinen Umständen namenlos bleiben kann.

Unter diesen Verhältnissen ist es gewiss richtiger, für das gewöhnliche grüne Farbstoffgemisch den eingebürgerten Namen Chlorophyll beizubehalten und für den nenen Bestandtheil desselben einen Namen zu bilden. Ich würde den Namen Kyanophyll* vorschlagen. Das „Chlor o ph yll“ wäre eine Mischung von „X a n tho ph yll“ und „K y a n ophyll*. Als gemeinschaftlichen Namen für beide Farbstoffe könnte man den Namen "Chlorophyllfarbstoffe“ gebrauchen, ein Name, der meines Erachtens weniger Missverständnissen ausgesetzt ist als die Bezeichnung „Chlorophylloide Farbstoffe". Eher liesse sich die Bezeichnung xanthophylloide und kyanophylloide Farbstoffe für die dem Xantho- und Kyanophyll nah verwandten, mit ihnen aber nicht identischen (?) unten anzuführenden gelben und blaugrünen Farbstoffe gebrauchen.

b. Der goldgelbe Bestandtheil des Chlorophylls.

Der nach der angegebenen Methode dargestellte, in Alcohol gelöste Farbstoff ist von rein goldgelber Farbe und zeigt im Gegensatz zu dem

* Der Name ist freilich falsch gebildet; allein das theilt er mit dem einmal eingebürgerten „Chlorophyll", "den gewiss Niemand umgebildet wissen möchte; und so mag bei der Bildung eines neuen Namens die Analogie höher als die sprachlich richtige Composition angeschlagen werden. 
blaugrünen Farbstoff nicht die mindeste Flnorescenz, * wie schon Fishol (a. a. O.) und GerLand-Rauwenhoff (a. a. 0. p. 15) bemerkt haben; wo an demselben eine geringe rothe Fluorescenz wahrzunehmen, war stets auch bei der spectroscopischen Untersuchung noch eine Spur des Bandes I als Zeichen beigemischten blaugrünen Farbstoffs wahrzunehmen.

Das Spectrum dieser Lösung in concentrirtem Zustande zeigt einfach eine continuirliche Absorption des blauen und violetten Theiles, die etwa bei 450 schattenartig beginnt und bei 480 sehon $\mathrm{zu}$ einer totalen Hinwegnahme des Lichts geworden ist, die bis an's Ende des Spectrums reicht. Die Strahlen vom Anfang des Roth, durch Orange, Gelb und Lichtgrün gehen ungehindert "durch die Lösung.

Ein solches Spectrum, an dem freilich nichts Charakteristisches zu sehen, geben Gerland und Rauwenhoff von dem Filhol'schen gelben Farbstoff in Fig. $8 \alpha \beta$. Das eigentliche und charakteristische Spectrum, das aus schönen breiten Absorptionsbändern gebildet ist, die hier aber in der continuirlichen Absorption versteckt liegen, kommt erst zum Vorschein, wenn man eine sehr dünne Schicht der Lösung oder eine sehr verdünnte Lösung nimmt, die nur hellgelb erscheint.

In diesem Falle sieht man in dem überhaupt etwas verdunkelten Blau und Violett drei sehr schöne breite Absorptionsbänder. Taf. II, Fig. 3.

Das erste (1) und auffallendste liegt gewöhnlich gleich hinter F; es ist das intensivste aber schmälste von den dreien, immerhin aber breiter, als eines der 4 Bänder, die beim Chlorophyll im ersten Spectrumtheile liegen. Es hebt gewöhnlich etwas hinter, selten mit oder vor F schattenartig an, schwillt allmählig zu einer fast schwarzen Absorption an und lauft eben so allmählig, als es begonnen, schattenartig aus. Es ist das Band welches wir beim Chlorophyll als V kennen gelernt haben.

Ein zweites (2), viel breiteres aber weniger intensives, beginnt etwa in der Mitte zwischen F und G, erreicht nur eine geringe Intensität in seiner Mitte und endet in der Weise, wie es begonnen, vor oder mit G.

* Hier wie üherall, wo von Fluorescenz oder Mangel derselben die Rede ist, wurde dieselbe bei Sonnenlicht mittelst einer Sammellinse untersucht. 
Endlich ist, fast plötzlich, das violette Ende des. Spectrums von $960 \mathrm{ab}$, total hinweggenommen (3).

Zwischen diesen Bändern ist das Spectrum mehr oder weniger verdunkelt, mehr zwischen 2 und 3, als zwischen jenem und 1, wenigstens sieht man bei der Veränderung der Schichtendicke (wenn vorher die Bänder zu einer continuirlichen Absorption des ganzen zweiten Theiles zusammengeflossen waren), dass die Bänder 1 und 2 sich eher von einander lösen (individualisiren) als 2 von 3.

Die genauere Lage der Bänder wird aus folgenden Beispielen ersichtlich :

123

1. Deutsia gracilis $545-570-610680-780-820$ beginnt 920

2. Ribes aureum $520-590-660700-770-850 \div 910$

3. Caltha palustris

4. Hedera Helix.

5. Cladophora sp. $550-580-610700-770-840-930$

6. Selaginella hortensis 540-575-610 700-790-880 - 960

7. Lappa major 520-570-620 700-760-820 -- 930

8. Aspidium spinulosum $530-570-610700-775-850-$

9. Sambucus nigra $530-570-610690-760-830-900$

Dampft man bei niederer Temperatur die weingeistige Lösung zur Trockne ein, so erhält man eine tief gelbbraune, homogene, etwas klebrige Masse, die leicht Feuchtigkeit anzieht und beim Wiederlösen sich meist unverändert zeigt. Man sieht dann auch, dass sich die Masse ebensowohl in Aether, Benzol, Schwefelkohlenstoff als in Alcohol, nicht aber in Wasser aufnehmen lässt (in letzterem wenigstens nur ein verschwindend geringer Theil, worüber unten näher zu berichten ist). Setzt man zu der alcoholischen Lösung einige Tropfen Schwefeloder Salzsäure, so bleibt die Lösung nur noch kurze Zeit gelb - allerdings verschwindell sofort die Bänder und tritt eine continuirliche Absorption an deren Stelle - alsdann nimmt sie eine smaragdgrüne, dann spangrüne und endlich eine schön indigblaue Farbe an. Die Zeit innerhalb welcher dies ror sich geht, ist je nach der Menge der zugesetz.ten Säure verschieden - von einigen Minuten bis zu mehreren Stunden oder einem Tage. Die näheren chemischen Erscheinungen, wie sie Firhol (a. a. O.) schildert, habe ich nicht verfolgt, dagegen habe ich das Spectrum besonders der grünen Lösung geprüft, da man an einen Zusammenhang dieser Flüssigkeit mit Chlorophyllgrün 
hätte denken können, wenn auch die Nuance der Färbung von vornherein wenig dazu auffordert. Es ist aber zwischen dem Spectrum der smaragd- oder spangrünen Lösung und dem des Chlorophylls nicht die geringste Aehnlichkeit. Während bei letzterem ein Bandspectrum vorhanden ist, zeigt die durch Säuren grün gewordene gelbe Lösung nur continuirliche Hinwegnahme eines Theiles des rothen und violetten Spectrumendes.

Setzt man organische Säuren (Essig-, Wein-, Aepfel-, Citronensäure) zu der Lösung, so ist für's Erste weder mit blossem Auge noch spectroskopisch eine Aenderung wahrzunehmen. Bleiben die Säuren aber längere Zeit. (Stunden bis Tage, im Finstern) mit dem Farbstoff in Berührung, so verbleichen allmählig die Bänder $d$. h. sie werden immer schwächer und machen allmählig einer allerdings viel matteren continuirlichen Absorption von Blau und Violett Platz.

Aus dem Gesagten geht hinreichend hervor, dass man durch $\mathrm{Zu}-$ satz von organischen Säuren zu Chlorophyll, wie es FilHoL gethan, den gelben Farbstoff zwar nicht für's Erste, wohl aber nach kurzer Zeit alterirt, und dass somit dessen Darstellungsmethode immerhin prekär ist.

Setzt man den gelben Farbstoff in einem Reagirröhrchen frei dem Sonnenlicht aus, so wird dasselbe schon nach einer halben oder ganzen Stunde merklich blasser und verbleicht endlich gänzlich. Ganz Hand in Hand damit geht das allmählige Verblassen der Absorptionsbänder, die schon bevor der Farbstoff völlig ausgebleicht ist, einer continuirlichen Absorption Platz gemacht hatten. -

Im Anschluss an die Reactionen, welche der gelbe Chlorophyllbestandtheil der Salzsäure (auch Schwefelsäure) gegenüber gibt, mögen einige Bemerkungen zur Erklärung mehrerer bekannter Erscheinungen gemacht werden.

Es ist gewiss, dass das Chlorophyll die Eigenthümlichkeit, mit Salzsäure z. B. zuerst gelbbraun, zuletzt spangrün und blaugrün zu werden, dem genannten Verhalten seines gelben Bestandsheils der Säure gegenüber verdankt. Die Chlorophylllösung nähert sich in dem Maașse in ihrer Farbennüance dem Blau, als der gelbe Farbstoff allmählich durch die Säure in grün, blaugrün und blan übergeführt wird. Die Beobachtung Micheli's (a. a. 0.), dass wenige Tropfen der Säure die Chlorophylllösung sofort verfärben, viel Säure dagegen sofort 
blaugrüne Färbung hervorrufe, ist ganz richtig. Sie ist aber nicht so zu verstehen, als ob wenige Tropfen nicht ebenfalls schliesslich blaugrüne Färbung erzeugten; sie bedürfen dazu nur längerer Zeit, während mit viel Säure die Reaction (auf den gelben Farbstoff) fast augenblickiich eintritt.

Es erklärt sich ferner in derselben Weise, dass Chlorophyllkörner mit Salz- oder Schwefelsäure spangrün und blaugrün werden.

Endlich ist noch hervorzuheben, dass die Färbung des Fremy'schen Phylloxanthines der Hauptsache nach durch den blaugefärbten gelben Farbstoff hervorgerufen ist, wenn auch das Spectrum desselben (vgl. oben) zeigt, dass in demselben zugleich zersetzter blaugrüner Farbstoff (bräunlich von Farbe) vorhanden ist.

c. Der blaugrüne Bestandtheil des Chlorophylls.

Die tieforüne Lösung, die man im Benzol beim Schütteln einer weingeistigen Chlorophylllösung 'erhält, hat, wie bemerkt, einen sehr deutlichen Stich in's Blaue, was besonders auffällt, wenn man daneben eine gewöhnliche weingeistige Chlorophylllösung hält. Diese letztere erscheint dagegen deutlich gelbgrün, d. h. Grün mit einem Stich in's Gelbe. Die blaugrüne Färbung der Benzollösung versteht sich auch sofort beim Einblick in's Spectroskop, wo dieselbe beträchtlich mehr Blau durchlässt als das Chlorophyll.

Diese Flüssigkeit fluorescirt sehr stark roth, viel energischer als Chlorophyll, aber nicht in dem arteriellen Blutroth wie dieses, sondern mehr karminroth. Beides ist, glaube ich, hinreichend erklärlich, aus dem Vorhandensein des nicht fluorescirenden gelben Farbstoffs im Chlorophyll, dessen Existenz die Flnorescenz einerseits dämpft und andrerseits, da sich die Fluorescenzfarbe mit dessen Farbe nothwendig mischen muss, dieselbe in einer dem Gelb näher gelegenen Nüance des Roth erscheinen lässt.

Das Spectrum dieser Lösung im concentrirten Zustande ist von dem einer gewöhnlichen Chlorophyllösung kaum zu unterscheiden. Der ganze erste Theil von Roth bis Grün ist, ganz wie dort, von 4 Bändern eingenommen, die nach Bau, relativer Stärke und Lage (soweit sie nicht durch das Lösungsmittel wenig verändert ist) genau mit denen übereinstimmen, die wir beim Chlorophyll kennen gelernt haben. Taf. I. Fig. 4).

Das erste Band, zwischen B und C, ist das stärkste, intensiv kin.lus, Chlorophyllfarbstoffe. 
schwarz, beiderseits scharf begrenzt, nirgends eine Spur einer Duplicatur an demselben.

Das zweite, zwischen C und D gelegen, von den 3 (ausser I) bei weitem das stärkste, wie die zwei folgenden beiderseits abgeschattet; das dritte folgt gleich hinter D schwächer als II und stärker als IV, das bei 300 oder 310 gelegen als ein freier schmaler Schatten erscheint.

Die Verdunkelungen zwischen ihnen stärker in I-II als in II-III u. s. w.

Von 400 ab beginnt eine anschwellende Verdunkelung, die bei 480 zur totalen Hinwegnahme des blauen und violetten Lichtes geworden ist.

Das Charakteristische, vom Spectrum des Chlorophylls Abweichende, tritt erst hervor, wenn man die Lösung sehr verdünnt, so, dass die Streifen im ersten Theil bis auf I und etwa II verschwunden sind. Dann sieht man im zweiten Theil hinter F 3 breite Absorptionsbänder, die von denen des Chlorophylls abweichen. Auch hier ist der ganze zweite Theil verdunkelt und innerhalb der Verdunkelungen treten die Absorptionsbänder als Anschwellungen der Verdunkelung hervor.

Etwa in der Mitte, zwischen $\mathrm{F}$ und $\mathrm{G}$ gelegen, zwischen 1 und 2 des gelben Farbstoffs liegt eine breite, aber nur schwache Absorption, die wir als 5 bezeichnen.

Ein zweites Band (b) von tiefer Dunkelheit, aber weniger dunkel als I, beiderseits ziemlich kurz schattenartig auslaufend, liegt vor und auf der Linie G.

Als drittes Band (7) bezeichnen wir die rasch beginnende totale Absorption, die das Ende des Spectrums hinwegnimmt.

Lage der Bänder :

$$
\text { I II III IV }
$$

5

6

Deutzia gracilis 40-80 $120190310 \quad 630-670-730 \quad 800-850-900960$ Sambucus nigra 35-80 $120185300 \quad 600-670-740 \quad 830-870-910$ "

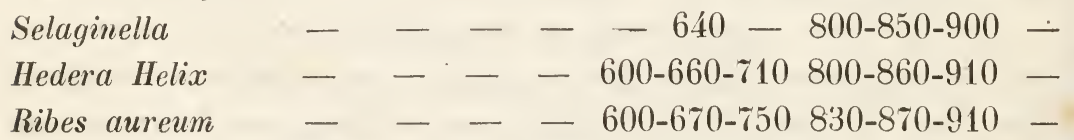

In ähnlicher Weise, wie mit Benzol, kamn man den blaugrünen Farbstoff auch mit Schwefelkohlenstoft aus der weingeistigen Chlorophylllösung aufnehmen. Nur ist die Lage der Bänder in diesem nach dem oben Bemerkten eine etwas weiter gegen das rothe Ende verschobene. 
Der Farbstoff zeichnet sich durch eine ausserordentliche Empfindlichkeit gegen Säuren aus; er ist es, dem das Chlorophyll überhaupt seine grosse Veränderlichkeit rerdankt. Die geringste Spur einer organischen oder anorganischen Säure (Salz-, Schwefel-, Phosphorsäure) reicht hin, die schön grüne Farbe in ein schmutziges Gelbbraun oder Braungrün zu verwandeln, und das Spectrum sehr wesentlich zu ändern. Die Bänder $5-7$ verschwinden angenblicklich und an Stelle derselben tritt eine schwache Verdunkelung, resp. continuirliche Absorption von Blau und Violett. In gleichem treten die Verschiebungen und Bauänderungen der Bänder I-IV, die wir beim Chlorophyll kennen gelernt haben, auf, und Band IV b erscheint. Hier ist es auch, wo das Band I mitunter ausserordentlich dentlich einen schattenartigen Anhang auf sein er brechbareren Seite zeigt.

\section{Das Chlorophyllspectrum eine Combination aus den Spectren der beiden Farbstoffe.}

Es ist einer der besten Beweise dafür, dass durch die angewandte Methode zwei unveränderte Bestandtheile des "Chlorophylls" von einander geschieden wurden, dass sich aus der Zusammenmischung der beiden Farbstoffe das Chlorophyll mit seinem typischen Spectrum genau wieder herstellen lässt, und man zeigen kann, dass das Chlorophyllspectrum nichts Anderes als eine Combination der Spectra der beiden Farbstoffe ist.

Wenn wir die im Vorstehenden geschilderten Spectren der beiden Farbstoffe und das früher besprochene Chlorophyllspectrum mit einander vergleichen, so ergibt sich ohne Zweifel Folgendes:

1) Die 4 Absorptionsbänder I-IV des "Chlorophylls" gehören dem blaugrünen Bestandtheil dieser Mischung an; da dieselben nach Lage, Zahl und Bau auf"s Genaueste einander entsprechen.

2) Die Absorption $V$ des Chlorophylls wird durch den gelben Farbstoff im Chlorophyll hervorgerufen; aus demselben Grunde.

3) Die Endabsorption im violetten Theile wird sowohl rom gelben als vom blaugrünen Bestandtheil hervorgebracht.

4) Das Band VI des Chlorophylls ist, wie bemerkt, sehr ausgezeichnet durch seinen Bau: es ist in der Mitte, vor G, von fast schwarzer Intensität, endet auf der brechbareren Seite ziemlich rasch, hebt dagegen von der andern Seite her ziemlich allmählig an. Diese Eigenthümlichkeit erklärt sich daraus, dass an dieser Stelle zwei Bän- 
der, das Band 6 des blaugrünen und Band 2 des gelben Farbstoffs aufeinander fallen. Band 6 ist ein sehr intensives beiderseits kurz schattenartig verlaufendes, auf $G$, es. bildet die Mitte und zweite plötzlich endende Hälfte des Bandes VI; unmittelbar davor liegt aber Band 2 des gelben Farbstoffs, das ziemlich schwach ist; dieses ist bei der Bildung der ersten, mehr allmählig anhebenden Hälfte des Streifens VI betheiligt. So ist also Band VI des Chlorophylls eine Combination aus zwei nicht ganz aufeinander fallenden Bändern, dem Bande 6 des einen, dem Bande 2 des andern Farbstoffs. - Dass das Band 5 des blaugrünen Farbstoffs im Chlorophyll nicht zum Vorschein kommt, ist leicht begreiflich: da es ausserordentlich schwach ist, so erscheint es zwischen V und VI des Chlorophylls noch als eine Erhellung, verursacht aber gleichwohl zwischen beiben die Verdüsterung des Blau.

Damit das Gesagte klar in die Augen trete, will ich eine Anzahl Beispiele anführen, in denen die Lage der Bänder des Chlorophylls in weingeistiger Solution und die der unmittelbar darauf getrennten Farbstoffe nebeneinander gesetzt sind.

1. Deutzia gracilis.

Chlorophyll.

I

II

III

IV

V $\quad 500-570-650$

VI

VII

120

190

310
Kyanophyll.

$40-80$

120

190

310
Xanthophyll.

5. $630-670-730$

6. $800-850-900$

7. 960

2. Ribes aureum.

Chlorophyll.

$\begin{array}{rc}\text { I } & 40-80 \\ \text { II } & 120 \\ \text { III } & 190 \\ \text { IV } & 300 \\ \text { V } & 530-600-680 \\ \text { VI } & 765-820-880 \\ \text { VII } & 960\end{array}$

Kyanophyll.

gleich.

5. $600-670-740$

1. $520-590-660$

7. 960
6. $83 ?-870-910$
Xanthophyll.

2. $680-750-820$

3. 920 
3. Sambuc,us nigra.

$\begin{array}{rccc} & \text { Chlorophyll. } & \text { Kyanophyll. } & \text { Xanthophyll. } \\ \text { I } & 30-75 & 35-70 & - \\ \text { II } & 95-135 & 100-130 & - \\ \text { III } & 175-210 & 170-220 & - \\ \text { IV } & 300-310 & 310 & - \\ \text { V } & 530-575-630 & - & 530-570-630 \\ \text { VI } & 750-850-900 & \text { 5. Mitte } 650 & 690-760-820 \\ \text { VII } & 960 & 6.795-920 & 955\end{array}$

Aus dem Vergleich der vorstehenden Zahlen wird man sehen, dass die oben angeführten Sätze richtig sind, olne alle Frage, was die Bänder I-V und VII angeht; hinsichtlich des Bandes VI können Zweifel entstehen, indem die vorstehenden Zahlen für diesen Streifen nicht ganz genau zusammenpassen. Das ist von vornherein gar nicht zu erwarten, weil in Weingeist und Benzol die Lage vermöge der Verschiedenheit des Lösungsmittels etwas rerschieden sein $\mathrm{musS}$; andrerseits der niemals genau zu regulirende Concentrationsgrad auf die Lage von Anfang und Ende eines Bandes wesentlichen Einfluss hat.

Uebrigens darf es ein glücklicher Zufall genannt werden, dass in der Farbstoffmischung, die wir Chlorophyll nennen, die einzelnen Absorptionsstreifen des Spectrums sich so genau auf die der einzelnen Farbstoffe zurückführen lassen; denn wir wissen aus dem Wenigen, was über die Spectra von Mischungen absorbirender Körper vorliegt *, dass die Spectra derselben durchaus nicht immer eine e in fac he Co m bination der Spectra (Uebereinanderlagerung der Spectra) der einzelnen absorbirenden Körper sind; und es würde selbst dann, wenn das Chlorophyllspectrum im zweiten Theile eine ganz andere Physiognomie hätte, als die Spectra der beiden es combinirenden Farbstoffe, gar nicht folgen, dass etwa die beiden Farbstoffe nicht in blosser Mischung vorhanden seien.

Hier wollen wir auch noch einmal auf die Veränderungen zurückkommen, welche das Chlorophyll sowohl bei der sog. freiwilligen Zersetzung, als bei der Einwirkung gewisser Agentien erleidet, in der Ab-

* Vgl. Melde, Ueber die Absorption des Lichts durch Gemische von farbigen Flüssigkeiten. Pogg. Ann. Bd. 124, 1865, S. 91-93. - Band 126, S. 124-285. - Feussner, Sitzb. Berl. Ac. 1865, S. 145. - Sorby, Quat. Journ. Micr. Soc., Vol. XV. 1867, p. 453. 
sicht, diese Veränderungen der Mischung mit Bezug auf die Veränderungen der Bestandtheile zu erklären.

Wir haben oben gesehen, dass das freiwillig zersetzte Chlorophyll seine Streifen I--IV im ersten Theile selır eigenthümlich verändert, dazu noch einen Streifen IVb erhalten hat, dass im zweiten Theile alle Bänder verschwinden und eine continuirliche Absorption an deren Stelle getreten ist. Nach dem, was wir über die beiden Farbstoffe des Chlorophylls wissen, erklärt sich die Sache einfach. Der blaugrüne Farbstoff geht bei dieser Zersetzung an seinen Bändern alle die Veränderungen ein, die wir bei den Bändern I-IV b des Chlorophylls gesehen haben - sie rüluren also von diesem her. Derselbe verliert auch seine Bänder im Blau und Violett. Andrerseits gehen auch die Streifen des gelben Farbstoffs unter gleichen Verhältnissen zu Grunde, und es ist klar, dass unter den Umständen im Blau und Violett nur noch continuirliche Absorption wahrgenommen werden kann.

Die Einwirkung organischer Säuren und ihre Veränderung: an den Bändern I-IVb erklärt sich ebenso, wie vorher. Wir wissen dass der blaugrüne Farbstoff diese Aenderungen erleidet, zugleich aber auch, dass die Bänder 5 - 7 desselben eingehen. - Anders der gelbe Farbstoff, dieser wird von organischen Säuren spectralanalytisch zunächst nicht alterirt. Es ist daher natürlich, dass das Band V (dem gelben Farbstoff angehörig) bei Einwirkung organischer Säuren nicht verschwindet, es ist ebenso erklärlich, dass im zweiten Theil des Spectrums in diesem Falle geradezu die Streifen des gelben Farbstoffs zum Vorschein kommen. - Freilich bei längerer Wirkung verschwinden diese Streifen, wie im Chlorophyll, so im gelben Farbstoff.

Einwirkung der Salzsäure. Die Veränderungen durch Salzsäure sind nur dadurch verschieden, dass durch sie die Bänder des zweiten Theiles sofort gänzlich verschwinden; begreiflicher Weise, da durch sie der gelbe Farbstoff ebenfalls alsbald sein Bandspectrum verliert.

\section{Muthmassliche andere Bestandtheile des Chlorophylls.}

Ich bin nicht der Meinung, dass mit der vorstehenden Trennung des Chlorophylls in zwei Farbstoffe bewiesen ist, dass andere Bestandtheile in demselben überhaupt nicht vorhanden sein könnten; nur so viel ist gewiss, dass die beiden erhaltenen Farbstoffe wirkliche und unveränlerte Mischungsbestandtheile desselben sind. Es ist aber immer- 
hin möglich, dass dieselben selbst noch Gemische verschiedener Farbstoffe darstellen, ohnehin hat ja STOckES angegeben, dass das Chlorphyll aus 4 Farbstoffen, 2 gelben und 2 grünen bestehe. Was die letzteren anbelangt, so habe ich gar keinen Anhaltspunkt für die etwaige Zerlegung des blaugrünen Kyanophylls in weitere Componenten; auch für den "gelben Farbstoff, so weit er nur in Alcohol löslich, ist mir im Laufe meiner Untersuchungen Nichts vorgekommen, was von Ferne auf eine weitere Entmischungsmöglichkeit hinleite.

Dagegen liegen in der früheren Literatur Andeutungen vor über einen im Wasser löslichen gelben Farbstoff, den man bei Chlorophylluntersuchungen hin und wieder gesehen hat; freilich wurde derselbe bald als wesentlich zum Chlorophyll gehörig, bald als zufälliger und gänzlich ausserwesentlicher Begleiter angesehen. Es ist bei den kurzen und widersprechenden Angaben über diesen Körper schwer zu sagen, wie weit es sich dabei um ein und dasselbe oder um verschiedene Dinge gehandelt hat.

Obwohl das Auskochen grüner Blätter vor der Extraction mit Alcohol schon von STockes vorgenommen wurde, ist doch, wie es scheint, Sumuler der Erste gewesen, welcher eine Färbung des Decocts bestimmt erwähnt; er sagt, dass sein Decoct "hellbraun" war und ,grünlich gelb* fluorescirte.

Eingehender wurde erst von Filhor * und Micheli (a. a. 0. S. 7) ein in Wasser löslicher gelber Fartstoff betont und beschrieben. Ersterer, der denselben anch in gelben Blüthen beschreibt, gibt die chemischen Eigenschaften desselben näher an; die Angaben des letzteren sind schon oben erwähnt worden.

Hagevbach spricht wiederum von einem Körper , mit grüner Fluorescenz* (а. a. O. S. 251 und 256) und lässt es ïbrigens zweifelhaft, ob er etwas mit dem Chlorophyll selbst zu thun habe.

Meine Erfahrungen kann ich kurz in Folgendem zusammenfassen.

Sehe ich ab von den Decocten trockener Blätter, an denen man ganz gewöhnlich gelbe oder braungelbe Farbe gewalırt, so habe ich wiederholt bei kurzen Abkochungen frischer grüner Blätter Decocte g'esehen, die gelblich, äusserst selten solche, die ausgesprochen und schön gelb waren; so erinnere ich mich deren besonders schön von Caltha und Primula officinalis. Entsinne ich mich recht, so waren die Blätter der Art stets ältere,

* Compt. rend. L. 1860, p. 5453. 
während junge B lätter dem IVasser eine kaum merkliche Färbung verliehen. Dagegen kann man, soweit meine Erfahrungen gehen, constant eine reichliche Menge in Wasser löslichen gelben Farbstoffs erhalten, wenn man gelb gewordene Herbstblätter (Linde, Rosskastanie, Ulme) kocht, wo er sich neben dem in Alcohol löslichen Xanthophyll findet. Derselbe gab, im Wasser untersucht, nur eine continuirliche Absorption von Blau und Violett und wurde durch Mineralsäuren nicht ander's gefärbt.

Die Erfahrungen, die ich über diesen Gegenstand gemacht, sind nicht zahlreich genug, um eine definitive Antwort auf die Frage nach der Existenz oder Nichtexistenz eines selbstständigen, im Wasser löslichen gelben Farbstofis zu geben. Soviel allerdings schien mir gewiss zu sein, dass ein solcher mit Ausnahme herbstlicher Blätter nur in so verschwindend geringer Menge vorhanden sein könne, dass er mit den beiden andern Farbstoffell füglich nicht in eine Reihe der Bedentung gestellt werden dürfe.

Wir haben unten bei SoRBY's Untersuchungen noch einmal auf den Gegenstand zurückzukommen.

\section{Verbreitung der Farbstoffe im Pflanzenreich u. s. w.}

Die Zusammensetzung des "Chlorophylls" aus einer Mischung (wenigstens) zweier Farbstoffe - einem gelben und blaugrünen habe ich bei allen untersuchten „Chlorophyll-Pflanzen* gefunden, d. h. bei allen Pflanzen, die eine Färbung von der Nuance des Grasgrün haben. Zum Theil. sind die Pflanzen namentlich schon bei den beiden Farbstoffen selbst aufgeführt worden; im Uebrigen ist es nicht nöthig, sie hier noch einmal namhaft zu machen, da es alle jene sind, die oben beim Chlorophyllspectrum genannt wurden. Es geht aus dem dortigen Verzeichniss hervor, dass es bei allen untersuchten Mono- und Dicotylen, bei Lycopodiaceen, Farnen, Moosen und grasgrünen Algen der Fall ist. Schon Filhol hat bemerkt (a. a. 0. S. 338), dass er seine Zerlegung bei Conferven, Moosen, Farnen, Mono- und Dicotylen hat ausführen können. Und es unterliegt wohl keinem Zweifel, dass alle chlorophyllgrünen, oder wenn man lieber will, gras gr ü̈nen Pflanzen und Pflanzentheile diese Mischung zweier Farbstoffe enthalten.

Es wäre nun eine besondere Aufgabe, die absolute und relative Menge dieser Farbstoffe in den verschiedenen Pflanzengattungen und 
Arten, wie in einzelnen Theilen einer Pflanze, und in diesen wieder in verschiedenen Altersstadien zu untersuchen. Es scheint mir sicher, dass die vęrschiedenen Nuancen des Grün, die man bei Vergleichung der Pflanzen gewahrt, zum Theil wenigstens ron einer quantitativen Verschiedenheit der Mischung dieser Farbstoffe herrührt; ebenso dass das relative Verhältniss der Farbstoffe mit dem Alter der Organe nicht unbeträchtlich wechselt. Es ist ja eine allbekannte Erscheinung, dass jugendliche Blätter ein gèlbgrünes Aussehen, ältere öfter ein auffallend tief- fast blaugrünes Ansehen gewinnen. Die Erscheinung war in dem kalten Frühling dieses Jahres (1871) in dem hiesigen botanischen Garten besonders deutlich zu gewahren an den im Freien eben beblätterten lichtgrïnen Pappeln, Ahornen, Linden einerseits, und den eben ins Freie gebrachten tiefgrünen, ja blaugrün erscheinenden Pflanzen der Kalthäuser andrerseits.

Ich behalte mir ror, über diesen Gegenstand quantitative Untersuchungen anzustellen, wenn es mir gelungen sein wird, die Farbstoffe möglichst rein darzustellen. Bis jetz.t habe ich blos soviel gesehen, dass bei gelbgrünen Blättern das dem gelben Farbstoffe angehörige Band $\mathrm{V}$ besonders stark herrortritt.

\section{Farbstoffe bunter Organismen.}

Durch die Thatsache, dass das Chlorophyll eine Farbstoffmischung aus wenigstens zwei Bestandtheilen ist, wird nun auch ein engeres Band geschlungen zwischen den Chlorophyllpflanzen einerseits und nicht chlorophyllgrün-, wir wollen kurz sagen buntgefärbten Zellkrypto gamen (Flechten, Algen) andrerseits, in welchen schon früher neben einem grünen Farbstoff, der kurz als ,Chlorophyll " bezeichnet worden ist, ein zweiter in Aleohol löslicher Farbstoff, ron mehr oder weniger gelber Farbe festgestellt wurde.

Nachdem durch Cohr, Askenasy, Rosanoff u. A. gezeigt worden war, dass in den verschiedensten buntgefärbten niederen Organismen (Florideen, Fucaceen, Oscillarien, Glaucogonidien ron Flechten) neben einem den sichtbaren Farbenton angebenden in Wasser löslichen Farbstoff, auch ein in Alcohol löslicher Farbstoff von bald mehr, bald weniger grünel Farbe existirt, den diese Autoren als Chlorophyll bezeichneten, haben Muldardet und ich (a. a: 0.) gezeigt, dass dieser 
letztere Farbstoff, entsprechend seiner stets mehr gelb- und braungrünen Farbe, nicht reines "Chlorophyll", sondern ein Gemisch ist aus zwei Farbstoffen, einem gelben, den wir Phycoxanthin nanten und einem grünen, den wir für gewöhnliches „Chlorophyll“ (der Phanerogamen im gewöhnlichen, allgemein gebrauchten Sinn) ansprachen.

In einer späteren Untersuchung hat Millardet (Compt. rendus T. 68 , p. 462) ein Gleiches für die Fucaceen erwiesen.

Die Darstellungsmethode, die wir für die Tremung der beiden Farbstoffe verwendet haben, war Schütteln einer weingeistigen Lösung mit Benzol. Es ging in das Benzol eine grüne Lösung über, die wir für Chlorophyll hielten, während im Weingeist das gelbe Phycoxanthin zurückblieb. Die im Benzol befindliche Lösung bot allerdings die gewöhnlichen Charaktere des Chlorophylls, auch das Spectrum desselben; freilich ist zu bemerken, dass wir in der zweiten Hälfte des Spectrums, wie es damals gebräuchlich war, nur eine continuirliche Absorption constatirten.

Man sieht leicht, dass unter den jetzigen Verhältnissen nicht feststeht, ob der betreffende in Benzol übergehende Körper ,Chlorophyll“ im ältern Sinn, d. h. eine Mischung zweier Farbstoffe oder ob er unser blangrüner Farbstoff (Bestandtheil) des "Chlorophylls" ist; letzteres ist sogar nach der Darstellungsmethode wahrscheinlich.

Es kann entschieden werden durch Untersuchung der Absorptionen in der zweiten Hälfte des Spectrums.

Aber auch hinsichtlich des gelben Phycoxanthins ist eine Nachuntersuchung wünschenswerth, da eine spätere Untersuchung unseres Phycoxanthins* Zweifel an der Richtigkeit unserer Beobachtung erhoben hat.

Ich habe zur Zeit unsere Untersuchungen nur an einer grossen Oscillarie wiederholt und an dieser Resultate erhalten, welche unsere früheren Beobachtungen im Ganzen bestätigen, im Besonderen aber so modificiren, dass sie sich an die hier gewonnenen Resultate besser anschliessen. Ich zweifle nicht, dass die an der Oscillarie gemachten Erfahrungen sich ohne grossen Fehler auf die Mehrzahl der Pflanzen

* Askenasy, Bot. Ztg. 1869. S. 790. Anm, 
übertragen lassen, die wir a. a. 0. untersucht haben (Diatomeen, Flechten).

Eine nicht näher bestimmte Oscillarie, ziemlich rein an den Brunnensteinen unserer Glashäuser befindlich, wurde in einer Reibschale zerrieben und darauf sofort mit kochendem Alcohol extrahirt. Dieser färbt sich zunächșt fast rein orangegelb, aber in dem Maasse, als die Einwirkung weitergeht, erhält er einen Stich ins Grüne und ist nach einigen Minuten tief olivenbraun gefärbt und mit starker rother Fluorescenz versehen.

Schüttelt man solche Lösung mit Benzol, so tritt sehr rasch eine Sonderung in zwei Farbstoffe ein. Das Benzol erscheint schön und rein blaugrün, genau wie unser Kyanophyll, der Alcohol aber tiefgoldnoch öfter orangegelb, nicht selten mit einem Stich ins Rosafarbene. Jene Flüssigkeit fluorescirt schön karminroth, diese nicht.

Der Versuch wurde öfter, mit frischen und mit trockenen Oscillarien, im Sommer und im Spätherbst, stets mit demselben Erfolge wiederholt.

Die blaugrü ne Benzollösung (Taf. III, Fig. 1) verhält sich äusserlich, nach Farbe und Fluorescenz, wie chemisch gegen Säuren, ganz wie der blaugrüne Farbstoff des gewöhnlichen Chlorophylls. Auch spectralanalytisch zeigt sie auf den ersten Blick keinen Unterschied, bei genauerer Vergleichung aber erscheint ein $\mathrm{B}$ and, das fünfte, in seiner Lage constant verschieden; es liegt nicht wie beim gewöhnlichen Farbstoff hinter, sondern a uf der Linie F; auch erschien Band IV recht schwach; andere Differenzen konnten nicht wahrgenommen werden.

Lage der Bänder:

2 Solutionen im Juni gemacht.

$\begin{array}{ll}\text { I } & 65-80 \\ \text { II } & 125 \\ \text { III } & 195 \\ \text { IV } & 300 \\ \text { V } & 435-510-580 \\ \text { VI } & 780-830-880 \\ \text { VII } & -\end{array}$

$45-70$

115

185

kaum sichtbar

$450-490-530$

wie vorher

960 
Eine Solution vom 12. October.

$$
\begin{aligned}
& \text { I } 40-70 \\
& \text { II } 115 \\
& \text { III } 190 \\
& \text { IV } 300 \\
& \text { V } 440-490-540 \\
& \text { VI } 800-850-900 \\
& \text { VII } 980 .
\end{aligned}
$$

Versetzt man die Lösung mit Säuren, so treten alle die Aenderungen ein, die oben für die blaugrüne Benzollösung aus gewöhnlichem Chlorophyll geschildert worden sind.

Die orangefarbene Weingeistlösung, ohne alle Fluorescenz, zeigt, wie das Xanthophyll des Chlorophylls, nur Absorption im Blau und Violett; es fällt aber sofort auf, dass vor dem ersten Band im Blaugrün noch ein schwächeres und schmäleres Band angesetzt ist, durch welches das Ansehen des Spectrums, das sonst mit dem des gewöhnlichen gelben Farbstoffs ganz übereinstimmt, sehr verändert erscheint. Taf. III. Fig. 2.

Lage der Bänder:

$$
\begin{aligned}
& 1 \text { a } 350-400-450 \\
& 1 \text { b } 500-550-600 \\
& 2 \text { 700-750-800 } \\
& 3 \text { 900 }
\end{aligned}
$$

Eine zweite Lösung:

$$
\begin{aligned}
& 1 \text { a } 380-430-480 \\
& 1 \text { b } 520-560-600 \\
& 2 \text { Mitte } 740 \\
& 3 \text { von } 900 \text { an }
\end{aligned}
$$

Eine Dritte ergab die Mitte von 1 a auf 435 . die von 1 b auf 560 .

Selbstverständlich tritt bei starken Concentrationen der Lösung eine totale Absorption des ganzen blauen und violetten Spectraltheiles (360) ein, eine Verdunkelung schon von 300 an.

Die Erscheinung, dass der Alcohol beim Ausziehen der Oscillarien sich zunächst nur orangegelb färbt, erklärt sich jetzt leicht daraus, dass der gelbe Farbstoff überhaupt leichter im Alcohol löslich ist als der blaugrüne Farbstoff. - Die braungrüne Färbung der Lösung nach 
der Extraction überhaupt zeigt darauf hin, dass das Verhältniss der beiden Farbstoffe in der Alge ein anderes als bei den höheren Pflanzen, und zwar ein quantitativ zu Gunsten des gelben Farbstoffes geändertes ist. -

Aus dem Angegebenen geht in Bezug auf unsere frühere Arbeit Folgendes hervor:

1) Was wir - Mrluardet und ich - als "Chlorophyll * bezeichneten, ist nicht das gewöhnliche Chlorophyll der höheren Pflanzen, sondern der blaugrüne Bestandtheil desselben.

2) Was wir Phycoxanthin nannten, ist, wie es scheint, nicht ein reiner Farbstoff, sondern der gelbe Farbstoff, wie er eben präparirt wurde, vermischt mit etwas blaugrünem. Da wir unsere Farbstoffe mit grosser Sorgfalt präparirt und gereinigt hatten, so ist mir schwer erklärlich, wie von dem blaugrünen Farbstoff noch so fest inhäriren konnte. Es ist aber ein Doppeltes denklich. Einmal ist es nicht unmöglich, dass verschiedene Arten der Oscillarien, oder dass dieselben Oscillarien zu verschiedenen Zeiten ihrer Entwicklung hinsichtlich der Trennung der beiden Farbstoffe sich verschieden verhalten, dass es zu gewissen Zeiten leicht, in anderen sehr schwierig gelang. Andererseits hat die Präparationsmethode, wie wir oben gesehen, einigen Einfluss; es ist z. B., wie oben bemerkt, bei Farnen gewöhnlich unmöglich gewesen, die beiden Farbstoffe ${ }^{\circ}$ von eirander zu trennen, wenn die Blätter vorher gekocht waren. - Meine jetzige und frühere Methode waren insoferu verschieden, als diesmal die schwach zerriebenen Oscillarien sogleich mit kochendem Alcohol extrahirt wurden; früher wurden die lange und fein zerriebenen Oscillarien vorerst (zur Gewinnung des Phycocyans) mit Wasser extrahirt und dann mit kaltem Alcohol ausgezogen.

Endlich habe ich in letzterer Zeit noch eine merkwürdige Erfahrung gemacht, die zeigt, dass unter Umständen dieselben Lösungsbeziehungsweise Trennungsmittel sich verschieden verhalten. Ich habe zur Trennung des blangrünen Farbstofỉs aus dem Weingeist das gewöhnliche Benzol, Benzin der Apotheken, verwendet; als ich rersuchte, mit chemisch reinem Benzol aus dem hiesigen chemischen Laboratorium die Trennung zu bewirken, gelang sie, trotz mehrfacher Versuche, durchaus nicht: es trat eine einfache Mischung des Benzols mit dem Alcohol ein. Woran die Sache liegen mag, habe ich nicht untersucht. 
In Bezug auf die gewöhnlichen Chlorophyllbestandtheile ergibt sich aus dieser Oscillarienuntersuchung Folgendes:

1) Das Kyanophyll der Oscillarie ist mit dem der höheren Pflanzen nicht ganz identisch, wohl aber sehr nahe verwandt ; es unterscheidet sich durch etwas andere Lage des Bandes 5 .

2) Der gelbe Farbstoff, unser Phycoxanthin, ist von dem Xanthophyll der höheren Pflanzen durch den Zutritt eines Bandes im Grün unterschieden, sonst aber ebenfalls gleich, also gewiss als nahe verwandt anzusehen. 


\section{Die Verwandten des gelben Chlorophyll- Farbstoffes.}

Wie schon früher erwähnt wurde, war es die Existenz des Bandes $\mathrm{V}$ im Chlorophyllspectrum, das ich schon vorher in den gelben Blumenfarbstoffen und dem etiolirter Pflanzen wahrgenommen hatte, die zur Auffindung des gelben Chlorophyllbestandtheils einen Fingerzeig gab.

Und dieser gelbe Chlorophyllfarbstoff wird erst physiologisch bedentungsvoll, wenn sich nachweisen lässt, dass er identisch oder wenigstens verwandt ist mit den genannten Farbstoffen, die wir so häufig mit ihm in Verbindung treten sehen.

Es ist allbekannt, dass die etiolirten Pflanzen am Licht ergrünen, d. h. also eine Mischung von 2 Farbstoffen erzeugen.

Würde sich herausstellen, dass der gelbe Chlorophyllbestandtheil mit dem gelben Farbstoff etiolirter Pflanzen identisch ist, so würde die Thatsache der Ergrünung ihrer Erklärung einen Schritt näler gebracht. Man würde dam dieselbe so ausdrücken können: Beim Ergrünen entsteht neben dem bereits vorhandenen gelben Farbstoff noch ein zweiter, blaugrüner, und die nächstliegende Frage würde sein, entsteht dieser Farbstoff unabhängig von dem gelben, oder aus diesem?

Andererseits ist bekannt, dass viele gelben Blüthen und Früchte ursprünglich grün sind. Wenn das Anthoxanthin identisch mit dem Xanthophyll des Chlorophylls wäre, so würde auch hier die Einsicht in die Erscheinung um etwas gefördert.

Es waren nun zunächst diese beiden gelben Farbstoffe etiolirter Pflanzen und der Blumen, deren Spectrum ich näher prüfte, um das Verhältniss derselben zum gelben Chlorophyllbestandtheil kennen zu 


\section{- $112-$}

lernen. Die Untersuchung hat ihre völlige Identität, in einzelnen Fällen nahe Verwandtschaft gelehrt; die oben gestellten Fragen sind bejaht und die Áufgaben in der angegebenen Richtung zu lösen.

\section{Der Farbstoff etiolirter Pflanzen.}

Der weingeistige Auszug aus den Blättern etiolirter Gerste ist rein goldgelb, ohne Spur von Fluorescenz, wie schon Askenasy (a. a. O. S. 229) angegeben; er wird durch Salz-oder Schwefelsäure zunächst smaragd-, dann spangrün und endlich schön indigblau gefärbt: je nach der Menge der Säure geht die Färbung mehr oder weniger rasch vor sich; rascher geschah sie nach meinen Erfahrungen durch Salz-, als durch Schwefelsäure. Mit letzterer danerte es gewöhnlich mehrere Stunden bis zur Grün-, oft über einen Tag bis zur Blaufärbung. Die Langsamkeit der Erscheinung in letzterem Fall mag wohl daran Schuld gewesen sein, dass Askenasy (a. a. 0.) die Färbung nicht gesehen und geleugnet hat.

Das Spectrum der Lösung in concentrirtem Zustande oder in dickerer Schicht ist eine continuirliche Absorption des Blau und Violett von 480 an, die schattenartig schon bei 450 anhebt; - während der ganze vordere Theil des Spectrums ungehindert durchgeht, von Roth bis Grün.

Nimmt man eine recht verdünnte, nur hellgelbe Lösung so gewahrt man ein Spectrum, das mit dem des gelben Chlorophyllfarbstoffs total übereinkommt, Taf. II. Fig. 4. Es genügt, die Lage der Bänder anzugeben :

$$
\begin{aligned}
& \text { 1. } 500-560-620 \\
& \text { 2. } 680-750-810 \\
& \text { 3. von } 890 \mathrm{ab} .
\end{aligned}
$$

Zwischen den Bändern liegen Verdunkelungen, die zwischen 2 und 3 stärker als zwischen 1 und 2 erscheinen; wesshalb auch bei zunehmender Concentration die Bänder 2 und 3 zuerst zusammenfliessen, während 1 noch individualisirt bleibt; ron einem derartigen nicht typischen Concentrationsgrad hat Askevasy (a. a. 0. Fig. 3) ein Bild gegeben.

Setzt man den Farbstoff dem Licht aus, so verbleicht derselbe allmählich gänzlich und verliert schon vorher seine Bänder, indem eine continuirliche Absorption des Blau und Violett an ihre Stelle tritt. 
In diesem Zustand fand ich auch (in einem Falle) keine Grün- und Blaufärbung mehr durch Säuren.

Ein lebendes Blatt der Gerste vor den Apparat gebracht, gab folgende Lage der Bänder:

$$
\begin{aligned}
& \text { 1. } 420-460-500 \\
& \text { 2. undeutlich Mitte bei } 670 \text {. }
\end{aligned}
$$

Nan sieht daraus, dass auch für den gelben Farbstoff die Regel gilt, dass die lebenden Farbstoffkörper ein nach dem rothen Ende hin verschobenes Spectrum geben.

Ganz gleich der Gerste verhält sich der Farbstoff bei Ornithogalum nutans.

1) Lage der Bänder in alcoholischer Farbstofflösung:
1. $530-570-610$
2. $665-740-820$
3. beginnt 900 .

2) Am lebenden Blatte:

$$
\begin{aligned}
& \text { 1. } 450-510-565 \\
& \text { 2. } 610-670-730 \text {. }
\end{aligned}
$$

Diese beiden Beispiele werden, wenn ich hinzufüge, dass bei Hafer, Hyacinthen, Bohnen, Crocus und Ma is ganz dasselbe statt hat, genügen, um zu zeigen, dass die spectralanalytischen und die charakteristischen chemischen Reactionen durchweg übereinstimmen $z$ wischen dem Farbstoff etiolirter Pflanzen und dem gelben Farbbestandtheil des Chlorophylls, und dass sonach zweifelsohne beide Farbstoffe identisch sind. -

Indem nun, nach dem oben Angedeuteten, die Frage entsteht, wie sich der gelbe Farbstoff verhalte zu dem blaugrünen, wenn eine etiolirte Pflanze ergrünt, ob vielleicht der letztere aus dem ersteren entstehe, oder ob derselbe unabhängig von diesem sich bilde: ist es vor Allem kaum nöthig den Gedanken zurückzuweisen, als ob eine so einfache genetische Beziehung möglich sei, wie sie sich Fremy (Compt. rend. T. L. 1860, p. 410 und 412) gedacht. Derselbe, bekannt mit der Thatsache, dass etiolirte Blätter durch Säuredämpfe oder Säuren (Salzsäure) sich grün färben, meinte (wie aus seinen Aeusserungen 
p. 410-411 und 412 a. a. 0 zu schliessen ist*), dass diese grüne Farbe in Beziehung stehe zum Chlorophyll. - Ich habe bereits oben bei dem gelben Farbstoff des Chlorophylls darauf aufmerksam gemacht, dass die gelbe Farbe, durch Säuren ergrünt, spectralanalytisch keine Spur Aehnlichkeit mit dem Chlorophyllspectrum hat; ganz dasselbe gilt auch von dem Spectrum des Farbstoff's etiolirter, Pflanzen.

Ein vermuthlicher genetischer Zusammenhang zwischen dem gelben und blaugrünen Farbstoff beim Ergrünen etiolirter Pflanzen lässt sich meines Erachtens auf einem andern Wege sicher nach-oder zurückweisen. Wenn nemlich beim Ergrünen der neue Bestandtheil auf Kosten des vorhandenen entsteht, so wird, vorausgesetzt dass der letztere nicht sofort sich neuerzeugt, eine Differenz in der Menge des vorhandenen gelben Farbstoffes nach dem Ergrünen gegenüber der ursprünglichen Menge vorhanden sein. Versuche, die ich in der Art anstellte, dass ich die Menge des gelben Farhstoffs in einem bestimmten Trockengewicht etiolirter Gerstenblätter vor und nach dem Ergrünen bestimmte, haben in der That eine ansehnliche Abnahme nach dem Ergrünen ergeben. Da mir die Versuche aber noch nicht genau genug erschienen, und fortgesetzt werden sollen, so unterlasse ich, hier näher darauf einzugehen.

\section{Blumen-, Frucht- und Samengelb.}

- Dass unter den gelben Farben der Blüthen und Früchte der gelbe Chlorophyllbestandtheil vorkomme, war von vornherein schon dadurch wahrscheinlich, dass, wenigstens in den meisten Fällen, der Farbstoff nicht nur wie beim Chlorophyll an eine protoplasmatische Grundlage gebunden ist, sondern auch vielfach aus letzterm scheinbar hervorgehen gesehen wird. Es ist allgemein bekannt, dass die gelben Früchte z. B. der Solanumarten, von Lycopersicum, der Aurantiaceen, die Schein-

* „Les feuilles étiolées soumises à l'action des vapeurs acides prennent rapidement une coloration verte, il existe donc des rapports très-simples entre les corps qui donnent aux feuilles leur coloration verte et ceux qui les colorent en jaune." p. $410-411$.

Fremy hält den gelben Farbstoff für Phylloxanthëine (ein Körper der aus seinem Phyllocyanine entsteht), während die herbstlichen Blätter nach ihm Phylloxanthine enthalten.

Da sein Phyllocyanine schon ein Salzsäurezersetzungsproduct ist, so kann ein daraus entstandener Körper kaum etwas anderes sein.

Uebrigens ist diese Färbung der Blätter zuerst von Sachs gefunden worden vgl. dessen Exp. phys. S. 9. 
früchte der Rose u. s. w. ursprünglich grün sind und dass das Gelb dadurch entsteht, dass die grünen Chlorophyllkörner mit oder ohne Beibehaltung der Form eine gelbe Farbe annehmen. * Man könnte annehmen, dass in diesem Falle der blangrüne Farbstoff verschwinde, der gelbe in ursprünglicher Nenge oder vermehrt allein zurückbleibe.

Die Untersuchungen über solche Blüthen-, Frucht- und Samentheile zeigen in der That, dass bei einem grossen Theil derselben der gelbe Farbstoff geradezu identisch ist mit dem gelben Chlorophyllbestandtheil, bei einem andern Theile lässt sich nur eine nahe Verwandschaft finden - eine Mannichfaltigkeit, die nach den in der Literatur über den Gegenstand zerstreuten Angaben (siehe unten) gerade nicht unerwartet ist.

1) Blüthenblätter, die in der Knospenlage grün oder wenigstens grünlich, später aber mehr oder weniger goldgelb gefärbt sind, und deren Farbstoff an Protoplasmakörner gebunden ist, enthalten in allen untersuchten Fällen einen in Weingeist (Aether, Chloroform) löslichen Farbstoff, der nicht fluorescirt und gegen Salz- oder Schwefelsäure sich wie der gelbe Chlorophyllfarbstoff verhält. **

In gleicher Weise ist auch das Spectrum dieses Farbstoffs identisch mit dem des gelben Chlorophyllfarbstoffs.

Ein weingeistiger Auszug aus den Blumenblättern z. B. von Ranunculus gibt im Blau und Violett bei stärkerer Concentration eine Verdunkelung von 440, eine totale Absorption von 480 an; bei Verdünnung zeigt er die drei schönen Bänder, die wir oben besprochen. Es genügt hier auf das Spectrum Taf. II, Fig. 5 von Doronicum hinzuweisen und zum Belege des Gesagten die Lage der Bänder bei einer Anzahl Auszügen aus Blumenblättern anzuführen:

1.

Eranthis hyemalis

Hibbertia volubilis

Mimulus luteus

Calceolavia rugosa

Doronicum Pardalianches

Scorzonera hispanica
2.

$\begin{array}{cccc}530-580-630 & 710-780-825 & \text { beginnt } & 960 \\ 520-565-610 & 680-760-840 & & 960 \\ 510-555-610 & 680-750-820 & & 920 \\ 540-575-610 & 680-750-820 & & - \\ 510-560-610 & 680-760-840 & & \\ -570- & -760- & & -\end{array}$
S. 131.

* Vergl. die Literatur bei KRaus, Pringsh. Jahrb. für wiss. Bot. VIII,

** Diese charakteristische Reaction wurde für Blüthenblätter zuerst von Ma r quart (Blüthenfarben S. 67) gesehen. 
1.

Brassica nigra

$540-585-630$

$690-765-830$

beginnt 960

Gentiana lutea

$-560-$

$-750-$

Forsythia

$550-600-650$

Cucurbita Pepo - 560 -

$735-790-860$

In gleicher Weise verhalten sich Azalea pontica, Chelidonium majus, Corydalis lutea, Matricaria Chamomilla (Scheibenblüthen), Caltha palustris, Ranunculus polyanthemos.

Die Untersuchung der lebenden Blätter zeigt auch hier eine Lageänderung der Bänder, Verschiebung gegen das rothe Ende, so, dass das erste Band vor $\mathrm{F}$ zu liegen kommt, z. B.:

1.

\section{Eranthis}

Hibbertia

Mimulus

Brassica

$$
445-510-570
$$$$
430-480-545
$$$$
420-490-560
$$$$
440-510-580
$$

2.

3.

$$
\begin{gathered}
630-695-770 \\
-700-- \\
- \\
600-670-750
\end{gathered}
$$

Die Früchte von Solanum Pseudocapsicum geben einen Farbstoff der sich nach Reaction* und Spectrum gleich den geschilderten Blüthenfarbstoffen verhält.

\section{Spectrum}

der Fruchtschale selbst

1.

2.

$$
445-500-550
$$

Mitte 680 der alcoh. Lösung.

$$
\begin{aligned}
& 530-570-610 \\
& 675-725-780
\end{aligned}
$$

2) bei einigen gelben Organen, die mehr oder weniger or ange $\mathrm{Nuance}$ besitzen, wie bei den Blüthen von Berberis Darwini und dem Samenmantel von Evonymus europaeus ist der Bau der Bänder und ihre Zahl nicht geändert, dagegen zeigen sie (in weingeistiger Solution) eine etwas andere Lage (vor F):

Berberis Darwini, Blüthenblätter:

$$
\begin{array}{cc}
1 . & 2 . \\
460-500-540 & 620-690-760
\end{array}
$$

* A. a. O. S. 132 habe ich angegeben, dass sich der alcoholische Auszug aus den Beeren durch $\mathrm{HCl}$ spangrün färbt; es ist dies nicht die End färbung, sondern ein Zwischenstadium. Die Färbung ist auch hier successive smaragd-, spangrün, indigblau. Schwefelsäure wirkt ziemlich inconstant. A. a. O. hatte ich keine Reaction bekommen; neuerdings ist sie mir gelungen. 
Evonymus europaeus, Arillus:

1.

$$
450-500-550
$$

2.

$$
620-680-740
$$

3.

960

3) Aus den Blumenblättern von Eschscholtzia californica habe ich eine weingeistige Lösung erhalten, von schön orangegelber Farbe, die sich gegen Salzsäure wie die anderen Lösungen verhielt, aber ein Spectrum gab, das, von dem andern abweichend, mit dem des Phycoxanthins grosse Aehnlichkeit hat. Vor das erste intensivere Band im Blau ist nemlich wie dort ein schwächeres und schmäleres angesetzt. Im Uebrigen war die Lage der Bänder bei verschiedenen Lösungen etwas ungleich.

In concentrirten Lösungen war eine schwache Verdunkelung von 370 , bei andern von 380 an bemerklich, die bei 400 oder 420 in eine totale Verfinsterung bis ans violette Ende überging.

Die schwächern Lösungen zeigten folgende Bänderlage:

1) Frische Lösungen vom Juli:

1 a $445-485-525$

1 b $565-600-645$

2 als leichte Anschwellungen, deren Mitte $\mathbf{7 7 5}$;

2) ebensolche:

$$
\begin{array}{lc}
1 \text { a } & 430-465-500 \\
1 \text { b } & 550-590-640 \\
2 & \text { Mitte } 765 \\
3 & \text { von } 930 \text { an; }
\end{array}
$$

3) eine ebensolche:

$$
\begin{array}{cc}
1 \text { a } & 450-485-525 \\
1 \text { b } & 540-600-660 \\
2 & \text { Mitte } 760 \\
3 & 965 ;
\end{array}
$$

4) eine solche vom 14. October:

$$
\begin{array}{lc}
1 \text { a } & 420-460-500 \\
1 \text { b } & 520-585-650 \\
2 & \text { Mitte } 790 \\
3 & \text { von } 980 \mathrm{ab} .
\end{array}
$$

Die unter diesen Farbstoffen unterschiedenen 3 Gruppen haben, wie man sieht, mit dem betrachteten gelben Chlorophyllfarbstoff mehr oder weniger Verwandtschaft. Wie dieser an Protoplasma gebunden, 
stimmen sie auch hinsichtlich der Löslichkeit, Reaction gegen Säuren und Licht, ganz überein; spectralanalytisch sind sie ihm bald völlig gleich (Gruppe 1), bald nach Lage (2), bald nach Zahl und Lage der Bänder (3) etwas abweichend.

Die Identität der unter 1) genannten Blumenfarbstoffe mit dem gelben Chlorophyllbestandtheil ist zweifellos; unter diese Gruppe gehören ohne Zweifel die meisten goldgelben Blumenfarben.

Auch hinsichtlich der unter 2) aufgeführten Farbstoffe kann wenigstens an einer nahen Verwandschaft nicht gezweifelt werden, da es sich bloss um eine Verschiebung der Bänder handelt.

Die dritte Gruppe freilich von Eschscholtzia* ist dem Spectrum noch entfernter stehend; näher steht sie dem Phycoxanthin, mit dem sie wo nicht identisch, doch sehr nahe verwandt ist. Uebrigens will ich bemerken, dass ich an den Eschscholtzia-Exemplaren unseres Gartens mehrmals goldgelbe Blumenblätter gefunden habe, deren Farbstoff ein Spectrum gab, das sich von dem des gewöhnlichen gelben Farbstoffs in Nichts unterschied. Es war:
1. $550-595-650$
2. $700-770-840$
3. totale Verfinsterung von 965 an.

Es scheint mir näher zu liegen, eine nahe Beziehung der beiden Farbstoffe anzunehmen, als zu glauben, dass an ein und derselben Pflanze in den Blüthen zwei ganz differente Farbstoffe gebildet werden. -

Der Vollständigkeit halber möge hier auch noch einiger Blüthenfarbstoffe gedacht werden, die zunächst ausser aller Verwandschaft mit den eben aufgeführten Farbstoffen zu stehen scheinen, indem sie in Wasser löslich, in Benzol, Aether oder Schwefelkohlenstoff unlöslich erscheinen. Sie kommen, wie schon MARQUart wusste (Blüthenfarben S. 60), bei manchen Blüthen vor; sie sind nicht an Protoplasmakörner gebunden, sondern diffus im Zellinhalt gelöst.** Sie finden

* Es schien mir auch der Farbstoff von Gazania rigens das Spectrum der Eschscholtzia zu geben, und vielleicht gehören viele lebhaft orangefarbene Blüthen hieher; wenigstens scheint auch Erysimum Perofstiianum nach Sorby ein ähnliches Spectrum zu haben.

** Ich lasse dahin gestellt, welcher Beschaffenheit die von ihm durchdrungene Grundmasse sei. 
sich z. B. in den gelbblühenden Dahlien. $\mathrm{Ob}$ die gelben Blüthen der Acacien (Hildebrandt, Prings. Jahrb. Bd. III, S. 647) denselben Farbstoff enthalten, bleibt dahingestellt. Dieser, wie der vorige, geben mit Salzsäure nicht die bekannte Färbung und haben, wie ich bereits früher mittheilte (Sitzb. Erlanger ph.-med. Soc. 1871, 10. Juli) eine continuirliche Absorption in Blau und Violett.

Für Dahlia und Calceolaria hatte dies Sorby (Proceed. R. Soc. 1867, p. 454) schon früher angegeben. Auch Thudichum (Centralbl. f. med. Wiss. von Rosenthal VII. 1869. S. 4) hat solche Farbstoffe gefunden.*

Diese nicht weiter hiehergehörigen und vielleicht sehr mannichfaltigen Farbstoffe bedürfen einer eingehenderen Untersuchung, die, wie es scheint, schon in Aussicht steht.**

\section{Nomenclatur und Literatur.}

Der gelbe Farbstoff etiolirter Pflanzen, ein grosser Bruchtheil der gelben Blüthenfarbstoffe sind identisch, ein anderer Theil nahe verwandt mit dem gelben Chlorophyllfarbstoff, und demnach mit diesem unter einem Namen zusammenzufassen.

Der alte von Marquart (Blüthenfarben, S. 66) eingeführte Name Anthoxanthin ist jedenfalls überflüssig geworden; ohnehin waren von ihm darunter wesentlich verschiedene Dinge (so der in Wasser lösliche Farbstoff von Crocus maesiacus, der von Papaver nudicaule u. s. w.) zusammengefasst worden.

Ingleichem kann der Name Xanthin, den Frewy und Crö̈z (Journ. Chem. et Pharm. S. III, T. XXV. 1854. p, 249) für die in Alcohol löslichen gelben Blüthenfarben, im Gegensatz zu den in Wasser löslichen (Dahlia), den sie Xanthëin nannten, entbehrt worden.

Frevy (Compt. rend. T. LXI. 1865. p. 190) behauptet, der gelbe Blumenfarbstoff werde durch Salzsäure roth gefärbt und folgert daraus die Verschiedenheit desselben von seinem Phylloxanthine; letzteres ist gewiss richtig, dagegen nicht die Beobachtung einer Rothfärbung. Dies hat auch schon Filhol (Compt. rend. T. LXI. p. 373)

\footnotetext{
* Vgl. auch Filhol über "Xanthogéne“, Compt. rend. L. 1860. S. 545. ** Prantl, Bot. Ztg. 1871. S. 425 .
} 
bemerkt und richtig die Blaufärbung durch Schwefelsäure angegeben. Uebrigens ist derselbe ebenfalls im Irrthum insofern, als er die Identität des gelben Blüthenfarbstoffs und seines gelben Chlorphyllfarbstoffs läugnet. Wir haben gesehen, dass Spectra und Säurereaction derselben vollständig zusammenstimmen. Auch ist es nicht richtig, dass Meyen, wie er meint, zuerst in seiner Pflanzenphysiologie (II, 445) die genannte Blaufärbung durch Säuren hervorgerufen habe; vielmehr ist der ganze Passus über Blüthenfarben an dieser Stelle nach Marquart gegeben, der, wie oben bemerkt wurde, zuerst diese charakteristische Reaction gefunden hat.

Es ist hier auch der Ort, einer schon oben erwähnten Arbeit Thudrchun's über gelbe thierische und pflanzliche Stoffe* zu gedenken. Derselbe hat eime Menge gelbgefärbter organischer Substanzen, aus dem Thier- und Pflanzenkörper hauptsächlich spectroskopisch untersucht und gefunden, dass die massgebenden Farbstoffe derselben gemeinschaftliche Charaktere zeigen. Sie sind löslich in Alcohol, Aether etc., unlöslich in Wasser, krystallisiren in rhombischen Tafeln und geben ein Spectrum mit 3 Absorptionsbändern in Blau und Violett. Wie aus den Zeichnungen der Spectren einer alcoholischen Lösung des Farbstoffs der Corpora lutea und eines ätherischen von Eigelb ersicbtlich, liegen zwei Bänder zwischen $b$ und $G$ (rechts und links von $\mathrm{F}$ ?), ein drittes gleich hinter G, und eine Endabsorption beginnt bei $H$. Er betrachtet die Farbstoffe als einen und nemnt denselben Lutein.

Unter den untersuchten Objecten befinden sich auch die Blüthenund Fruchtfarben zahlreicher Pflanzen, die nach ihm , ein gleiches oder ein äusserst ähnliches" Spectrum geben.

Es ist nun zunächst hervorzuheben, dass das Spectrum, das er von seinem Lutein gibt, durchaus nicht übereinstimmt mit dem, welches wir oben für die goldgelben Blüthenfarbstoffe gefunden haben, und dass somit, die Richtigkeit der 'T'Hudichur'schen Spectra zugegeben, kein Grund vorhanden wäre, die thierischen gelben Farbstoffe (Eigelb) mit den Blüthenfarbstoffen zu identificiren.

Freilich ist das Spectrum, welches PreYer (Blutkrystalle S. 50 und 190) von ätherischer Lösung des Eigelbfarbstoffes gibt, wesentlich verschieden von dem Thudichus's und nahezu gleich dem unsers

* Results of researches on Luteine and the spectra of yellow organic substances, contained in animals and plants. Proceed. Roy. Soc. of London. Vol. XVI. 1869, p. 253-56. Auch im Centralbl. f. med. Wiss. von Rosenthal. VII. 1869. S. $1-5$. 
Blüthenfarbstoffs. Einige Versuche, die ich über das Spectrum des Eigelbs gemacht habe, zeigen bei ätherischer und Chloroform-Lösung ein Spectrum, das mit dem Preyer'schen gut übereinstimmt. Ich erhielt:

1) ätherische Lösung 3 Bänder (Endabsorption zugerechnet) in folgender Lage:
1. $490-540-590$
2. $640-710-780$
3. Ton 960 ab.

2) Lösung in Chloroform 4 Bänder:

1. $445-500-560$

2. $615-670-745$

3. bei G eine sehr geringe Anschwellung.

4. totale Absorption ron 1000 an.

Man sieht, dass dieses Spectrum sehr wohl übereinstimmt mit dem Spectrum des Farbstofts von Physalis Alkekengi (siehe oben S. 59) oder mit dem der Blumenblätter von Berberis Daruini, oder mit dem des Farbstoffs von Evonymus (siehe S. 116-117).

Bringt man für die erstgenannte Pflanze in Betracht, dass dies Spectrum in Alcohol, nicht in Aether, beobachtet ist, so möchte man die Spectra roн Physalis und dem Eigelb identisch nennen. Erwägt man ferner noch, dass der Farbstoff des Eigelb gegen Salzsäure und Licht (Blaufärbung - Bleichung) sich ganz wie der unserer Blüthenfarben verhält: so könnte man versucht sein, denselben für chemisch identisch mit einzelnen unserer gelben Pflanzenfarbstoffe und nahe verwandt mit den meisten anderen zu halten.

Ich glaube aber, dass wir hinsichtlich solcher Schlüsse von spectralanalytischer Identität auf chemische Identität überhaupt z. Z. noch sehr vorsichtig sein müssen. Es gilt freilich hinsichtlich der Metallspectra als Axiom, dass gleiche Spectra gleichen Stoffen entsprechen, betreffs der Absorptionsspectra complicirt gebauter Körper scheint jedoch die Sache weniger sicher: es ist zur Zeit noch nicht bewiesen, dass Stofie, die gleiche Spectra geben, auch unbedingt chemisch gleich sind, wenigstens sind die Meinungen der Spectralanalytiker darüber getheilt; während Thudichun den Satz bejaht (a. a. 0.), spricht sich Preyer direct dagegen aus (a. a. O. S. 99-100)́

Wenn die Thatsachen so hinsichtlich der Identität der Spectra liegen, so ist klar, dass wir hinsichtlich unserer Schlüsse bei ähn- 
lichen Spectren noch viel weniger sichere Basis haben, und dass wir noch weniger Recht haben, von der Aehnlichkeit der Spectra und dem Grade derselben auf nähere oder fernere Verwandschaft zu schliessen.

Unter diesen Umständen scheint es mir vorläufig mit SoRBY* nicht gerathen, diese thierischen und pflanzlichen Farbstoffe, die ähnliche Spectra geben, ohne Weiteres zu identificiren und unter einem Namen (Lutein) zusammenzustellen.

Vielleicht dürfte es mit den eben angeführten Grundsätzen im Widerspruch zu stehen scheinen, dass im Vorhergehenden Blüthenfarbstoffe, mit ähnlichen Spectren, als chemisch verwandt bezeichnet, angesehen wurden. Dies geschah aber nicht allein auf Grund ihrer Spectra, sondern mit Rücksicht auf ihr gleiches chemisches Verhalten (gegen Säuren und Licht) und insbesondere auf ihr ähnliches morphologisches Verhalten.

* Anwendung des Spectroscops zu technischen Zwecken u. s. w. Vierteljahrschr. f. Gesundheitspfl. Bd. II, p. 60-61. 


\section{A $n \mathrm{~h}$ a $\mathrm{ng}$.}

\section{Sorby's Arbeit über die Farbstoffe herbstlicher Blätter.}

Die oben S. 87 citirten Untersuchungen Sorby's (Various tints of autumnal foliage. Quat. Journ. of Science. N. XXIV. Jan. 1871. p. 64-77) erstrecken sich nicht, wie der Titel etwa vermuthen lässt, bloss auf die herbstlichen Blätter, es werden vielmehr auch die Farbstoffe gewöhnlicher grüner Blätter berücksichtigt, und dies reranlasst mich, seine Beobachtungen mit den meinigen hier nachträglich und eingehend zu vergleichen. Freilich wird dies ziemlich erschwert dadurch, dass in seiner Arbeit die Darstellungsmethode und auch die Charakteristik der Farbstoffe so summarisch gegeben sind, dass es mitunter geradezu unmöglich ist, über Identität oder Verschiedenheit seiner und meiner Producte zu urtheilen. Es wäre desshalb sehr wünschenswerth, dass Sorby seine Untersuchungen austührlicher veröffentliche. Einige Anhaltspunkte für seine Farbstoffe geben die Spectra, die er in einer früheren Untersuchung (Quat. Journ. Micr. Soc. 1869, Octob.) verzeichnet hat.

SORBY unterscheidet in seiner oben genannten Arbeit in frischen grünen Blättern 3 Farbstoffe, die sich nach ihm leicht von einander trennen lassen. Er sagt a. a. 0. p. $69-\mathbf{7 0 \text { : }}$

„Unfaded green leaves are coloured mainly by chlorophyll, but the tint is very much modified by xanthophyll, and by colours of the chrysophyll group. The presence of these, in varying relative and absolute amount, explains in a most satisfactory manner all the various brighter and darker greens met with in different leaves in different conditions. It is doubtfull if chlorophyll has ever been see free from xanthophyll. On heating green leaves with alcohol, a bright green 
solution is obtained. On agitating with bisulphide of carbon, this sinks to the bottom with the greater part of the chlorophyll and some xanthophyll in solution, whilst the alcohol retains most of the xanthophyll and some chlorophyll. After agitating this with a little fresh bisulphide, evaporating to dryness, and dissolving out the chrysophyll by water, when dry, the impure xanthophyll may be disșolved in bisulphide of carbon."

Es ist mun vor. Allem hervorzuheben, dass SoRby unter diesen 3 Namen, Chlorophyll, Chrysophyll und Xanthophyll, nicht je einen einzigen Farbstoff versteht, sondern sie als Bezeichnungen für Farbstoffgruppen betrachtet, Gruppen, deren einzelne Glieder zwar durch gemeinschaftliche Merkmale sich als zusammengehörig erweisen, sonst aber von einander in verschiedenen Dingen abweichen.

Die Charakteristik dieser 3 Gruppen ist folgende:

1) Die Chlorophyllgru ppe. Die hieher gehörigen Farbstoffe sind löslich in Alcohol und Schwefelkohlenstoff; ihr Spectrum zeigt ein wohlmarkirtes Absorptionsband im Roth (p. 66). Von Unterarten (Farbstoffen) dieser Gruppe macht er vier namhaft. Ein Farbstoff kommt in verhältnissmäsisiger Reinheit in einer Oscillarie vor; in den gewöhnlichen Blättern ist dieser, wie es ihm scheint, mit einem andern, der besondere Absorptionen gibt, gemischt vorhanden.

Als einen dritten Farbstoff der Gruppe betrachtet er den, welcher durch Säurewirkung auf die beiden erstern entsteht, und der normal in braunwerdenden Blätter'n vorbanden ist. Endlich kommt in welken (faded) Conferven ein Farbstoff vor, der sich vor den andern durch Bläuung bei Zusatz von Salzsäure zur alcoholischen Solution auszeichnet $(p .65)$.

2) Die Xanthophyllgruppe (p. 66) umfasst Farbstoffe, die unlöslich im Wasser, aber löslich in Alcohol und Schwefelkohlenstoff sind; sie geben Absorptionen bloss am blauen Ende, mehr oder weniger scharfe Bänder; ihre Farbe ist gelb oder orange. Die einzelnen Farbstoffe, die in Blüthen, Früchten, Wurzeln u. s. w. vorkommen, unterscheiden sich von einander durch den Bau und die Lage der Absorptionsstreifen; zwei derselben sind in Blättern gewöhnlich. Als Typen dieser beiden betrachtet er die Farbstoffe, welche in dem orangegelben äusseren, und goldgelben innern Gewebe der Wurzel von Daucus Carota vorkommen.

${ }_{n}$ Both give spectra with two rather obscure absorption-bands, 
which lie further from the blue end in the case of colour from the external layer of the carrot, and the colour of this is orange, and of the other yellow."

Der gelbe ist nach ihm der gewöhnliche; der orangefarbene soll z. B. im Gummibaum (Ficus elastica) vorkommen (p. 66).

3) Die Farbstoffe seiner Chrysophyllgrupe endlich haben mehr oder weniger goldgelbe Farbe, sind in $\mathrm{W}$ asser, auch in wässerigem Alcohol, nicht aber in Schwefelkohlenstoff löslich. Die verschiedenen Arten (4), die er aber nicht näher beschreibt, sind durch besondere Absorptionsbänder; die sie bei der Behandlung mit Reagentien geben, characterisirt (p. 68).

Beim Vergleich seiner Resultate mit den unserigen ist zunächst festzuhalten, dass seine Darstellungsmethode der Farbstoffe im Wesen von der unserigen nicht verschieden ist; er wendet bloss statt des Benzols Schwefelkohlenstofi an; dies führt, wie ich mich überzeugt habe, zu demselben Resultate wie die Anwendung ron Benzol. Es ist ganz gleichgültig, ob man eine weingeistige Chlorophylllösung mit Benzol oder Schwefelkohlenstoff behandelt; bei der Trennung erscheint der gelbe Farbstofi im Alcohol, der blaugrüne in Benzol oder Schwefelkohlenstoff.

Wo sich also Abweichungen in unseren Resultaten finden, können die Ursachen derselben nicht in der Darstellungsmethode gesucht werden. Uebrigens wird sich gleich zeigen, dass, mehr als die von uns gefundenen Thatsachen, die Auffassung derselben Verschiedenheit unserer Resultate begründet.

Während nemlich alle meine Untersuchungen mit Rücksicht und basirt auf die bereits vorhandenen deutschen und französischen Vorarbeiten chemischer, morphologischer und physiologischer Natur unternommen, und überall in Beziehung gesetzt sind zu den_in der Pflanzenphysiologie momentan ventilirten Fragen, hat SorBy - und das geht nicht etwa bloss aus dem Mangel von Literaturcitaten, sondern aus der ganzen Haltung der Arbeit hervor -- seine Anschauungen bloss auf die ron ihm gefundenen Eigenschaften und chemischen Kennzeichen gegründet. Auf erstere insbesondere legt SORBY ein grösseres Gewicht als ich. Während für ihn schon klei ne Lageun te rschiede (blosse Verschiebungen der Bänder) bei sonstiger Identität der Spectra und bei völlig gleichem chemischen Verhalten zweier Farbstoffe hinreichen, dieselben als 2 verschiedene Species einer Gruppe zu be- 
trachten, habe ich, wie man aus dem oben aufgeführten Listen ersieht, solche kleine Ungleichleiten (bei sonstiger Gleichheit) gering angeschlagen und die betreffenden Farbstofie höchstens als Modificationen ein und desselben Körpers aufgefasst. Maassgebend war mir dabei der Gedanke, dass bei sonstigem (morphologischen und chemischen) Gleichverlalten kleine spectralanalytische Verschiedenheiten um so weniger betont werden dürfen, als mir solche bei ein und demselben Körper gelegentlich vorgekommen sind (vgl. unten).

Nach dieser allgemeinen Bemerkung führe ich kurz an, was ich Thatsächliches zu Sorвy's Resultaten hinzuzufügen habe.

Es ist gewiss, dass das, was Sorby als Chlorophyll bezeichnet * ganz mit unserm blaugrünen Farbstoff (Kyanophyll) übereinkommt. Es ist sowohl aus der Darstellungsmethode als aus der Charakteristik dieser Gruppe zu entnehmen. Die Spectralanalyse zeigt, dass der blaugrüne Farbstoff, der beim Schütteln einer weingeistigen Chlorophylllösung mit Schwefelkohlenstoff in letzteren übergeht, ganz. die Charaktere zeigt, welche unsere blaugrüne Benzollösung hat. Sorby kennt nun vier verschiedene hieher gehörige Farbstoffe; der eine kommt in Oscillarien vor. Auch ich habe dort einen etwas abweichenden blaugrünen Farbstoff gesehen. Einen zweiten findet er in den grünen Blättern mit dem ersten gemischt. Ich selbst habe in den Blättern bloss einen, und diesen eben von Oscillarien abweichend gesehen. Die Möglichkeit, dass die grünen Blätter etwa in bestimmten Entwicklungsstadien Modificationen des Farbstoffs zeigen, darf immerhin im Auge behalten werden. Als einen dritten hieher gehörigen Farbstoff betrachtet er, wie wir oben gesehen, das zersetzte Chlorophyll; es liesse sich das insofern thun, als in absterbenden herbstlichen Blättern, in erfrornen Blättern, in der That solches ,zersetztes * Chlorophyll vorkommt; insofern es aber in beiden Fällen meines Erachtens in Folge der Einwirkung der Pflanzensäuren oder pflanzensauren Salze auf das Chlorophyll der getödteten Zelle entsteht, ziehe ich es vor, diesen Farbstoff als ein Derivat, als ein Zersetzungsproduct zu betrachten.

Endlich will SoRBy in welken Conferven noch eine Art Chlorophyll gefunden haben, ausgezeichnet durch Bläuung der alcoholi-

* Gegen die Zulässigkeit dieses Namens für den blaugrünen Farbstoff habe ich mich schon oben ausgesprochen. 
schen Solution mittelst Salzsäure. Ich möchte vor Allem glauben, dass welke Pflanzen kein tadelloses Material zur Herstellung reiner Farbstofie sind; andererseits habe ich in einer Conferve, die frisch war, nichts Anderes als die gewöhnlichen Farbstoffe gefunden (vgl. oben). Es fällt auf, dass Sorbr von alcoholiseher Solution spricht; wahrscheinlich, dass er den Farbstoff in dieser Flüssigkeit aufnahm, weil sie sich mit Salzsäure leicht mischen lässt; sollte er aber gewöhn liche alcoholische Chlorophyllsolution gemeint haben, in welcher der gelbe Farbstoff neben dem blaugrünen noch vorhanden ist, so erklärte sich die Bläuung leicht aus der Einwirkung der Salzsäure auf ersteren. -

Das, was Sorby Xanthophyll nennt, stimmt im Allgemeinen mit dem gelben Chlorophyllfarbstoff, den wir gewonnen, überein, sowohl was die Löslichkeits-Verhältnisse, als das Spectrum im Allgemeinen anlangt; rechnen wir die verschiedenen Abweichungen bei den Blumenfarben hinzu, so können auch wir, wenn man will, mehrere Unterarten des Farbstofis, oder eine Farbstoffgruppe mit mehreren Gliedern unterscheiden.

Darin freilich weichen seine Resultate von den meinigen ab, dass er in den grünen Pflanzentheilen zweierlei Farbstoffe gefunden hat, von denen der eine mit unserm übereinstimmende, der gewöhnliche ist, während ihn ein zweiter überall da ersetzt, wo die Blätter beim Vergilben mehr orangefarben erscheinen ("Indian rubber tree" - Ficus elastica).

Um über diese beiden Farbstoffe in's Klare zu kommen, habe ich seine Angaben so weit als möglich war, nachgeprüft, bin aber dabei zu andern Resultaten gekommen als er:

Was zunächst die Blätter von Ficus elastica angeht, so habe ich den hochgelben sich entfärbenden Blättern der Pflanze mit Alcohol einen Farbstoff entzogen, der genau das Spectrum wiedergab, welches ich bei allen anderen Pflanzen am gelben Farbstoff wahrgenommen (Band 1. Mitte 580).

Auch hinsichtlich der Farbstoffe von Daucus Carota stimmen meine Resultate nicht mit den seinen überein. Während Sorby aus Rinde und Holz zwei durch die Lage der Bänder verschiedene Farbstoffe erhielt*, ergab mir die Untersuchung einer gelben Rübensorte,

* Eine specielle Angabe über die Bandlage macht Sorby in seinem Aufsatz im Quat. Journ. Micr. Soc. Oct. 1869. Uebers. in Vierteljahrschr. f. Gesund- 
deren Rinde sehr tief rothgelb, deren Holz schön goldgelb war, aus beiden Theilen gleich gefärbte alcoholische Auszüge mit kaum nennenswerth verschiedenen Spectren:

1) Auszug aus der Rinde, goldgelb:

$$
\begin{aligned}
& \text { Band 1. } \quad 450-535-620 \\
& \text { Band 2. } \quad 670-730-790 \text {. }
\end{aligned}
$$

2) Auszug aus dem Holzkörper, goldgelb:

$$
\begin{array}{ll}
\text { Band 1. } & 470-535-620 \\
\text { Band 2. } & 660-735-825 .
\end{array}
$$

Eine solche Gleichheit der Farbstoffe in beiden Theilen konnte um so weniger Wunder nehmen, als auch von morphologiseher (Kanstren, Bot. Unters. I. S. 42 ff) und chemischer Seite (HuseMann, Pflanzenstoffe, S. 821) bis jetzt kein Unterschied im Farbstoff zwischen äusserer und innerer Schichte der gelben Rübe constatirt worden ist. *

Stimmen demnach in Hinsicht auf den gelben Farbstoff grüner Blätter unsere Resultate nicht, so kann man andererseits beim Vergleich der Bänderlage des gelben Farbstoffs (s. S. 95) aus den verschiedenen Pflanzen ziemliche Differenzen der Lage währnehmen, und würde man bloss die Extreme der Lage herausgreifen, so könnte man sich ganz wohl zu der Ansicht bekennen, dass innerhalb der grünen Pflanzentheile mehrere gelbe Farbstoffe, charakterisirt durch verschiedene Lage der Bänder, vorkämen. Man wird aber beim Vergleich der Tabelle gewahren, dass diese Extreme reichlich durch Zwischenglieder verbunden sind und dass es,

heitspflege von Reclam. Bd. II. S. 60. - Iclı möchte hier bemerken, dass nach meinen Beobachtungen gewisse $\mathrm{g}$ el be F a r bst offe, so insbesondere der von Daucus und das Eige lb bei wiederholten Untersuchungen sehr inconstante Spectra gegeben haben. So z. B. habe ich bei demselben Extract von Daucus, der das eben angeführte Spectrum hat, nachdem er, wohlverwalırt, mehrere Tage stand, neben den angeführten Bändern noch eine sehr deutliche Anschwelluug auf der Linie $\mathrm{G}$ gesehen. Da ich die Sache nicht näher verfolgt habe, so kann ich nicht entsclıeiden, worin der Grund der Erscheinung liegt. - Das genaue Spectrum dieser Stoffe müsste erst durch eine ausführliche, alle Nebenumstände berücksichtigende Untersuchung festgestellt werden. Für uns ist die Inconstanz des Spectrums ein Grund mehr, diese Farbstoffe mit dem gelben Chlorophyllfarbstoff nicht "zu identificiren.

* Uebrigens sieht man, dass der gelbe Farbstoff von Daucus von dem gewöhnlichen gelben Farbstoff grüner Blätter etwas abweiclıt und etwa mit denl von l'hysalis übereinstimmt. 
bei Beachtung dieser, nicht möglich ist, Anfang oder Ende für die Trennung zı finden. Dies und das gleiche chemische Verhalten bewogen mich, diese Farbstoffe vorläufig als einen einzigen zu betrachten, dessen Bandlage etwas variirt.

Was endlich die letzte Gruppe, die in Wasser löslichen gelben Farbstoffe, die er Chrysophyll nennt, angeht, so ist schon oben darauf hingewiesen worden, dass auch ich beim Auskochen mit Wasser aus frischen älteren grünen Blättern öfter, aus gelben herbstlichen Blättern stets, einen Farbstoft gewonnen habe, der spectralanalytisch, durch die continuirliche Absorption des Blau und Violett, von dem weingeistigen Xanthophyll rerschieden war.

Auch wenn man den weingeistigen gelben Farbstoff des auf die gewöhnliche Weise hergestellten Xanthophyll, abdampft und mit Wasser behandelt, kann man gelegentlich eine gelbe Lösung erhalten. Es bleibt mir aber dabei zweifelhaft, ob dieser in Wasser lösliche Körper nicht ein Zersetzungsproduct ist, das sich erst beim Abdampfen zur Trockne, sei es durch Einwirkung der atmosphärischen Luft oder durch die in der Lösung befindlichen Salze, bildet.

Von besonderem Gewichte scheint mir aber schliesslich die Thatsache, dass nach der Intensität der Färbung der Flüssigkeit zu schliessen, der in Wasser lösliche Farbstofl in allen Fällen, wo er bei grünen Blättern gesehen wurde, gegen den in Alcohol löslichen in verschwindend geringer Menge vorhanden war, so dass er gegen diesen kaum in Betracht zu setzen schien.

Daher scheint es mir auch nicht der Natur entsprechend, wenn Sorby (a. a. 0. p. 75) die lebenskräftigen Blätter durch das Vorhandensein von „Chlorophyll und Chrysophyll* (unserm Kyanophyll und dem spärlichen, in Wasser löslichen, gelben Farbstofí) characterisirt; sie müssten nach meinen Erfahrungen durch das Vorhandensein von Chlorophyll und Xanthophyll (in seinem Sinne) und die herbstlichen Blätter durch Xanthophyll und Chrysophyll characterisirt werden. -

Uebrigens betrachte ich, wie bereits oben bemerkt, die Acten über diese in Wasser löslichen Farbstoffe nicht als geschlossen; sie verdienen eine neue und eingehendere Prüfung. 


\section{Ergeb n is s e.}

Ich fasse die positiven Ergebnisse der vorliegenden Arbeiten in folgenden Sätzen summarisch zusainmen:

1) Das Absorptionsspectrum einer weingeistigen, unveränderten Chlorophyllösung zeigt sicben Bänder, von denen vier (I - TV) schmale in der ersten, drei breite $(\mathrm{V}-\mathrm{VII})$ in der zweiten Spectralhälfte liegen.

Die vier ersten Bänder liegen in Roth, Orange, Gelb und Lichtgrün; das erste, zwischen $\mathrm{B}$ und $\mathrm{C}$ gelegen, ist allein scharf begrenzt und eine totale Absorption, alle andern, schattenartig begrenzt, folgen sich in der Stärke (Breite und Intensität) nach der Reihenfolge ihrer Nummern.

Von den drei Bändern im zweiten Theile liegt eines gleich hinter $\mathrm{F}$, ein sehr intensives vor und auf $\mathrm{G}$, die Endabsorption des Violett stellt das siebente Band dar.

2) Alle untersuchten Mono- und Dicotylen, Farne, Moose und Chlorophyllalgen geben das gleiche Spectrum.

Abweichend wurde das Spectrum einer Oscillarie gefunden.

3) Das Spectrum der Lösung - und das ist eben der Beweis für seine Richtigkeit - stimmt in allem Wesentlichen mit dem des lebenden Blattes überein. Ein Hauptunterschied ist, dass bei letzterem die Bänder gleichsinnig gegen das rothe Spectrumende verschoben sind. Wahrscheinlich hängt dies mit der grösseren Dichtigkeit des Mediums zusammen, in welches der Farbstoff im Blatte eingelagert ist.

4) Denn, soweit die Versuche reichen, zeigt sich, dass die Lage der Bänder des Chlorophylls (und seiner Farbstoffe) mit der Dichtigkeit des Lösungsmittels (Aether, Weingeist, Schwefelkohlenstoff) 
schwankt; die Bänder rücken um so weiter gegen das rothe Ende hin, je dichter das Medium und umgekehrt.

5) Das Chlorophyllspectrum ist ein Combinationsspectrum: es entsteht durch Uebereinanderlagerung der Spectra (wenigstens) zweier Farbstoffe, eines gelben und eines blangrünen, von denen der erstere nur Absarptionen im Blau und Violett, der letztere in diesem und rorwiegend im Roth bis Grün besitzt.

„Chlorophyll", Chlorophyllfarbstoff, ist ein Farbstoffgemisch aus wenigstens zwei Pigmenten gebildet.

Die beiden Farbstofie werden am einfachsten und unverändert erhalten, wenn man eine alcoholische Chlorophyllösung mit Benzol schüt= telt, worauf in letzterem der blaugrüne, im Alcohol der gelbe Farbstoff erscheint.

6) Der blaugrüne Farbstoff (Kyanophyll) verursacht die Bänder des ,Chlorophylls* im Roth, Orange, Gelb und Grün (I-IV) und besitzt ausserdem drei Bänder im Blan und Violett, ron denen besonders das zweite den hervorragendsten Antheil an der Bildung des Bandes VI im .Chlorophyll* hat.

Er ist ausserordentlich empfin!lich gegen Licht und heagentien und Ursache der ausserordentlichen Empfindlichkeit des "Chlorophylls".

7) Der gelbe Farbstoff (Xanthophyll) besitzt drei Bänder, im Blau und Violett, ron denen das erste bei $F$ gelegene das Band $V$ des „Chlorophylls* hervorruft.

Weniger empfindlich gegen Licht und Säure, ist er durch Grünund endlich Blaufärbung mittelst Sal\%- und Schwefelsäure charakterisirt, welch' letzterer Eigenschaft das ,Chlorophyll* seine Eigenschaft rerdankt durch genannte Säuren spangrün zı werden.

8) Das Xanthophyll ist identisch mit dem Farbstoffe etiolirter Pflanzen und einem grossen Theile des Anthoxanthins; ein anderer Theil des letztern ist nahe verwandt damit. Die in Wasser löslichen gelben Farbstoffe haben, wie es scheint, gar keine Verwandtschaft dazu. (?)

9) Bunte Kryptogamen (Oscillarien) besitzen Kyanophyll und Xanthophyll, das mit dem der übrigen Pflanzen wohl nahe verwandt, spectralanalytisch aber nicht gleich ist. 


\section{T a f e l e r k l ä r ung.}

Die Spectra wurden nicht in Farben ausgeführt, weil es mir besonders darauf ankam, die Bänder nach den feinsten Nüancen ihres Baues, was Stärke, Abschattung; Begrenzung u. s. w. anlangt, und die zwischen liegenden, das Licht durchlassenden Stellen nach dem Grade ihrer Helligkeit richtig abzustufen - ein Vorhaben, das mir bei farbiger Ausführung zur Zeit unausführbar schien. Freilich ist es richtig, dass das Wesen des Spectrums zunächst durch seine Farben wiedergegeben wird, aber für jeden Kundigen ist es eben so sehr an den Frauenhofer'schen Linien kenntlich. Diese wurden daher überall in den Spectren angegeben, jedoch, um das Gesammtbild der Absorption nicht zu stören, nur in der Scala angedeutet, nicht durch das Spectrum selbst geführt.

Da es mir, wie Eingangs ausführlich besprochen wurde, nur auf eine qualitative, nicht eine quantitative Analyse der absorbirenden Flüssigkeiten ankam, so sind die Spectra - was ohnehin schwer auszuführen - nicht bei einem bestimmten, sondern bei einem jedesmal empirisch gefundenen, gerade gewünschten Concentrationsgrade der Flüssigkeit gezeichnet. Im Allgemeinen war es eine mittlere und eine sehr geringe Concentration. Das Nähere ist oben bemerkt.

Wo das Gegentheil nicht angegeben, ist das Lösungsmittel Alcohol von 0,816 spec. Gew. oder etwa 92 Gewichts-, 95 Voliumprocenten. Das verwendete Benzol war das in den Apotheken käufliche. 



\section{Tafel I.}

Fig. 1 (zu S. 13):

Das Spectrum eines Chlorophyllkoriss aus dem Blatte von Clivia. Mit Hartnack's Immersionssystem N. 9. gesehen. Das Präparat in Glycerin.

- 2 (zu S. 14):

Das Spectrum einer "Anthokyan"-haltigen unterseitigen Epidermiszelle von Tradescantia zebrina. Hartack's Objectiv N. 7 .

, 3 (zu S. 27 ff.):

Spectrum einer normalen weingeistigen Chlorophylllösung (Primula sinensis), mittlerer Concentration, nur die Bünder I-IV getremnt, V-VII in eine continuirliche Absorption zusammen geflossen zeigend.

- 4 (zu S. 32 ff.) :

Spectrum einer gleichen Lösung, die vordere Hälfte bei stärkerer, die hintere bei ganz schwacher Concentration darstellend. Zeigt alle Bänder des Chlorophylls.

, 5 (zu S. 47):

Das Spectrum eines lebenden Blattes von Deutzia scabra, in einfacher Iage. II bei 90 ; III bei 180 ; IV bei 270 .

, 6 (zu S. 48):

Dasselbe von einer zweifachen Lage Blätter.

" 7 (zu S. 62 ff.):

- Zersetztes Chlorophyll von Mentha piperita. Halbjührig. Im Dunkel aufbewahrt. I $30-80$; II $120--140$; III 230 ; IV a $290-360$; IV b $390 \cdot 490$. 


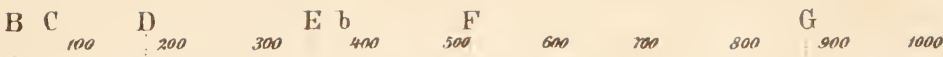

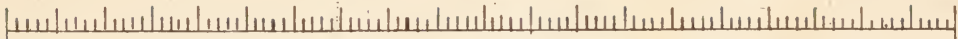

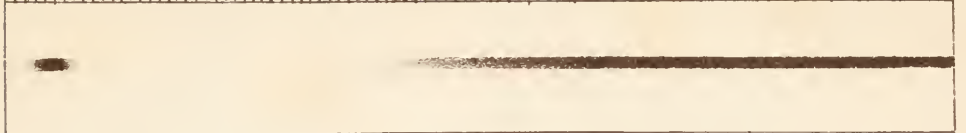

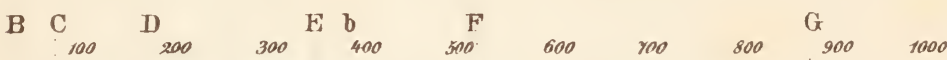

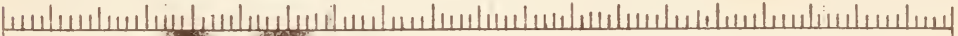

(2)
B C

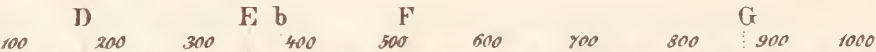

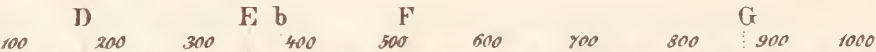

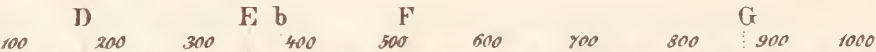
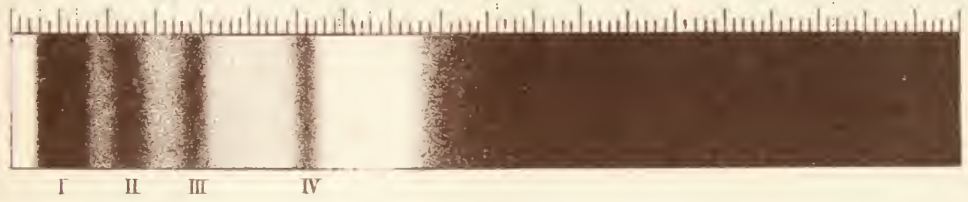
B C

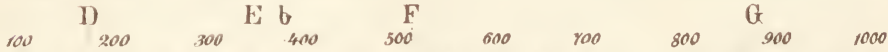

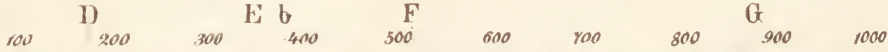

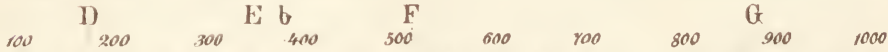

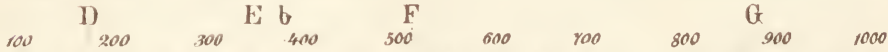

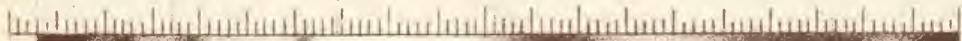

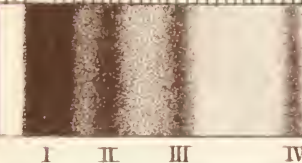

$\begin{array}{llll}\mathrm{B} & \mathrm{C} & \mathrm{D}_{200} & \\ & & & \\ & & & \end{array}$

E $\stackrel{b}{400}_{500}$

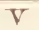

$600 \quad y 00 \quad 300$

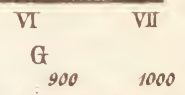

VI

$900 \quad 1000$

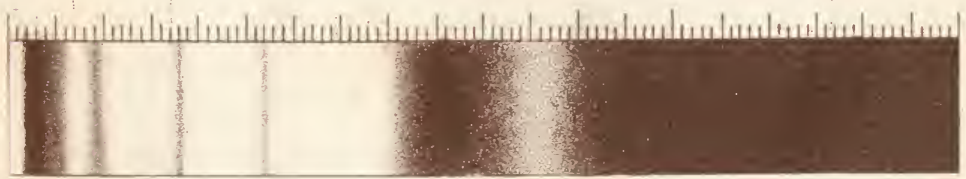

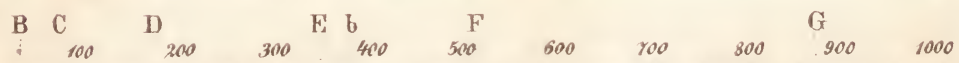

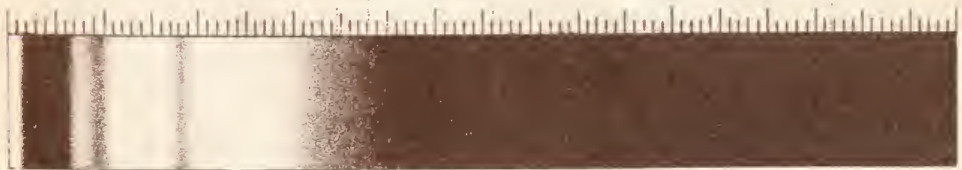

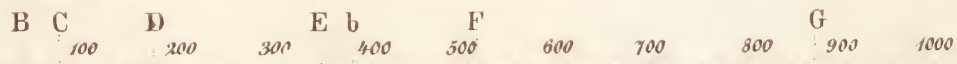

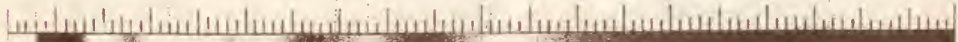

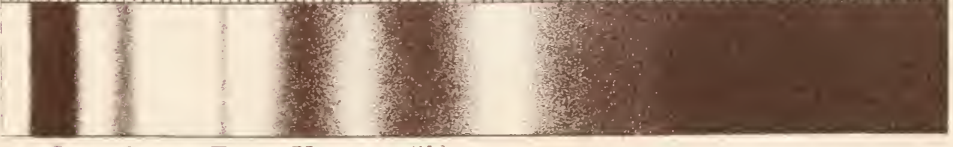






\section{Tafel II.}

Fig. 1 (zu S. 97 fr.):

Der blaugrüne Farbstoff des Chlorophylls in Benzol aus Deulzia scabra. Hintere Hälfte des Spectroms bei geringerer Concentration als die vordere. 5 von $580-750 ; 6$ von $820-920$.

"2 (zur S. 99):

Derselbe durch eine Spur Salzsäure zersetzt.

- 3 (zu S. 94 ff.):

Gelber Bestandtheil des Chlorophylls aus derselben Pflanze.

Schwache Concentration. Alcohol.

- 4 (zu S. 112):

Der Farbstoff etiolirter Gerste in Alcohol. Schwache Concentration. Bei stärkerer Lösung als im Text angegeben.

- 5 (zu S. 115):

Der gelbe Farbstofi aus den Zungenblumen von Doronicum Pardalianches. Alcoholische schwache Lösung.

, 6 (zu S. 116):

Spectrum des frischèn Blumenblattes von Brassica nigra. Schwache Lösung.

, 7 (zu S. 117):

Der Farbstoff von Eschscholtzia californica (Petala). Schwache Concentration. 

. 


\section{Tafel III.}

Fig. 1 (zu S. 107):

Der blaugrüne Farbstoff aus einer Oscillaria. In Benzol. Wie in Fig. 1, 'Taf. II.

- 2 (zu S. 108):

Der orangegelbe Farbstoff aus derselben Alge. „Phycoxanthin".

" 3 (zu S. 59):

Gelber Farbstoff aus den Fruchtkelchen von Physalis Allekengi. In Alcohol.

"4 (zu S. 60) :

Derselbe in Chloroform.

* 5 (zu S. 68 ff.) :

Alcoholisches Chlorophyll vou Deutzia scabra. Mit einem Tropfen Essigsäure versetzt. Anfängliche Wirkung.

, 6 (zu S. 68 ff.):

Dasselbe. Endwirkung.

. 7 (zu S. 74):

Gleiche Chlorophylllösung mit einem Tropfen Salzsäure (rauchend)

- Anfängliche Wirkung. 
Taf. III.

$\begin{array}{lllllllllll}\mathrm{B} & \mathrm{C} & \mathrm{D}_{200} & { }_{300} & \mathrm{E} & \mathrm{b} & \mathrm{F} & & & & \\ & & { }_{200} & 600 & 400 & 800 & 900 & 1000\end{array}$

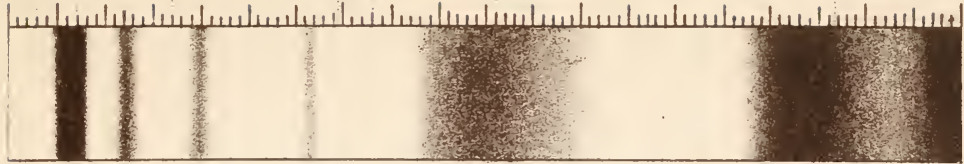

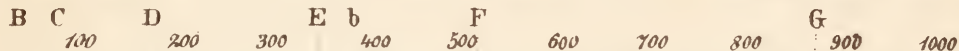

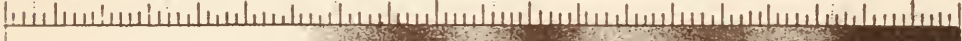

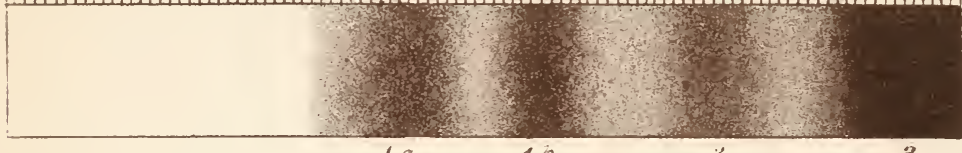

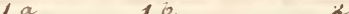

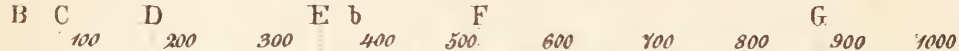

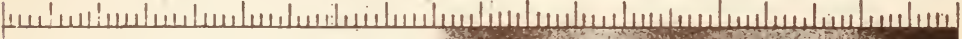

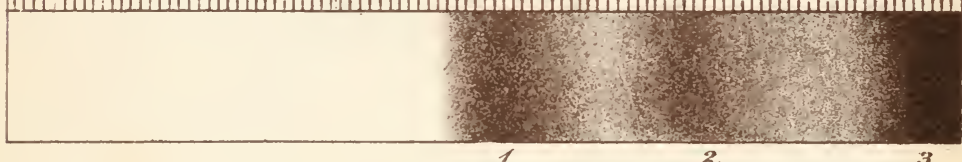

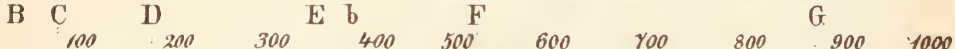

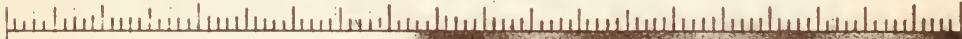

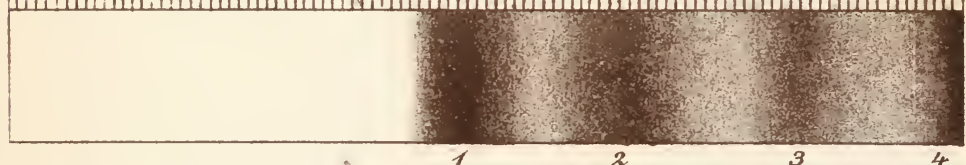

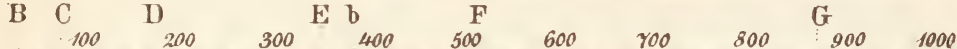

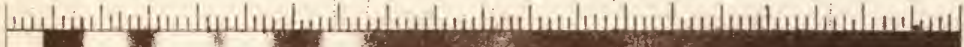

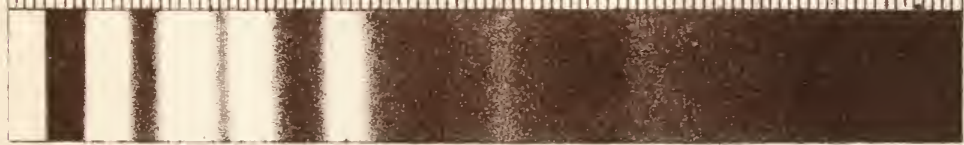

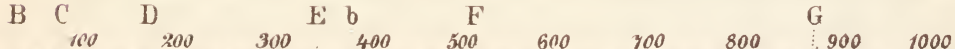

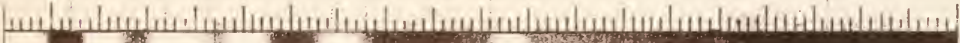

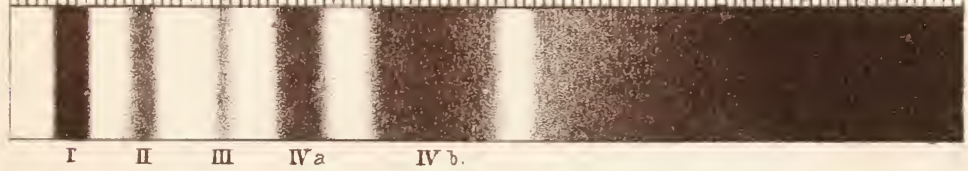

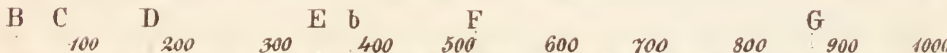

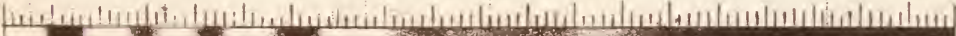

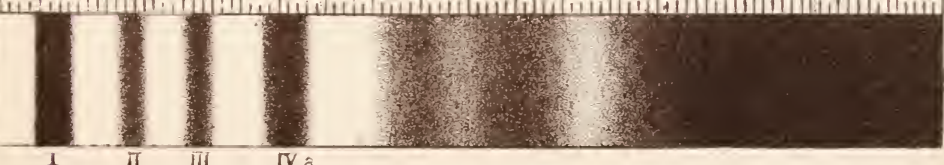






